Usando aplicações ricas para internet na criação de um ambiente para visualização e edição de regras SWRL

João Paulo Orlando 



\section{Usando aplicações ricas para internet na criação de um ambiente para visualização e edição de regras SWRL}

\section{João Paulo Orlando}

Orientador: Prof. Dr. Dilvan de Abreu Moreira

Dissertação apresentada ao Instituto de Ciências Matemáticas e de Computação - ICMC-USP, como parte dos requisitos para obtenção do título de Mestre em Ciências - Ciências de Computação e Matemática Computacional. VERSÃO REVISADA

\section{USP - São Carlos}

Julho de 2012 
Ficha catalográfica elaborada pela Biblioteca Prof. Achille Bassi e Seção Técnica de Informática, ICMC/USP, com os dados fornecidos pelo(a) autor(a) um ambiente para visualização e edição de regras SWRL / João Paulo Orlando; orientador Dilvan de Abreu Moreira -- São Carlos, 2012.

$112 \mathrm{p}$.

Dissertação (Mestrado - Programa de Pós-Graduação em Ciências de Computação e Matemática Computacional) -Instituto de Ciências Matemáticas e de Computação, Universidade de São Paulo, 2012.

1. Regras SWRL. 2. Composição de regras. 3. Visualização de regras. 4. Anotação de dados. 5. Web Semântica. I. Moreira, Dilvan de Abreu, orient. II. Título. 
Dedico este trabalho à minha mais que amada família. 



\section{Agradecimentos}

Agradeço aos meus pais, pois sem eles eu não poderia existir e sempre que precisei deles, eles me ajudaram. Nem tudo o que terei em minha vida toda será o suficiente para conseguir agradecer a eles. Amo vocês Bernardete e Itacir Neri Orlando. Ao meu irmão Josias Marcos Orlando, pelo apoio e pelos momentos de descontração. A todos os demais familiares um grande agradecimento por tudo e, principalmente em especial ao meu primo afilhado Gustavo que tem 3 anos, desejo a ele um futuro brilhante. E espero que um dia ele esteja aqui passando por todos esses momentos.

Queria deixar um agradecimento especial ao meu orientador Prof. Dr. Dilvan de Abreu Moreira, pela confiança e por toda a ajuda dedicada ao meu trabalho. E ainda agradeço a todos demais docentes (tanto do ICMC-USP, quanto aos da URI) que contribuíram para minha formação.

Aos amigos do ICMC, especialmente a Adriano Rivolli e Kleberson Serique que me ajudaram várias vezes no desenvolvimento deste mestrado.

Aos colegas de república que compartilham dos mesmos desafios acadêmicos: Bruno Guazzelli Batista, Bruno Tardiole Kuehne, Daniel Fernando Pigatto, Gabriel Massote Prado e Paulo Sérgio Franco Eustáquio.

E por fim, mas não menos importante, ao $\mathrm{CNPq}$ pelo apoio financeiro, ao Instituto de Ciências Matemáticas e de Computação e à Universidade de São Paulo pela estrutura disponibilizada para realização deste projeto. 

It matters not how strait the gate,

How charged with punishments the scroll,

I am the master of my fate:

I am the captain of my soul.

(William Ernest Henley - Invictus) 



\section{Resumo}

A Web Semântica é uma maneira de explorar a associação de significados explícitos aos conteúdos de documentos presentes na Web, para que esses possam ser processados diretamente ou indiretamente por máquinas. Para possibilitar esse processamento, os computadores necessitam ter acesso a coleções estruturadas de informações e a conjuntos de regras de inferência sobre esses conteúdos. O SWRL permite a combinação de regras e termos de ontologias (definidos por OWL) para aumentar a expressividade de ambos. Entretanto, conforme um conjunto de regras cresce, ele torna-se de difícil compreensão e sujeito a erros, especialmente quando mantido por mais de uma pessoa. Para que o SWRL se torne um verdadeiro padrão web, deverá ter a capacidade de lidar com grandes conjuntos de regras. Para encontrar soluções para este problema, primeiramente, foi realizado um levantamento sobre sistemas de regras de negócios, descobrindo os principais recursos e interfaces utilizados por eles, e então, com as descobertas, propusemos técnicas que usam novas representações visuais em uma aplicação web. Elas permitem detecção de erro, identificação de regras similares, agrupamento, visualização de regras e o reuso de átomos para novas regras. Estas técnicas estão implementadas no SWRL Editor, um plug-in open-source para o Web-Protégé (um editor de ontologias baseado na web) que utiliza ferramentas de colaboração para permitir que grupos de usuários possam não só ver e editar regras, mas também comentar e discutir sobre elas. Foram realizadas duas avaliações do SWRL Editor. A primeira avaliação foi um estudo de caso para duas ontologias da área biomédica (uma área onde regras SWRL são muito usadas) e a segunda uma comparação com os únicos três editores de regras SWRL encontrados na literatura. Nessa comparação foi mostrando que ele implementa mais recursos encontrados em sistemas de regras em geral.

Palavras-chaves: Regras SWRL; Composição de regras; Visualização de regras; Anotação de dados; Web Semântica. 



\section{Abstract}

The Semantic Web is a way to associate explicitly meaning to the content of web documents to allow them to be processed directly by machines. To allow this processing, computers need to have access to structured collections of information and sets of rules to reason about these content. The Semantic Web Rule Language (SWRL) allows the combination of rules and ontology terms, defined using the Web Ontology Language (OWL), to increase the expressiveness of both. However, as rule sets grow, they become difficult to understand and error prone, especially when used and maintained by more than one person. If SWRL is to become a true web standard, it has to be able to handle big rule sets. To find answers to this problem, we first surveyed business rule systems and found the key features and interfaces they used and then, based on our finds, we proposed techniques and tools that use new visual representations to edit rules in a web application. They allow error detection, rule similarity analysis, rule clustering visualization and atom reuse between rules. These tools are implemented in the SWRL Editor, an open source plug-in for Web-Protégé (a web-based ontology editor) that leverages Web-Protégé's collaborative tools to allow groups of users to not only view and edit rules but also comment and discuss about them. We have done two evaluations of the SWRL Editor. The first one was a case study of two ontologies from the biomedical domain, the second was a comparison with the SWRL editors available in the literature, there are only three. In this comparison, it has been shown that the SWRL Editor implements more of the key resources found on general rule systems than the other three editors.

Palavras-chaves: SWRL rules; Rule composition; Rule visualization; Data annotation; Semantic Web. 



\section{Lista de Figuras}

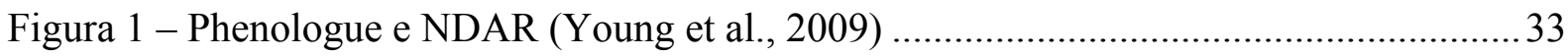

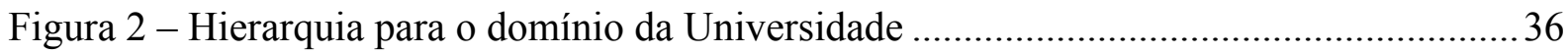

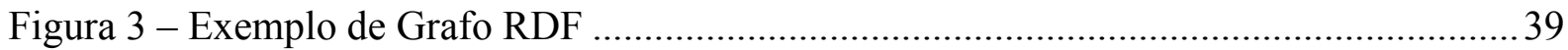

Figura 4 - Arquitetura do Web-Protégé (Tudorache, Vendetti e Noy, 2008)........................ 47

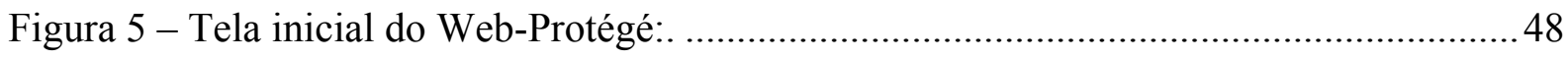

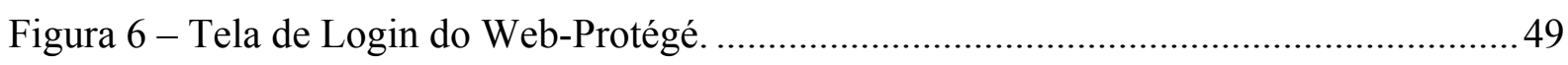

Figura 7 - Ontologia aberta no Web-Protégé:...................................................................... 49

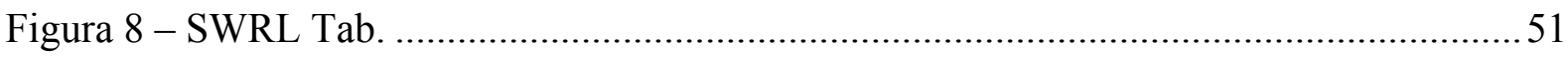

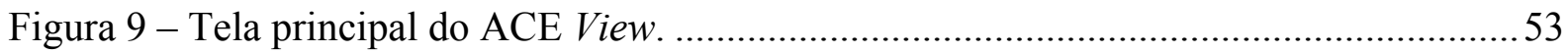

Figura 10 - Tabela de decisão em formato de planilha (IBM ILOG) ....................................56

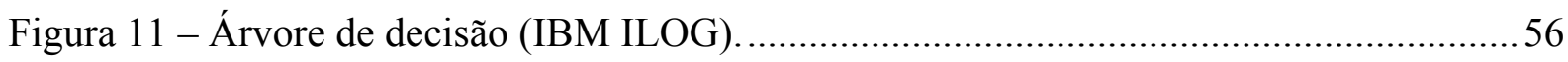

Figura 12 - Rule Graph - Dependência entre as regras (Axiomé)........................................57

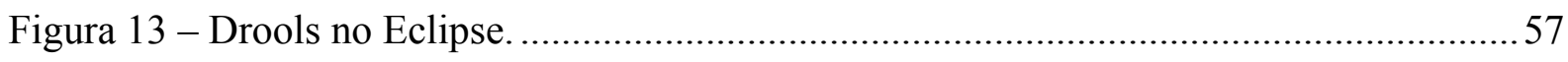

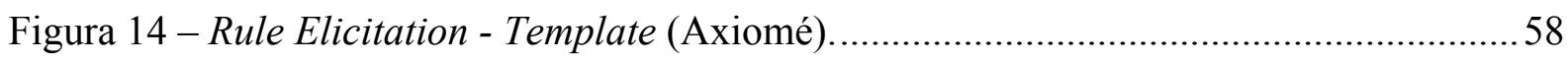

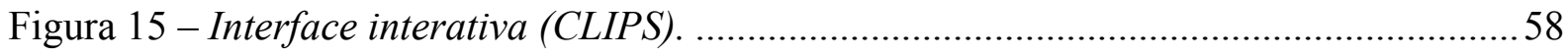

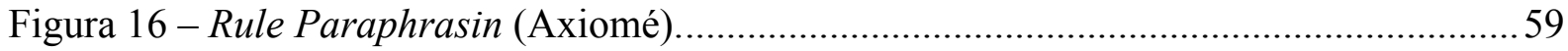

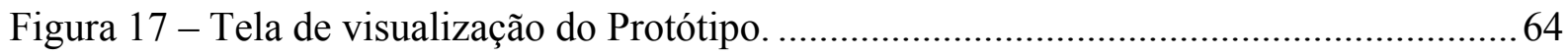

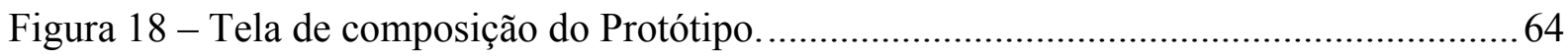

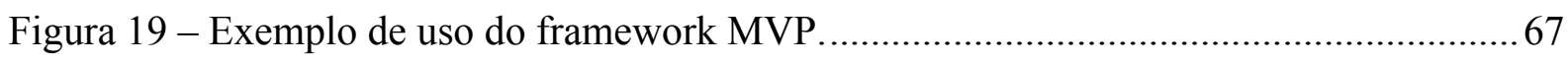

Figura 20 - Interfaces para a Representação das Regras do SWRL Editor. ........................... 72

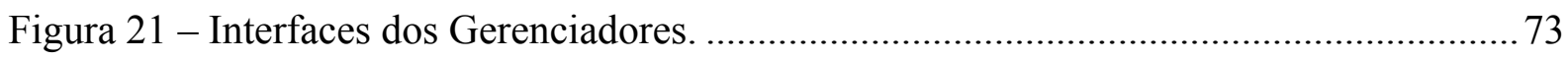

Figura 22 - Interfaces do Sistema de Carregamento Automático do Agrupamento................ 77

Figura 23 - Interfaces do Sistema de Carregamento Automático da Árvore de Decisão. ....... 78

Figura 24 - Tela após o acesso a ontologia da família........................................................... 79

Figura 25 - SWRL Editor - Visualização.................................................................... 81

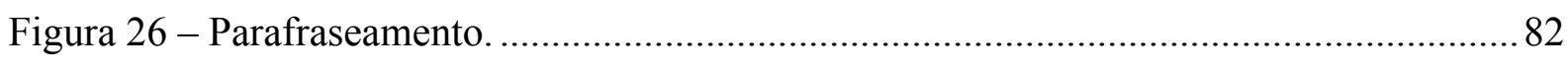

Figura 27 - Técnica de agrupamento do Axiomé ............................................................ 83

Figura 28 - Árvore de decisão - Ocorrência de átomos....................................................... 83

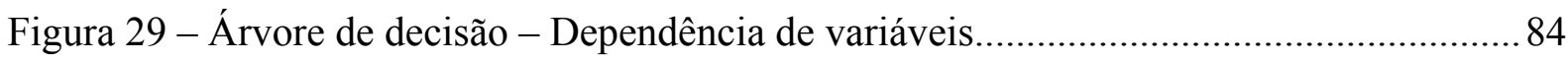




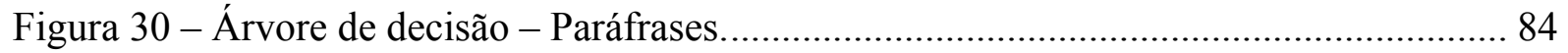

Figura 31 - Árvore de decisão - Identificação de regras com antecedentes iguais................. 85

Figura 32 - Árvore de decisão - Botão direito sobre os nós. ................................................ 85

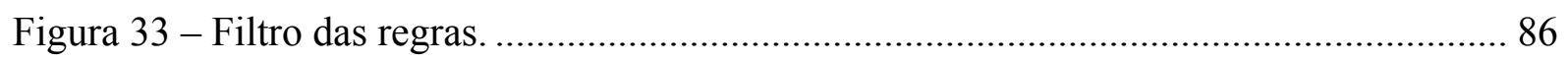

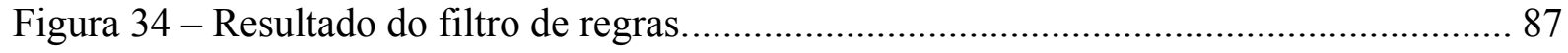

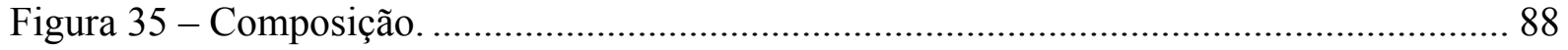

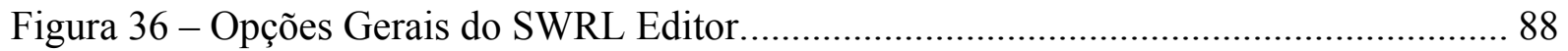

Figura 37 - Opções de Composição do SWRL Editor. ............................................................ 89

Figura 38 - Opções de Visualização do SWRL Editor.......................................................... 90

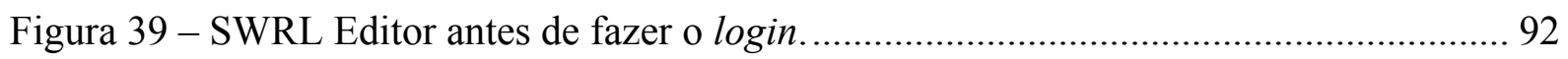

Figura 40 - Diagrama da árvore de dependência de variáveis do antecedente de uma regra.110 


\section{Lista de Tabelas}

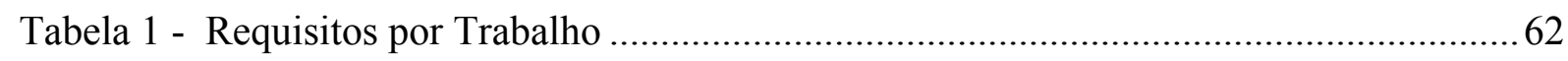

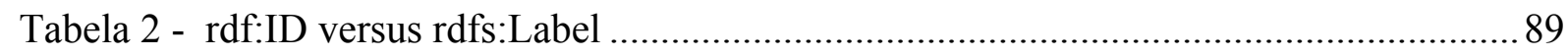

Tabela 3 - Comparação das características entre as principais ferramentas para edição de

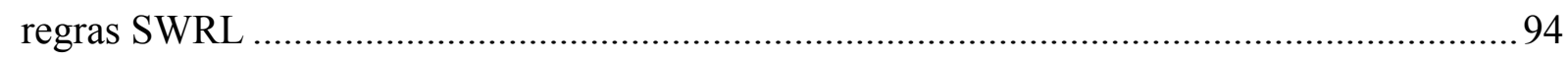

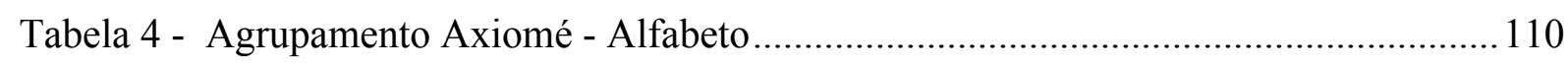

Tabela 5 - Agrupamento Axiomé - Quantificadores ....................................................... 111 



\section{Lista de Siglas e Abreviaturas}

ACE

AHIMA

AJAX

API

ASA

ASD

BRS

BMIR

CDC

CHAO

CLIPS

CSS

DL

DOM

EBI

GWT

HTML

IPTV

JAR

JDBC

JESS

JSNI

MVC

MVP

NCBO

NDAR

NGS

$\mathrm{NIH}$

OBO

ORM

OWL

PAC

RDF

RDFS

RIA

RMS

RPC

RuleML

SQL

SLA
Attempto Controlled English

American Health Information Management Association

Asynchronous Javascript And XML

Application Programming Interface

Autism Society of America

Autism Spectrum Disorder

Business Rule System

Biomedical Informatics Research

Center of Disease Control and Prevention

Changes and Annotations Ontology

C Language Integrated Production System

Cascading Style Sheets

Description Logic

Document Object Model

European Bioinformatics Institute

Google Web Toolkit

HyperText Markup Language

Internet Protocol Television

Java ARchive

Java Database Connectivity

Java Expert System Shell

JavaScript Native Interface

Model-view-controle

Model-view-presenter

National Center for Biomedical Ontology

National Database for Autism Research

Next-Generation Sequencing

National Institutes of Health

Open Biomedical Ontologies

Object Role Modeling

Web Ontology Language

Presentation-abstraction-control

Resource Description Framework

RDF Schema

Rich Internet application

Rule Management System

Remote Procedure Call

Rule Markup Language

Structured Query Language

Service Level Agreement 
SQWRL Semantic Query-Enhanced Web Rule Language

SRL Structured Rule Language

SWRL Semantic Web Rule Language

TRANSLATOR TRANSlator from LAnguage TO Rules

UML Unified Modeling Language

URL Uniform Resource Locator

URI Uniform Resource Identifier

W3C World Wide Web Consortium

WFA Workshop de Ferramentas e Aplicações

WWW World Wide Web

XHTML eXtensible Hypertext Markup Language

XML eXtensible Markup Language 


\section{Sumário}

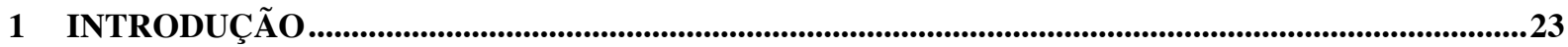

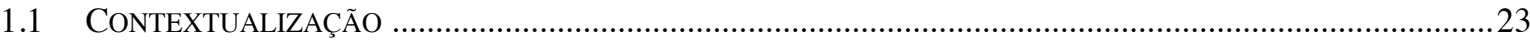

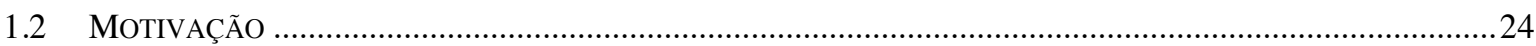

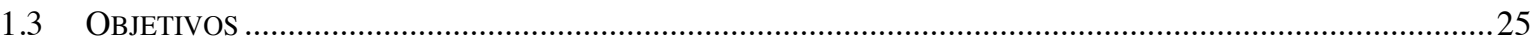

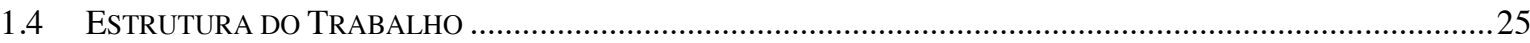

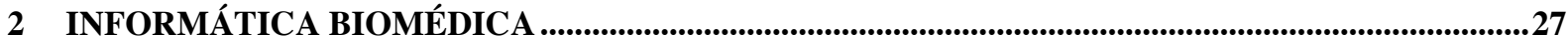

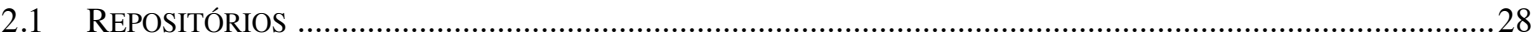

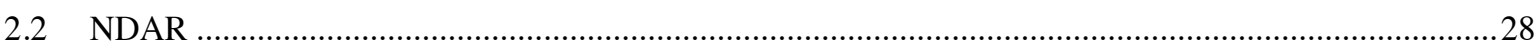

2.2 .1 Autismo

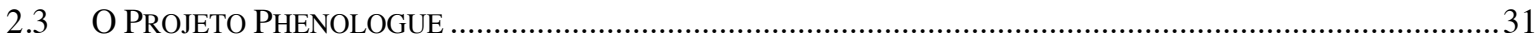

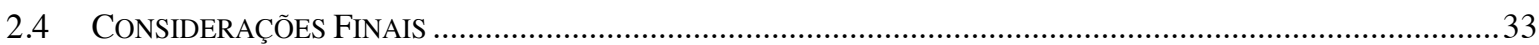

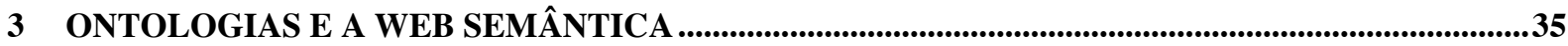

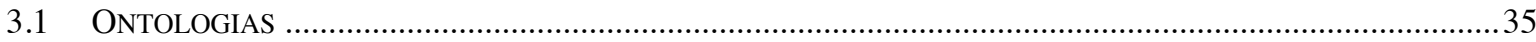

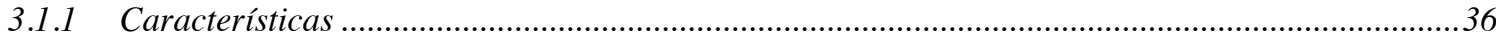

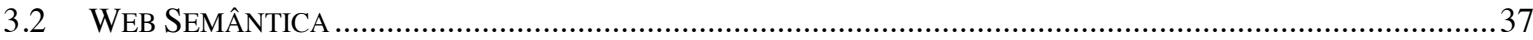

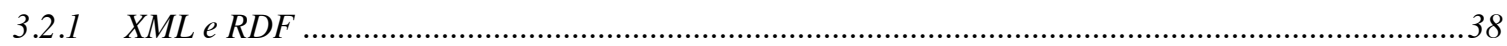

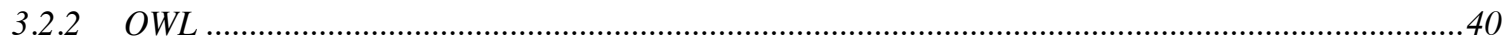

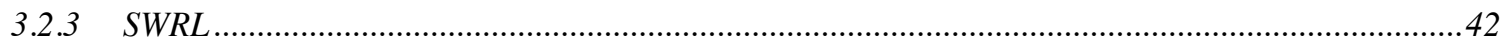

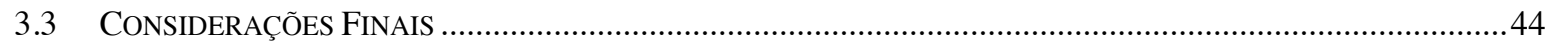

4 TRABALHOS RELACIONADOS .......................................................................................................................45

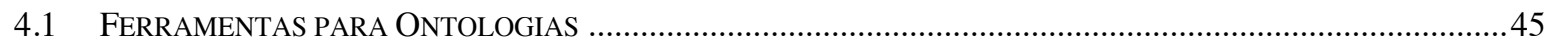

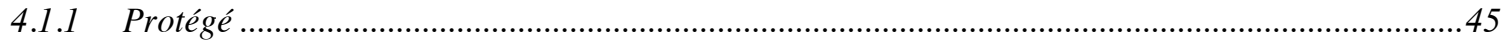

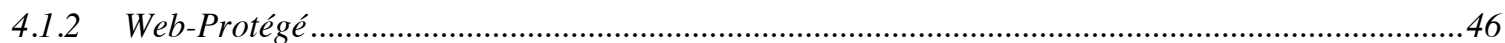

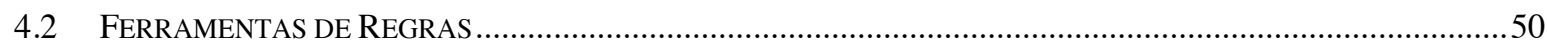

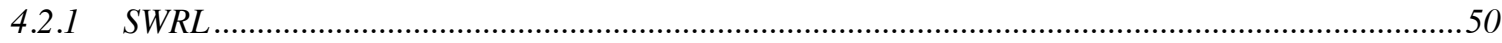

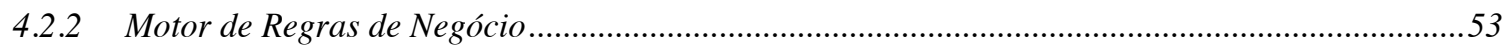

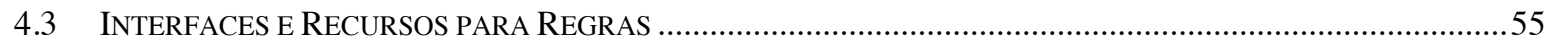

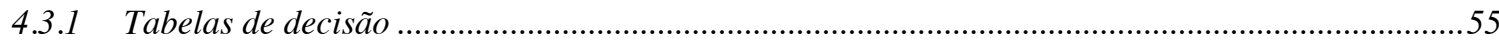

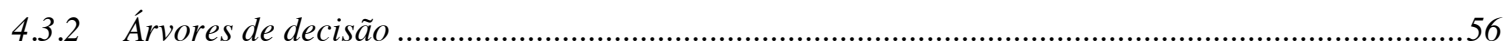

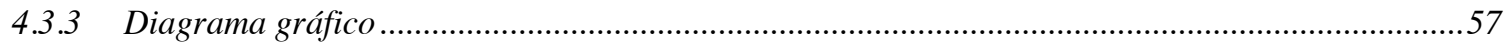

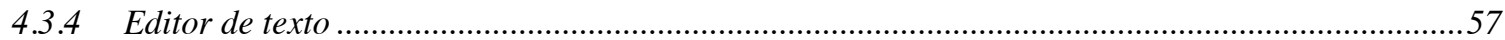

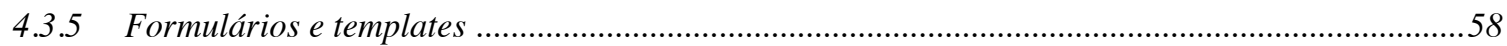

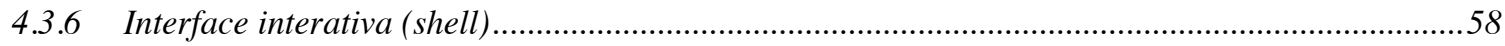




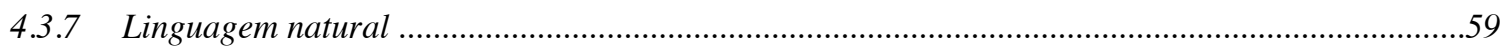

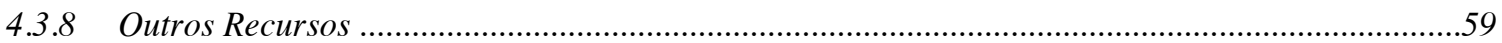

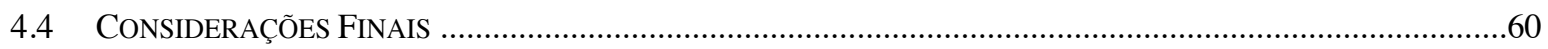

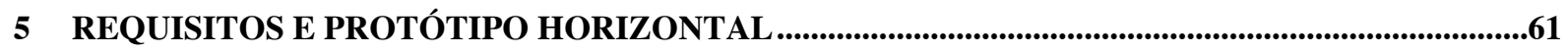

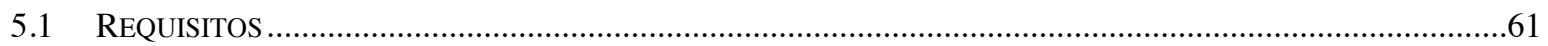

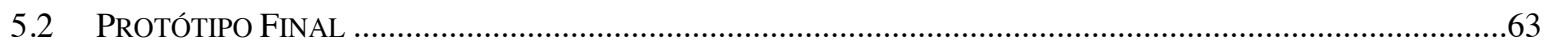

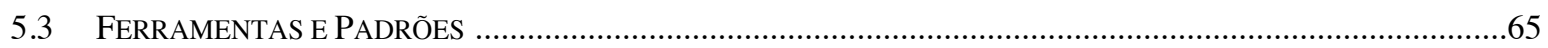

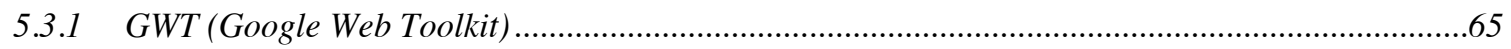

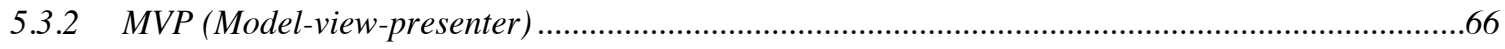

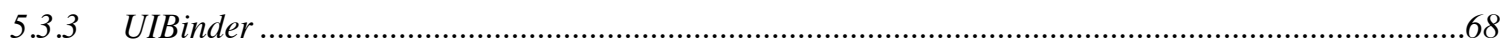

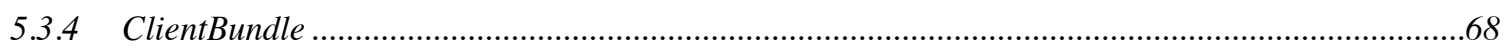

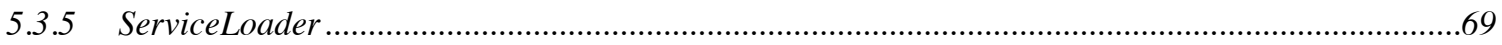

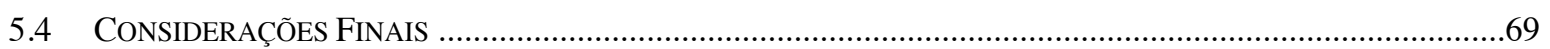

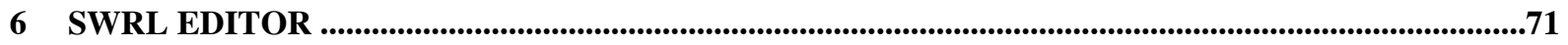

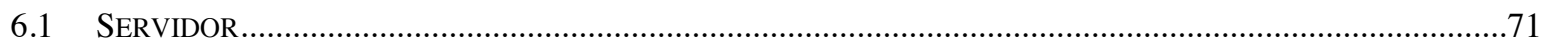

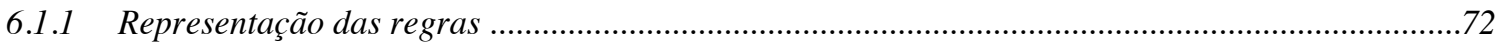

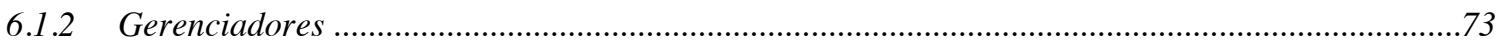

6.1.3 Gerenciador de atualizações .....................................................................................................74

6.1.4 Sistemas de carregamento automático de algoritmos ...................................................................75

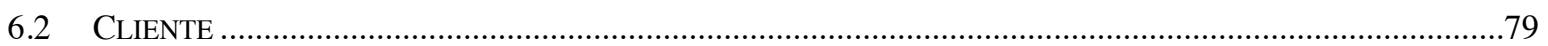

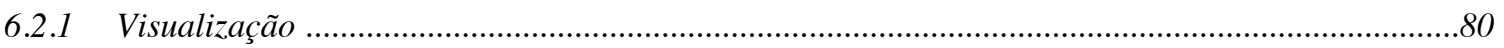

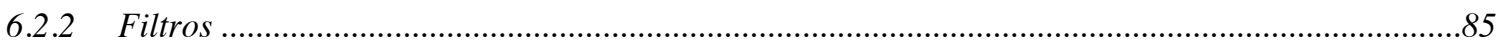

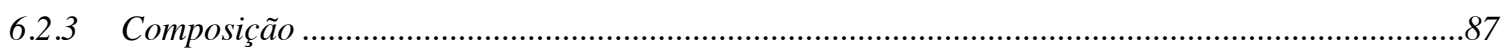

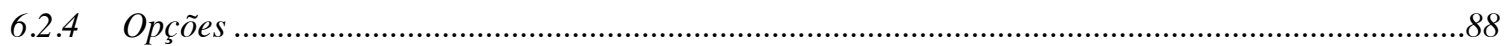

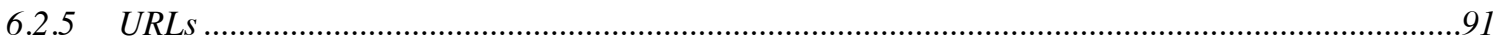

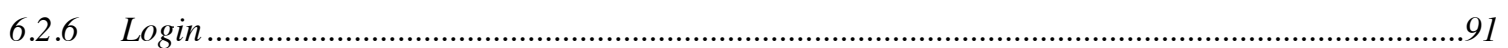

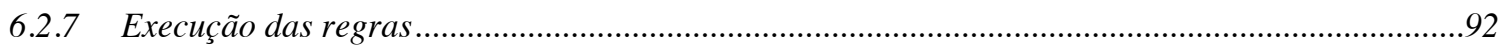

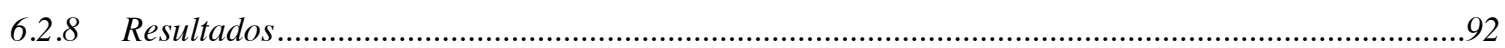

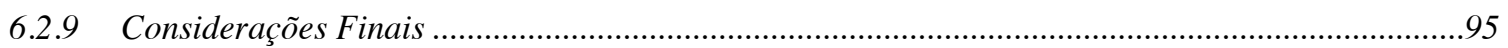

7 CONCLUSÃ

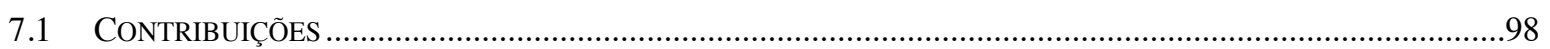

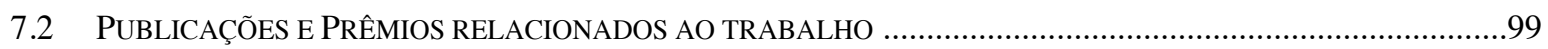

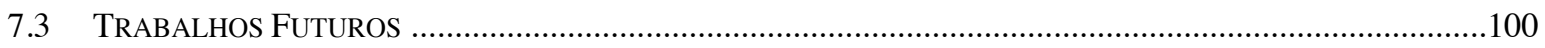

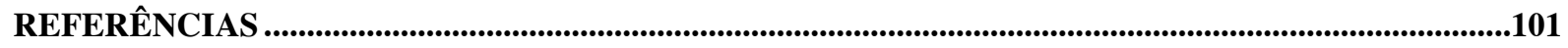




\section{Introdução}

\subsection{Contextualização}

A Web Semântica é uma maneira de explorar a associação de significados explícitos aos conteúdos de documentos presentes na Web, para que esses possam ser processados diretamente ou indiretamente por máquinas (Berners-Lee e Fischetti, 2008). Para possibilitar esse processamento, os computadores necessitam ter acesso a coleções estruturadas de informações (dados e metadados) e a conjuntos de regras de inferência sobre esses conteúdos (que ajudem no processo de dedução automática) para que seja possível o raciocínio automatizado sobre os mesmos (Berners-Lee, Hendler e Lassila, 2001).

A Web Semântica renovou e aumentou o interesse em sistemas baseados em regras e seu desenvolvimento (Zacharias, 2008). A SWRL (Semantic Web Rule Language) é a linguagem padrão para regras da Web Semântica. Muitas áreas de estudo na Computação estão usando SWRL, entre elas podemos citar: serviços sensíveis ao contexto (Wusheng et. al. , 2011), gestão de energia em ambientes domésticos (Rossello-Busquet et. al. , 2011), sistemas de $e$ learning (Vesin et. al. , 2011), gerenciamento de SLA (Service Level Agreement) para serviços de IPTV (Internet Protocol Television) (Seo et. al. , 2011), cálculos de redes de coautoria em redes sociais (Ahmedi, Abazi-Bexheti e Kadriu, 2011), sensores em ambientes inteligentes (Sadoun et. al., 2011), gerenciamento inteligente de fotos digitais (Chai et. al., 2010), extração de características (Ex.: de frequência cardíaca) no acompanhamento contínuo de eletrocardiogramas (Tanantong, Nantajeewarawat e Thiemjarus, 2011), etc.

$\mathrm{Na}$ área da informática biomédica, é possível citar outras aplicações de regras SWRL: atribuição de notas a tumores (Levy, O'Connor e Rubin, 2009), sugestão de drogas antidiabéticas corretas para que não ocorram efeitos colaterais (Chen, Bau e Huang, 2010) e para classificar fenótipos de Autismo (Hassanpour, O'Connor e Das, 2011). Sendo que, esse último ainda está em desenvolvimento e foi o projeto precursor que gerou a idéia central deste trabalho. Essas regras SWRL para classificar fenótipos de autismo, fazem parte de um projeto maior chamado Phenologue, no qual o professor Dr. Amar Das do Stanford Center for Biomedical informatics Research (BMIR - Stanford University School of Medicine) é o principal responsável.

O projeto Phenologue é uma nova tecnologia baseada em conhecimento que pode apoiar esforços colaborativos para adquirir, gerenciar, e realizar inferências a cerca de fenótipos de 
doenças (tais como autismo, esquizofrenia, depressão e transtorno bipolar) a partir de dados experimentais e resultados publicados. Um dos objetivos do projeto Phenologue é a categorização dos fenótipos associados ao autismo, devido a essa doença ter um espectro muito grande de ocorrência. Para essa categorização, regras SWRL estão sendo desenvolvidas para a Autism Ontology (Autism Phenologue Rules ${ }^{1}$ ) que, atualmente, tem 156 regras. Um dos principais problemas no uso de SWRL é que grandes conjuntos de regras são mantidos de forma colaborativa e, à medida que crescem, os desenvolvedores começam a ter problemas no seu gerenciamento. Para auxiliar no desenvolvimento desse conjunto de regras, foram concebidas idéias para facilitar a Visualização/Edição colaborativa das regras.

Este trabalho foi desenvolvido em colaboração com o grupo dos professores Dr. Mark Musen e Dr. Amar Das do Stanford Center for Biomedical Informatics Research (BMIR Stanford University School of Medicine).

\subsection{Motivação}

Um dos principais problemas no uso de SWRL é que a medida que o conjunto de regras cresce, os desenvolvedores começam a ter problemas no seu gerenciamento. Um conjunto grande de regras torna-se difícil de compreender e sujeito a erros, especialmente quando mantido por mais de uma pessoa (colaborativamente). Apesar disso, o SWRL carece de uma ferramenta para a manipulação de regras que seja mais do que um simples editor de texto. Os editores existentes para SWRL, encontramos apenas 3 na literatura, não utilizam as ferramentas e interfaces normalmente encontradas em editores de regras usados em outras áreas (Zacharias 2008), notadamente os editores para regras de negócios. Eles carecem de uma quantidade maior de recursos para os seus usuários, como arvores de decisão e agrupamento de regras, facilidades que existem a muito tempo em outras áreas. Essa é a lacuna que este trabalho pretende preencher.

Outro importante motivador deste trabalho, foi a nossa parceria com o BMIR-Stanford University. O BMIR é um dos responsáveis pelo Phenologue (projeto que originou a necessidade de um editor mais completo para regras SWRL). Inicialmente foi escolhido o Autismo (no projeto Phenologue) por ser uma condição neuro-desenvolvimental altamente herdada e diversa, cuja identificação dos genes responsáveis ainda não foi feita. Segundo o Center of Disease Control and Prevention (Kim et. al., 2011), nos Estados Unidos, o número

\footnotetext{
${ }^{1}$ Ontologia disponível em: http://purl.org/autism-ontology/1.0/autism-phenologue-rules.pprj
} 
de casos, em crianças de oito anos, vem aumentando nos últimos anos: em 2000 eram [1:150], em 2002 eram [1:150], em 2004 eram [1:125], em 2006 eram [1:110] e em 2008 chegaram a [1:88], isso é muito alarmante. Daí a importância de projetos como o Phenologue e da nossa contribuição junto ao BMIR.

\subsection{Objetivos}

O SWRL carece de uma ferramenta para a manipulação de regras que seja mais que um simples editor de texto. Por essa razão, o objetivo central deste trabalho é desenvolver soluções para implementar um editor de regras SWRL que incorpore as melhores técnicas em Edição/Visualização de outros domínios de regras (ex. Domínio de regras de negócio) para obter, ao final, uma ferramenta mais completa do que as atuais para a Edição/Visualização de regras SWRL.

Para alcançar esse objetivo, o Web-Protégé foi escolhido como base para o esse editor por ser a versão Web do Protégé, um editor de ontologias consolidado e de código aberto, que facilita a colaboração entre desenvolvedores de ontologias. Essa nova ferramenta usará como base e ampliará o conjunto de recursos desenvolvidos em Silva (2012) para criar um editor SWRL como um plug-in para o Web-Protégé. Essa ampliação de recursos terá dois objetivos:

- Ampliar recursos no servidor: Os objetivos aqui são permitir que usuários possam trabalhar colaborativamente com a nova ferramenta e fazer o desacoplamento das APIs do Web-Protégé (para permitir uma migração fácil para futuras versões do mesmo).

- Adequar a interface gráfica: Zacharias (2008) fez um levantamento onde apontou os melhores recursos/interfaces para edição de regras em geral. Constatamos que muitos desses recursos não estavam disponíveis ou eram muitos limitados em ferramentas para edição de regras SWRL. O objetivo então é implementar os recursos mais importantes ainda não disponíveis em Silva (2012) e levantados por Zacharias (2008), entre eles: árvore de decisão, filtros mais completos, autocompletar e parafraseamento de regras.

\subsection{Estrutura do Trabalho}

Este trabalho está organizado da seguinte forma: no Capítulo 2 (Informática Biomédica) é apresentada a área da Informática Biomédica a qual o conjunto de regras Autism Phenologue Rules pertence. Nesse capítulo também é apresentado o autismo e o NDAR (repositório semântico sobre o autismo). Na sequência, no Capítulo 3 (Ontologias e a Web Semântica) são 
apresentados conceitos sobre a Web Semântica: ontologias, OWL e SWRL. Já no Capítulo 4 (Trabalhos Relacionados), são apresentadas as ferramentas relacionadas ao projeto, começando com as ferramentas Protégé e Web-Protégé (essa última serviu de base para a ferramenta desenvolvida neste projeto); continuando com ferramentas relacionadas a regras de negócio e SWRL; e terminando com um levantamento de interfaces e recursos usados em editores de regras em geral. O Capítulo 5 (Pré-Desenvolvimento) apresenta os passos realizados antes do desenvolvimento da nova ferramenta: requisitos, protótipos, ferramentas e padrões de desenvolvimento que foram estudados. No Capítulo 6 (SWRL Editor) são apresentados todos os recursos desenvolvidos para a nova ferramenta (intitulada SWRL Editor), um estudo de caso da ferramenta duas ontologias e um comparativo com outras ferramentas para SWRL. Por fim, no Capítulo 7 (Conclusões) são apresentadas as considerações finais deste trabalho, juntamente com as contribuições alcançadas e sugestões para trabalhos futuros. 


\section{Informática Biomédica}

Informática Biomédica tem sido um "campo emergente" por décadas. A preocupação com a informação médica e o desejo de informatizar os serviços de saúde não são novidade. Já em 1962, a American Health Information Management Association (AHIMA) obteve suas primeiras verbas federais para automatizar e melhorar os métodos de triagem, foi assim que surgiram os primeiros sistemas informatizados em Biomedicina (Bernstam, Smith e Johnson, 2010).

Ainda não existe uma definição universalmente aceita de Informática Biomédica. Muitas vezes, qualquer atividade que se relaciona com a computação é rotulada de "informática". Existe ainda algum debate sobre a conveniência de uma definição já que qualquer definição significativa tem o potencial para excluir um bom trabalho ou restringir o uso da informática como um termo de marketing.

Dessa forma, um conceito para informática biomédica é de uma ciência da informação aplicada no contexto da biomedicina. Sendo assim, a informática biomédica tem a ver com todos os aspectos da compreensão e promoção da organização, análise, gestão e utilização eficazes das informações em saúde (Bernstam, Smith e Johnson, 2010).

Uma característica primária da Informática Biomédica ou Informática em Saúde é a sua natureza interdisciplinar: Ela conecta a Ciência da Computação, Medicina, Biologia e Saúde, e fornece uma sinergia que vai além de qualquer coisa que os pesquisadores em qualquer domínio único podem oferecer.

As informações em informática biomédica necessitam de uma forma de armazenamento. Por isso, na Seção 2.1 são apresentados alguns repositórios onde são mantidos esses tipos informações. Além disso, este trabalho está ligado ao projeto Phenologue (apresentado na Seção 2.3) que é a aplicação da informática para ajudar a identificar genes envolvidos com o autismo. Como o projeto Phenologue é fortemente relacionado ao NDAR, a Seção 2.2 apresentará os conceitos relacionados ao NDAR. 


\subsection{Repositórios}

Esforços para aquisição de dados e conhecimentos levaram à criação de repositórios na web. Seu objetivo principal é o compartilhamento de ontologias, aplicações, resultados de pesquisas, experimentos e publicações na Web (Thireou, Spyrou e Atlamazoglou, 2007). Destacamos aqui o BioPortal, o NCBO, o PubMed, o EBI e o OBO.

O NCBO (National Center for Biomedical Ontology) (http://www.bioontology.org) tem por objetivo apoiar os pesquisadores da área biomédica oferecendo ferramentas Web e desktop para o desenvolvimento, gerenciamento, conversão, mapeamento e anotação de ontologias. Além disso, o NCBO indexa ferramentas de terceiros, centraliza projetos colaborativos, disponibiliza fóruns de discussão e oferece treinamento especializado em bioinformática. A principal ferramenta do NCBO é o BioPortal (http://bioportal.bioontology.org), ele consiste em uma biblioteca virtual de ontologias em vários formatos, incluindo OWL, e um conjunto de ferramentas que permite o acesso e visualização dessas ontologias e também a realização de anotações semânticas de dados (Rubin et al., 2008).

O PubMed (http://www.ncbi.nlm.nih.gov/pubmed/) é o maior índice bibliográfico relacionado com as ciências da vida (Willinsky e Quint-Rapoport, 2007). Atualmente possui mais de 20 milhões de citações para documentos biomédicos. O PubMed inclui citações nos campos da Medicina, Enfermagem, Odontologia, Medicina Veterinária, Sistemas de Saúde e Ciências afins. Ele usa diversas ontologias (UMLS, MeSH, etc) para adicionar informação semântica a suas citações.

O EBI (European Bioinformatics Institute) (http://www.ebi.ac.uk/) gerencia bases de dados biológicos incluindo ácidos nucléicos, seqüências de proteínas e estruturas macromoleculares. É uma das poucas organizações que fornecem acesso a um conjunto de dados tão abrangente na área, destacam Brooksbank, Cameron e Thornton (2005).

O OBO (Open Biomedical Ontologies), que foi fundada pelo Gene Ontology Consortium em 2003, contém mais de 48 ontologias contribuídas por membros da comunidade biomédica (http://www.obofoundry.org/).

\subsection{NDAR}

O NDAR é um sistema da área de informática biomédica com um repositório de dados de pesquisas desenvolvido pelo National Institutes of Health $(\mathrm{NIH})$ para apoiar e acelerar o 
avanço da pesquisa sobre Autism Spectrum Disorders (ASD) (NDAR, 2010). O NDAR fornece a infra-estrutura para armazenamento, pesquisa e analise de diversos tipos de informações (NDAR, 2011). Uma das funcionalidades do NDAR é fornecer uma ferramenta de consulta para a construção de conjuntos de dados para responder a questões específicas relevantes para pesquisadores de autismo.

Além disso, o NDAR fornece armazenamento longitudinal de informações sobre um participante de pesquisas geradas por um ou mais estudos. Em outras palavras, o NDAR é capaz de associar imagens, informações genéticas, avaliações clínicas e outras informações de um único participante de uma dada pesquisa mesmo se esses dados tiverem sido coletados em diferentes locais ou através de diferentes estudos. Ao fazer isso, o NDAR permite que os pesquisadores tenham acesso a mais dados do que eles poderiam recolher por conta própria e fornece ferramentas robustas para analisar as informações, tornando mais fácil e rápido para investigadores reunirem, avaliarem e compartilharem as informações sobre pesquisas em autismo a partir de uma variedade de fontes.

Um dos objetivos do NDAR é proporcionar aos investigadores um recurso público para a coleta, arquivamento, recuperação, compartilhamento e análise de dados sobre o autismo (Tu et al., 2008).

Segundo NDAR (2010), outro objetivo do NDAR é ajudar a acelerar a pesquisa do autismo através da criação de uma infra-estrutura que integra conjuntos de dados heterogêneos sobre o autismo. Geralmente, o NDAR oferece os seguintes recursos:

- Comparações de dados entre vários sistemas de bioinformática;

- Implantação de ferramentas para pesquisadores da área de bioinformática;

- Compartilhamento de dados de pesquisa com a comunidade;

- Acesso para consulta a um repositório de dados de fenótipos, genomas, imagens e dados de pesquisas genealógicas;

O NDAR é uma plataforma segura para a comunidade que pesquisa ASD, abrangendo toda a gama de dados coletados por investigadores e combinando as tecnologias, a fim de (NDAR, 2011):

- Definir explicitamente a natureza dos dados e como eles foram coletados;

- Permitir a re-agregação e a re-análise dos dados;

- Assegurar a confidencialidade dos indivíduos da pesquisa;

- Promover a cooperação científica;

- Proporcionar um horário conveniente para a partilha de dados descritivos e experimentais; 
- Promover a padronização e harmonização das abordagens utilizadas na bioinformática para toda a comunidade ASD;

Outro conceito importante utilizado no NDAR são os repositórios federados, ou seja, os dados residentes no NDAR podem ficar conectados com outros bancos de dados localizados em outros lugares. Caso os recursos estejam federados ao NDAR, os pesquisadores serão capazes de acessar os dados e informações apenas com uma busca.

A arquitetura técnica do NDAR realiza essa ligação, independentemente da sua localização, e de uma forma que respeite as políticas e autorização das instituições e dos dados (NDAR, 2011). Segundo NDAR (2011), já há vários repositórios que estão federados ou em processo de federação:

- Pediatric MRI Data Repository - repositório abundante em fenótipos e dados de imagem de mais de 500 crianças com desenvolvimento típico, do nascimento à idade adulta;

- The Autism Tissue Program - um programa totalmente financiado pelo programa cientifico da Autism Speaks, que está empenhada em promover a aquisição, processamento e administração de dados clínicos sobre tecido cerebral;

- The Autism Genetic Resource Exchange - Um repositório de dados sobre mais de 1.000 famílias afetadas pelo ASD;

- The Interactive Autism Network - um repositório do Instituto Kennedy Krieger, com financiamento da Autism Speaks, que contém dados sobre 30 mil indivíduos e famílias com um diagnóstico de ASD que apresentaram voluntariamente informações de interesse científico;

\subsubsection{Autismo}

Autism Spectrum Disorder (ASD) é uma série de transtornos complexos no desenvolvimento mental, caracterizados por deficiências sociais, dificuldades de comunicação e padrões restritos, repetitivos e estereotipados de comportamento (Frith e Hill, 2003).

Assumpção e Pimentel (2000) descrevem a história do autismo começando por 1943, quando Leo Kanner descreveu o autismo como um quadro caracterizado por obsessividade, estereotipias e ecolalia, sob o nome "distúrbios autísticos do contato afetivo".

Assumpção e Pimentel (2000) afirmam que apenas em 1976 começou a mudar a concepção da doença de uma psicose para um distúrbio do desenvolvimento, assim o autismo 
passou a ser considerado uma deficiência mental. Atualmente Assumpção e Pimentel (2000) classificam o autismo em:

- Síndrome de Asperger: identificada antes dos 24 meses, de maior ocorrência no sexo masculino, a inteligência fica próxima da normalidade. Apresenta déficit na sociabilidade, interesses específicos e circunscritos com história familiar de problemas similares e baixa associação com quadros convulsivos;

- Síndrome de Rett: mais comum no sexo feminino, sendo reconhecida entre os 5 e 30 meses. Os indivíduos apresentam marcado déficit no desenvolvimento, com desaceleração do crescimento craniano, retardo intelectual marcado e forte associação com quadros convulsivos;

- Transtornos desintegrativos: os casos são identificados antes dos 24 meses, com predomínio no sexo masculino. Os indivíduos apresentam padrões de sociabilidade e comunicação pobres, e frequência de síndrome convulsiva associada;

- Os transtornos abrangentes não especificados: A idade de início é variável, predomínio no sexo masculino, comprometimento variável na área da sociabilidade, bom padrão comunicacional e pequeno comprometimento cognitivo;

O Center of Disease Control and Prevention (CDC), nos Estados Unidos, realizou uma pesquisa em 2008 (Kim et. al., 2011), sobre casos de autismo. Essa pesquisa confirmou que nos EUA existe uma criança com autismo para cada 88 crianças de oito anos de idade. Comparando com a primeira pesquisa feita em 2000, em que constatava a existência de um caso para cada 150 crianças, esses dados tornam-se mais preocupantes.

A ASA (Autism Society of America) estima que existam atualmente 1,5 milhões de americanos afetados pelo autismo. O mesmo quadro tem sido observado no Reino Unido, com a incidência subindo de 1:2500 em 1993 para 1:100 em 2009. Já no Brasil, o Projeto Autismo do Instituto de Psiquiatria do Hospital das Clínicas da Universidade de São Paulo, estima que em 2007 haviam cerca 1 milhão de casos de autismo. Estes números tornam a desordem tão preocupante como o câncer e a AIDS.

\subsection{O Projeto Phenologue}

Com a conclusão do sequenciamento do genoma humano e avanços na genotipagem e metodologias de análise, pesquisadores estão realizando progressos no sentido de encontrar determinantes biológicos para neuropatologias. Esses esforços, no entanto, não têm sido tão 
bem sucedidos em doenças mentais, tais como a esquizofrenia, a depressão, o transtorno bipolar e o autismo.

Uma razão muito citada para essa falta de progresso é o pouco uso de fenótipos intermediários (endophenotypes) que poderiam prover uma relação sinal-ruído genético maior que o simples uso de categorias de doenças (Flint e Bureau). Para resolver esse problema o projeto Phenologue (Hassanpour, O'Connor e Das, 2010) foi lançado: uma nova tecnologia baseada em conhecimento que pode apoiar esforços colaborativos para adquirir, gerenciar, e realizar inferências a cerca de fenótipos de doenças a partir de dados experimentais e resultados publicados.

Inicialmente o autismo foi escolhido como alvo por ser uma condição neurodesenvolvimental altamente herdada e diversa cuja identificação dos genes responsáveis ainda não foi feita. Outro fator é que estudos recentes têm demonstrado uma maior ocorrência de casos de autismo (Tu et al., 2008).

O Phenologue é baseado em genética psiquiátrica, tecnologias da Web Semânticas e firstorder reasoning e utiliza a ontologia do autismo que está sendo criada colaborativamente para o NDAR. O desenvolvimento dessa ontologia está sendo conduzido pelo professor Amar Das, do BMIR - Stanford University, e envolve especialistas em autismo e informática da Universidade e do NDAR. Ela estende ontologias disponíveis na $O B O$ Foundry (http://www.obofoundry.org/) e sua criação ocorreu por meio de uma revisão sistemática da literatura para identificar termos do domínio e relacionamentos relevantes para fenótipos de autismo (Tu et al. 2008).

Essa ontologia se concentra em um conjunto de conceitos fundamentais e suas relações para unificar diversos marcadores clínicos, comportamentais e biológicos do autismo, e irá apoiar a consulta e integração de dados a serem coletados pelo NDAR (Young et al., 2009). 


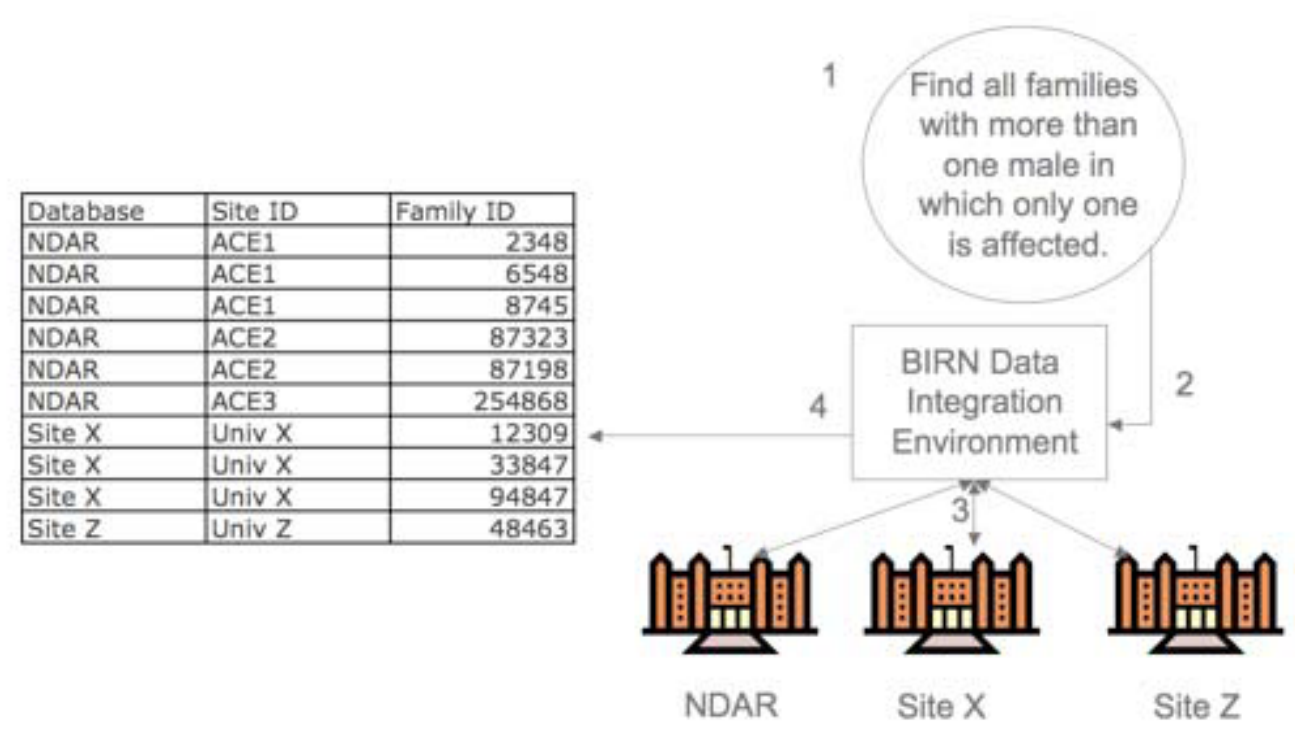

Figura 1 - Phenologue e NDAR (Young et al., 2009)

A Figura 1 mostra que as ferramentas do Phenologue poderão fazer consultas de informações que podem estar no NDAR, ou mesmo em alguma outra federação de repositórios de informação. Para tornar essas consultas possíveis, uma das principais metas do Phenologue é a realização de uma categorização de casos em fenótipos de autismo. Para isto, especialistas nesses casos estão usando a ontologia do autismo e a linguagem SWRL para criar regras para essa categorização. É precisamente na criação dessas regras que está o foco deste trabalho.

\subsection{Considerações Finais}

As estatísticas sobre o autismo são preocupantes, gerando a necessidade do crescimento das pesquisas nessa área. O Projeto Phenologue já é um esforço no sentido de encontrar esses determinantes biológicos para o autismo. Entre os objetivos do Projeto Phenologue, está a realização de uma categorização de casos em fenótipos de autismo. Para isso, estão sendo criando regras na linguagem SWRL que farão esta categorização. Para acelerar o desenvolvimento dessas regras, este trabalho apresenta uma nova ferramenta de edição colaborativa de regras SWRL. 



\section{Ontologias e a Web Semântica}

O principal objetivo desse capítulo é apresentar a linguagem de regras SWRL (Seção 3.2.3), com a qual a ferramenta desenvolvida trabalha. Ela é uma linguagem para regras na Web Semântica (Seção 3.2). A base da Web Semântica são ontologias, elas são modelos de representação do conhecimento em um domínio. Na Seção 3.1, elas são caracterizadas. $\mathrm{Na}$ seção 3.2 é apresentada a Web Semântica e suas principais linguagens: XML, RDF e OWL, mostrando as limitações de cada uma e assim explicando porque a necessidade da linguagem SWRL (um padrão para regras na Web Semântica).

\subsection{Ontologias}

O W3C (Heflin, 2004) afirma que as ontologias são vistas como a tecnologia de consolidação para a construção da Web Semântica. O termo é emprestado da Filosofia, em que uma ontologia é um relato sistemático da existência (Gruber, 1993).

Studer, Benjamins e Fensel (1998) definem ontologia como uma especificação formal e explícita de uma conceituação compartilhada. Conceituação se refere a um modelo abstrato de algum fenômeno no mundo, identificando os conceitos relevantes daquele fenômeno. Explícito significa que os conceitos utilizados e as restrições sobre seu uso são explicitamente definidos. Formal refere-se ao fato de que a ontologia deve ser legível pelas máquinas. Compartilhado refere-se à noção de que uma ontologia captura o conhecimento consensual, isto é, não é privado de algum indivíduo, mas aceito por um grupo.

Ontologias são utilizadas para promover a interoperabilidade entre sistemas, ao representarem os dados compartilhados por diversas aplicações (Uschold e Grüninger, 2004). Ontologias são amplamente utilizadas para fins diferentes e em diferentes comunidades.

Uschold e Jasper (1999) apresentaram outra definição para a palavra ontologia para popularizá-la em outras áreas. Para os autores, uma ontologia pode ter várias formas, mas necessariamente incluirá um vocabulário de termos e alguma especificação de seu significado. Isto inclui definições e uma indicação de como os conceitos estão inter-relacionados o que coletivamente impõe uma estrutura sobre o domínio e restringe a possível interpretação de termos. 


\subsubsection{Características}

Em geral, uma ontologia descreve formalmente um domínio. Os componentes básicos de uma ontologia são classes (organizadas em uma taxonomia), relações (que representam os tipos de interações entre os conceitos de um domínio), axiomas (usados para modelar sentenças sempre verdadeiras) e instâncias (utilizadas para representar elementos específicos, ou seja, os próprios dados) (Noy e McGuinness, 2001).

As classes denotam conceitos importantes do domínio (Antoniou e Harmelen, 2008). Por exemplo, em uma ontologia universitária funcionários, alunos, turmas, salas de aulas e disciplinas são alguns conceitos importantes.

As relações tipicamente incluem hierarquias de classes (Antoniou e Harmelen, 2008). Uma hierarquia especifica uma classe "Graduando" que é uma subclasse de "Estudante", ou seja, cada objeto da classe "Graduando" também está incluído em "Estudante". A Figura 2 mostra uma hierarquia para o domínio universitário.

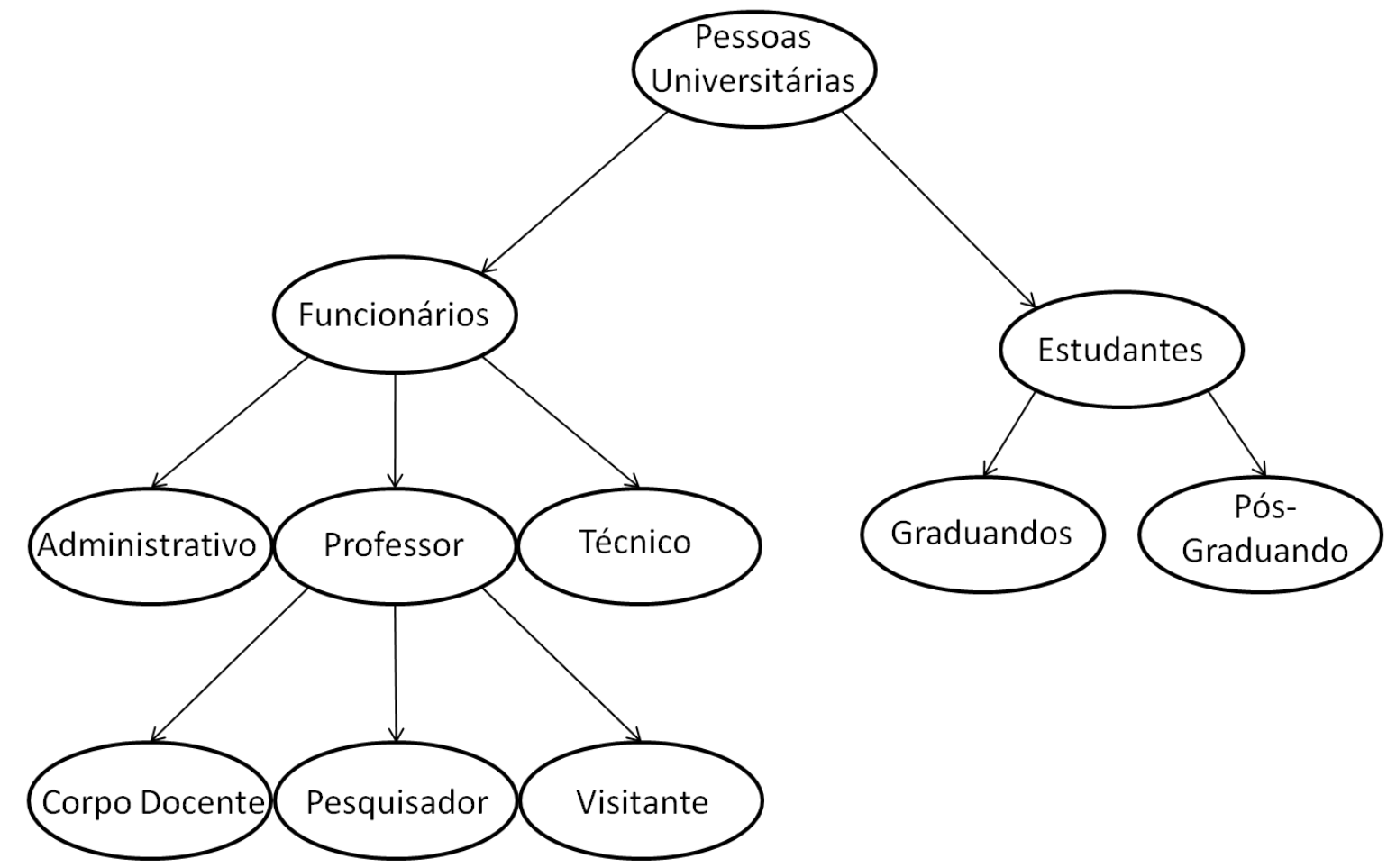

Figura 2 - Hierarquia para o domínio da Universidade

Além das relações de herança, ontologias podem conter regras assumidas como verdadeiras no domínio em questão, os axiomas. Alguns tipos de axiomas são: Propriedades (Ex: Funcionário Acadêmico ensina Estudantes), Restrições de Valores (Ex: apenas professores que fazem parte do corpo docente podem ministrar cursos), Disjunção (Ex: os grupos de funcionários administrativos e de professores são disjuntos) e Especificação lógica 
entre dois objetos (Ex: cada departamento deve incluir pelo menos 10 membros do corpo docente) (Antoniou e Harmelen, 2008).

Por último, as instâncias das classes fazem parte de uma ontologia. Elas são utilizadas para representar elementos específicos, ou seja, os próprios dados que, juntamente com a definição de uma ontologia, constituem a base de conhecimento (Noy e McGuinness, 2001). Os indivíduos representam objetos do domínio de interesse (Horridge et al., 2004).

Outra característica das ontologias é que elas devem fornecer um entendimento compartilhado de um domínio. Tal compreensão compartilhada é necessária para superar as diferenças de terminologia. As diferenças podem ser superadas através do mapeamento da terminologia específica, para uma ontologia compartilhada, ou através da definição de mapeamentos direto entre as ontologias. Em ambos os casos, é fácil perceber que as ontologias apóiam a interoperabilidade semântica.

\subsection{Web Semântica}

De acordo com Berners-Lee e Fischetti (2008), a Web Semântica é uma rede de dados que podem ser processados diretamente ou indiretamente por máquinas. Sendo que a iniciativa da criação da Web Semântica foi de Tim Berners-Lee, a própria pessoa que inventou o WWW no final dos anos oitenta (Antoniou e Harmelen, 2008).

Para possibilitar esta compreensão, os computadores necessitam ter acesso a coleções estruturadas de informações (dados e metadados) e a conjuntos de regras de inferência que ajudem no processo de dedução automática para que seja possível o raciocínio automatizado (Berners-lee, Hendler e Lassila, 2001).

Atualmente, muitas pesquisas estão sendo feitas para possibilitar de maneira eficiente os objetivos da web semântica. Esse desafio começa por prover uma linguagem que permita expressar não só os dados, mas ainda regras que possam inferir afirmações sobre os mesmos, e que sua utilização esteja disponível amplamente na web.

Nesse contexto, a web semântica possibilita que agentes computacionais (software) montem seus índices de busca baseados no significado da informação solicitada e cujo conteúdo remeta mais verdadeiramente ao propósito original de busca do usuário (Bernerslee, Hendler e Lassila, 2001).

Essa tecnologia vai nos levar a uma nova fase onde a tarefa árdua e manual de identificação, acesso e utilização das informações será atribuída com êxito ao computador, 
ajudando os seres humanos a mudar o seu foco de atividades voltadas a busca de dados para atividades voltadas a busca de conhecimento ( $\mathrm{Wu}, 2010)$.

Entretanto, é preciso ressaltar que a semântica não está somente relacionada ao conteúdo de um recurso, mas também à forma como este se relaciona com os demais recursos na web (Dziekaniak e Kirinus, 2004). Portanto, é essencial que os recursos disponibilizados sejam expressivos o bastante para que as máquinas ou agentes sejam capazes de processar e entender o real significado dos dados, intermediando as necessidades de cada usuário e as fontes de informações disponíveis (Dziekaniak e Kirinus, 2004).

Para que os recursos possam ser expressivos para máquinas são necessárias linguagens de representação. Para Berners-Lee, Hendler e Lassila (2001), só uma ontologia não seria suficiente para imprimir semântica à Web, requerendo a adoção de tecnologias, como por exemplo, XML (Extensible Markup Language) e RDF (Resource Description Framework). Além delas é possível citar a OWL (Web Ontology Language) que é uma recomendação da W3C para definir e instanciar ontologias na Web.

\subsubsection{XML e RDF}

XML é uma meta-linguagem universal para a definição de marcação. Ela fornece uma estrutura uniforme e um conjunto de ferramentas, como analisadores para intercâmbio de dados e metadados entre aplicações. No entanto XML não fornece qualquer meio para falar sobre a semântica, o significado, dos dados.

Nesse ponto entra o RDF (Resource Description Framework) que é uma especialização do XML, sendo o RDF um esquema para a definição de informações na Web, provendo tecnologia para expressar o significado de termos e conceitos de modo que os computadores possam facilmente processá-los (Berners-lee, Hendler e Lassila, 2001).

O RDF é um modelo padrão para trocas de dados na web. Ele tem características que facilitam a fusão de dados, mesmo quando os esquemas subjacentes diferem, e apóia especificamente a evolução dos esquemas ao longo do tempo sem a necessidade de que todos os consumidores de dados sejam alterados (Klyne, Carroll e McBride, 2004).

O RDF amplia a estrutura de links da Web para usar URIs para nomear a relação entre as coisas, bem como as duas extremidades do link (isto é normalmente referido como "tripla"). Com este modelo simples, ele permite que os dados estruturados e semi-estruturados possam ser misturados, expostos e compartilhados entre aplicações diferentes (Klyne, Carroll e McBride, 2004). 
Segundo Klyne, Carroll e McBride (2004), o RDF foi projetado para atender os seguintes objetivos: ter um modelo de dados simples, ter uma semântica formal e inferência com provas, usar um vocabulário extensível baseada em URIs, usar uma sintaxe baseada em XML, suportar o uso de datatypes do XML Schema e permitir fazer declarações sobre qualquer recurso.

O RDF tenta trazer interoperabilidade devido à grande quantidade de formatos diferentes existentes. RDF utiliza os seguintes conceitos (Klyne, Carroll e McBride, 2004):

- Grafo de Modelo de Dados (Graph data model);

- Vocabulário baseado em URIs (URI-based vocabulary);

- Tipos de dados (Datatypes)

- Literais (Literals)

- Sintaxe de serialização XML (XML serialization syntax)

- Entailment

A estrutura básica de qualquer expressão em RDF é uma coleção de triplas, cada uma composta por um sujeito, um predicado e um objeto. Um conjunto de triplas como é chamado um gráfico RDF (Klyne, Carroll e McBride, 2004). Isso pode ser ilustrado por um diagrama de nós e arcos dirigidos no qual cada tripla é representada como uma ligação nó-arco-nó. Cada tripla representa uma afirmação (statement). Por exemplo:

A página http://www.pagina.com tem como criador o Antônio.

Tem-se um recurso ou sujeito (http://WwW.pagina.com), uma propriedade ou predicado desse recurso (criador) e um valor ou objeto para essa propriedade (Antônio). Comumente se escreve como propriedade (sujeito, objeto) ou criador (http://www.pagina.com, Antônio).

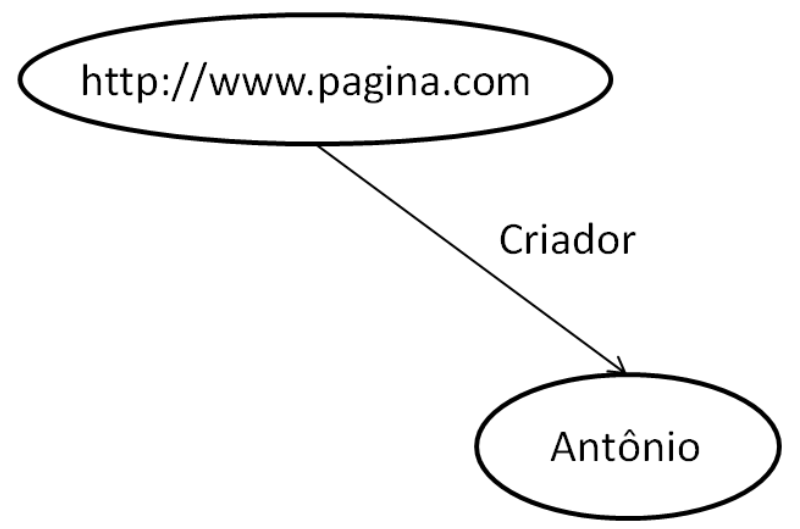

Figura 3 - Exemplo de Grafo RDF 
Na representação de grafos (Figura 3), os nós RDF são os seus sujeito e objeto com um arco ligando os dois, sempre direcionado para o objeto. Cada nó pode ser uma URI, um literal ou estar em branco (não podendo ser identificado). Os predicados são identificados por URIs e podem ser também nós em um grafo.

Quanto aos tipos de dados utilizados pelo RDF para representação de valores, eles podem ser números inteiros, números reais e datas (Klyne, Carroll e McBride, 2004). Um tipo de dado consiste em um espaço léxico, um espaço de valores ou um mapeamento léxico-paravalor. Um tipo de dado é identificado por uma ou mais URIs. A recomendação do W3C espera que os tipos de dados usados sejam definidos pelo XML-Schema.

Os literais são utilizados em RDF para identificar valores como números e datas por meio de uma representação léxica. Os literais podem ser o objeto de uma declaração RDF, mas não o sujeito ou o predicado. Existe uma forma recomendada de serialização de RDF em XML de forma a facilitar a troca de modelos RDF entre aplicações (Klyne, Carroll e McBride, 2004).

E por último, segundo Klyne, Carroll e McBride (2004), uma expressão RDF A é dita entail de outra expressão RDF B se todos os possíveis estados dos itens que fazem A verdadeira também fizerem B verdadeira, ou seja, se A é provada como verdadeira então B pode ser inferida como verdadeira.

Para Feigenbaum et al. (2007), o RDF é o mais fundamental bloco de construção para a Web Semântica pois, além de poder ser utilizado para criar dados semânticos, é também utilizado como base para as linguagens de ontologia da Web Semântica. Entretanto para Staab, Maedche e Handschuh (2001), os dados em RDF são fracamente interligados, de modo que a Web Semântica necessita de técnicas mais sofisticadas.

\subsubsection{OWL}

A OWL (Web Ontology Language) foi recomendada pelo W3C em 10 de fevereiro de 2004 para representar e compartilhar ontologias na Web (Smith, Welty e McGuinness, 2004). Essa linguagem foi projetada para aplicações que necessitam processar o conteúdo da informação em vez de apenas apresentar informações em nós (McGuinness e Harmelen, 2004).

OWL é uma linguagem que permite que a semântica seja explicitamente associada ao conteúdo dos dados na web e formalmente especificada através de ontologias, compartilhadas na Internet. OWL é baseada em XML e RDF, oferecendo mecanismos para uma semântica formal. Cabe salientar que a OWL é uma extensão do vocabulário do RDF. Em sua primeira 
versão a OWL possuía três sub-linguagens, projetadas para comunidades especificas: OWL Lite, OWL DL e OWL Full.

OWL Lite é para usuários que necessitam principalmente de uma classificação hierárquica e restrições simples (McGuinness e Harmelen, 2004). Por exemplo, embora suporte restrições de cardinalidade, ela só permite valores de cardinalidade 0 ou 1 .

OWL DL é para usuários que querem a máxima expressividade, enquanto mantém a computabilidade (todas as conclusões são garantidos para serem computáveis) e decidibilidade (todas as computações terminarão em tempo finito) (McGuinness e Harmelen, 2004). OWL DL inclui todas as construções da linguagem OWL, mas elas podem ser usadas somente sob certas restrições (por exemplo, enquanto uma classe pode ser subclasse de muitas classes, uma classe não pode ser uma instância de outra classe). OWL DL é assim chamada devido à sua correspondência com as lógicas de descrição (description logic), um campo de pesquisa que estuda as lógicas que formam a base formal da OWL (McGuinness e Harmelen, 2004).

OWL Full é direcionada para usuários que querem a máxima expressividade e a liberdade sintática do RDF sem nenhuma garantia computacional (McGuinness e Harmelen, 2004). É improvável que qualquer software de raciocínio seja capaz de suportar completamente cada recurso da OWL Full (McGuinness e Harmelen, 2004).

Cada uma destas sub-linguagens é uma extensão de sua anterior, tanto no que pode ser expresso quanto no que pode ser concluído. O seguinte conjunto de relações são validos e seus inversos não (McGuinness e Harmelen, 2004).

- Toda ontologia OWL Lite é uma ontologia OWL DL.

- Toda ontologia OWL DL é uma ontologia OWL Full.

- Toda conclusão OWL Lite válida é uma conclusão OWL DL válida.

- Toda conclusão OWL DL válida é uma conclusão OWL Full válida.

Recentemente o W3C agregou novos recursos à linguagem OWL dando origem a uma nova recomendação, chamada OWL 2, que é uma extensão e revisão da OWL (W3C OWL Working Group, 2009). OWL 2 adiciona novas funcionalidades em relação a sua $1^{\mathrm{a}}$ versão, algumas são pequenos detalhes como a união disjunta de classes, enquanto outras oferecem nova expressividade, como chaves, redes de propriedades, tipos de dados mais ricos, intervalos de dados, restrições de cardinalidade qualificada, propriedades assimétricas e reflexivas (W3C OWL Working Group, 2009).

Nessa nova versão também existem sub-linguagens conhecidas como profiles. Os profiles são versões restritas da OWL 2 com algum ganho específico para o processo de classificação 
e inferência, além de contribuírem para a resolução de problemas relacionados com escalabilidade e eficiência (Motik et al., 2009). Cada perfil é definido pelas restrições da OWL DL. Os principais profiles são: OWL 2 EL, OWL 2 QL, OWL 2 RL.

- OWL 2 EL é particularmente útil em aplicações que empregam ontologias que contêm um grande número de propriedades e / ou classes (Motik et al., 2009). Este perfil capta o poder expressivo usado por muitas ontologias e é um subconjunto do OWL 2 onde os problemas de raciocínio básico podem ser processados em tempo polinomial em relação ao tamanho da ontologia (Motik et al., 2009). Algoritmos de raciocínio dedicado para esse perfil estão disponíveis e têm-se demonstrado implementáveis de uma forma altamente escalável (Motik et al., 2009).

- OWL 2 QL é voltado para aplicações que utilizam grandes volumes de dados instanciados, e para quando a resposta da consulta é a tarefa mais importante (Motik et al., 2009). Em OWL 2 QL, para se responder a consultas, podem ser usados sistemas convencionais de bancos de dados relacionais (Motik et al., 2009).

- OWL 2 RL é voltado para aplicações que exigem raciocínio escalável sem sacrificar muito a força expressiva (Motik et al., 2009). Ele é projetado para os casos em que é necessária muita expressividade sem perder a eficiência (Motik et al., 2009).

\subsubsection{SWRL}

Infelizmente a expressividade de OWL nem sempre é suficiente para modelar todos os tipos de problemas na área biomédica (e mesmo na Web Semântica). Especialmente OWL não tem suporte para cláusulas de Horn (representa uma sentença de implicação), muito usadas em regras para sistemas de decisão na área médica. Para suprir essa deficiência, a SWRL (Semantic Web Rule Language) foi criada.

A SWRL é baseada em uma combinação de OWL DL e OWL Lite (O'Connor et al., 2005). Essa combinação amplia o conjunto de axiomas da linguagem OWL, mais especificamente para poder incluir cláusulas Horn (O’Connor et al., 2005). Essas regras podem ser usadas para inferir novos conhecimentos a partir de bases de conhecimento em OWL (O’Connor et al., 2005). SWRL permite que os usuários escrevam regras para raciocínio sobre os indivíduos OWL que podem inferir novos conhecimentos sobre esses indivíduos (SWRLLanguage, 2012).

Regras SWRL são escritas em termos de classes, propriedades, indivíduos, e valores de dados OWL (SWRLLanguage, 2012). Por exemplo, uma regra SWRL que expresse a seguinte 
afirmação: "uma pessoa qualquer que tenha qualquer carro será considerada um motorista", ficaria assim:

$$
\text { pessoa(?x) ^ temcarro(?x, true) }->\text { motorista(?x) }
$$

Ao executar-se a regra acima, o seu efeito seria classificar todos os indivíduos da classe pessoa que possuíssem carro como também pertencentes à classe motorista. A SWRL também permite trabalhar com um indivíduo específico de uma ontologia. Por exemplo, é possível escrever uma regra diretamente para um indivíduo João, pertencente à classe pessoa, e fazer uma classificação direta deste indivíduo. Um exemplo pode ser visto na regra abaixo:

$$
\text { pessoa (João) ^ temCarro(João, true) -> motorista (João) }
$$

A regra acima apenas funciona para o indivíduo conhecido como João. Um dos recursos mais poderosos do SWRL é a capacidade de usuários usarem built-ins definidos (SWRLLanguage, 2012). Built-in é um predicado que pode ter um ou mais argumentos e realiza uma operação com os argumentos, avaliando e retornando verdadeiro ou falso. Por exemplo, uma regra que classifica um indivíduo da classe pessoa que seja maior de 18 anos como da classe adulto pode ser vista abaixo:

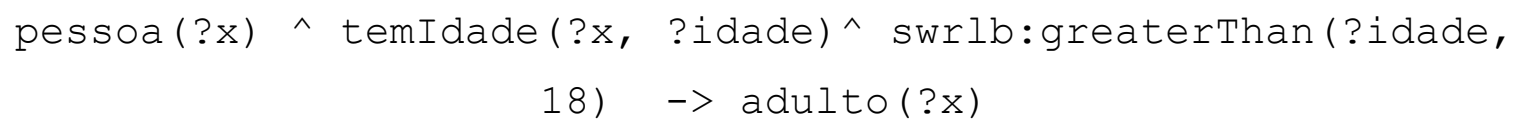

SWRL permite o uso de novas bibliotecas de built-ins e os usuários podem definir suas próprias bibliotecas, o que torna SWRL uma linguagem muito rica em recursos de representação. Por exemplo, poderia ser criada uma biblioteca que tivesse operações de conversão de valores e busca de termos em taxonomias.

Um exemplo mais complexo do uso de SWRL é mostrado por Hassanpour, O'Connor e Das (2009), neste exemplo o objetivo é estabelecer relações entre duas ou mais entidade de uma ontologia. O exemplo cria uma regra que estabelece regras de condução no estado da Califórnia para menores de 18 anos:

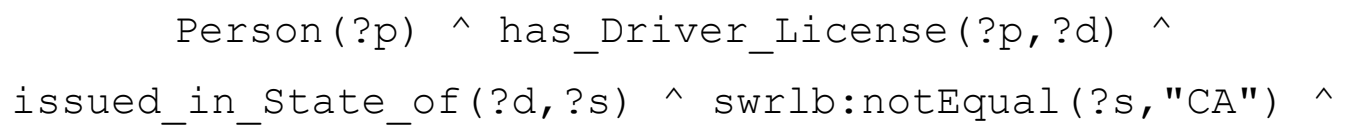




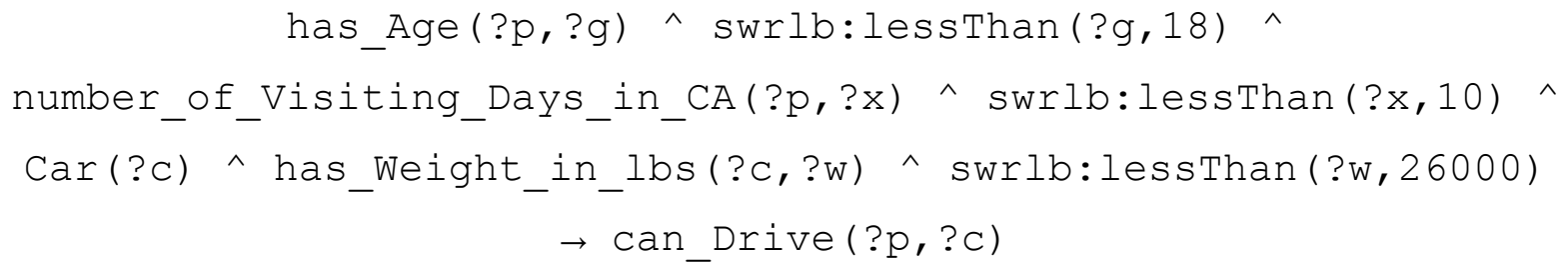

Traduzindo-se a regra acima para linguagem humana teríamos: "Um indivíduo com idade inferior a 18 anos, mas que possua carta de motorista, sendo de fora da Califórnia, visitando o estado por menos de 10 dias e dirigindo um veiculo com menos de 26000 libras, pode dirigir normalmente".

\subsection{Considerações Finais}

Nesse capítulo são introduzidos os conceitos básicos sobre a Web Semântica. Ela usa ontologias para descrever formalmente um domínio de conhecimento. Essas ontologias são descritas em OWL (recomendação W3C). Como OWL é limitado para modelar todos os tipos de problemas em certos domínios (ex. autismo), foi criada a linguagem SWRL. Com essa linguagem é possível inferir novos conhecimentos na ontologia. Porém, na medida que os conjuntos de regras crescem, os desenvolvedores começam a ter problemas no seu gerenciamento. Um conjunto grande de regras torna-se difícil de compreender e sujeito a erros, criando assim uma demanda por ferramentas que auxiliem no desenvolvimento das mesmas. 


\section{Trabalhos Relacionados}

Neste capítulo, é apresentada uma revisão sobre as principais ferramentas relacionadas com regras (SWRLTab, Axiomé, ACE View e Regras de Negócios) e relacionadas com o desenvolvimento da nova ferramenta (Protégé e Web-Protégé). O Protégé (amplamente utilizado por pesquisadores e desenvolvedores de ontologias) e o Web-Protégé (versão web do primeiro) são apresentados na seção ferramentas para Ontologias (Seção 4.1). Mais especificamente, as ferramentas que trabalham com regras são mostradas na Seção 4.2. Por último, na seção 4.3 será mostrado um resumo de todos os tipos de interfaces e recursos identificados em Silva (2012).

\subsection{Ferramentas para Ontologias}

As ferramentas Protégé e Web-Protégé são de suma importância para este mestrado, uma vez que a ferramenta desenvolvida será um plug-in para o Web-Protégé. O objetivo desta Seção é apresentar a ferramenta Web-Protégé tanto do ponto de vista de sua arquitetura quanto interface. Porém, para um melhor entendimento, primeiramente será tratado da história e importância do Protégé.

\subsubsection{Protégé}

O projeto Protégé surgiu no final da década de 90 com Mark Musen. Naquela época a aplicação apenas servia para aquisição e representação de conhecimento no domínio médico (Gennari et al., 2003). Desde então, passou por grandes mudanças e atualmente deixou de ser uma simples ferramenta para se tornar um conjunto de ferramentas destinadas ao desenvolvimento e uso de ontologias e aplicações baseadas em conhecimento (Rubin, Noy e Musen, 2007).

A versão do Protégé que começou a ter mais destaque foi a Protégé-2000. Ela tem muitos recursos e é base da ferramenta atual. O Protégé-2000 adotou o uso de frames para representação do conhecimento, a plataforma de desenvolvimento Java, a possibilidade de 
extensão da ferramenta e uma arquitetura baseada em plug-ins que é facilitada pelo uso da linguagem (Gennari et al., 2003).

Já em 2007, Rubin, Noy e Musen (2007) afirmaram que existiam mais de 70 mil usuários registrados do Protégé, usando o sistema para gerenciar terminologias e ontologias em diversos domínios. Nessa época, já estava disponível a versão Protégé 3 com a API ProtégéOWL, em que foi feita uma divisão da ferramenta em duas:

- O editor Protégé-Frame, destinado à construção de ontologias baseadas em frames, mantendo a compatibilidade com o Protégé-2000.

- O editor Protégé-OWL, usado para o desenvolvimento de ontologias em OWL e RDF.

Após o surgimento da OWL 2, foi desenvolvida a versão Protégé 4 (atualmente na Versão 4.2 Alpha). Embora existam características similares, as duas versões são consideravelmente diferentes. A principal e mais impactante mudança está relacionada com a arquitetura da aplicação Protégé, que deixou de ter um editor para frames, e agora se baseia na biblioteca OWL-API (OWL 2). As diferenças podem ser vistas no site da ferramenta ${ }^{2}$.

Originalmente, o Protégé 3 não oferecia a possibilidade de desenvolvimento de ontologias de forma colaborativa e era difícil manter grandes e complexas ontologias, podendo, por isso, não haver um consenso entre os diferentes especialistas construindo essas ontologias. Com essa demanda, foi desenvolvida uma extensão do Protégé denominada de Protégé Colaborativo (Tudorache, Noy e Musen, 2008).

\subsubsection{Web-Protégé}

O Web-Protégé é um editor open-source de ontologias, baseado no Protégé que funciona na Web (Tudorache, Vendetti e Noy, 2008). Ele foi desenvolvido usando o GWT (Google Web Toolkit). O principal motivo de se ter uma versão Web do Protégé é facilitar a colaboração entre desenvolvedores, já que não é necessário instalar programas locais. Nessa ferramenta, as ontologias estão disponíveis de forma centralizada e compartilhada. Como as ontologias estão se tornando cada vez maiores, é difícil que uma pessoa, ou um grupo pequeno de pessoas, consiga manter grandes ontologias de forma eficaz (Tudorache, Vendetti e Noy, 2008). Daí a necessidade do desenvolvimento colaborativo de ontologias.

\footnotetext{
${ }^{2}$ Migração para o Protégé4: http://protegewiki.stanford.edu/wiki/Protege4Migration\#Side_by_Side_Comparison
} 


\subsubsection{Arquitetura}

A Figura 4 mostra uma versão simplificada da arquitetura do Web-Protégé. O lado do servidor permite o acesso a serviços através da Ontology API (a versão da API atualmente usada é a Protege-OWL). Esta API Java contém métodos para leitura e escrita de ontologias OWL. Além disso, o componente do servidor fornece suporte para serviços de colaboração (Collaboration API), tais como anotações nos componentes da ontologia e controle de alterações (Tudorache, Vendetti e Noy, 2008).

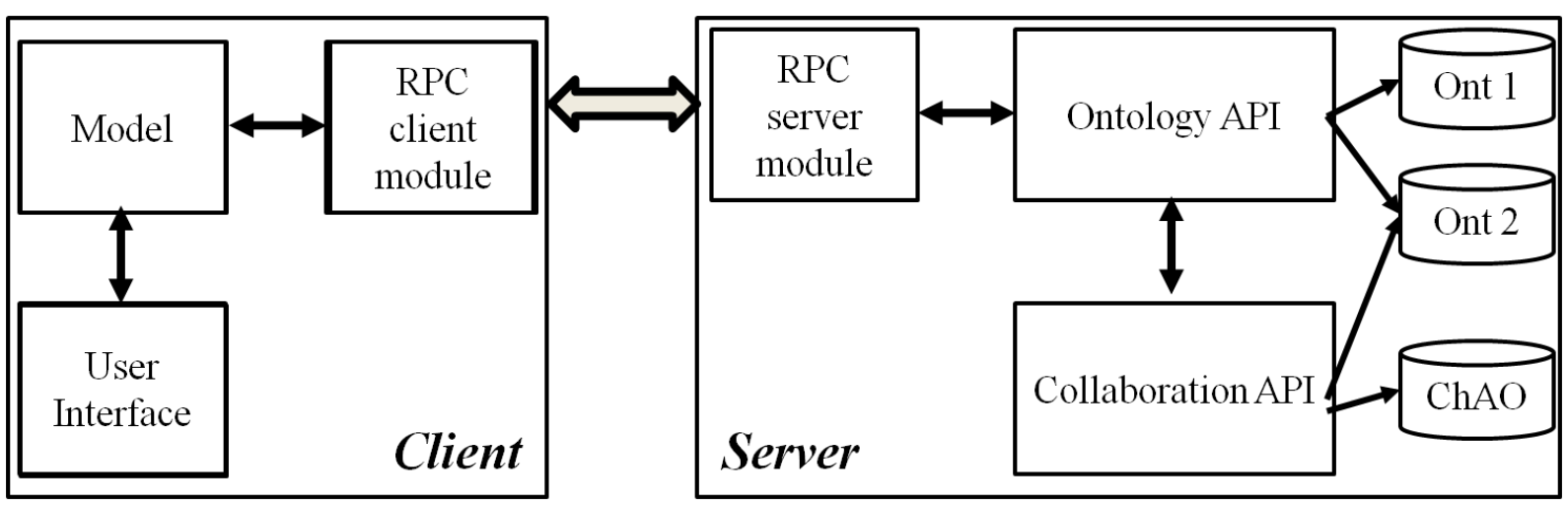

Figura 4 - Arquitetura do Web-Protégé (Tudorache, Vendetti e Noy, 2008).

Os usuários podem anexar anotações aos componentes da ontologia ou à ontologia como um todo. Existe uma ontologia para anotações chamada CHAO (Changes and Annotations Ontology) (Noy et al. 2006). CHAO contém classes que definem os tipos de anotações (por exemplo: comentário, proposta) e classes para descrever os diferentes tipos de alterações que um usuário pode fazer em uma sessão de edição (por exemplo, Class Created) (Tudorache, Vendetti e Noy, 2008).

Com esta arquitetura, o Web-Protégé pode acompanhar as mudanças na ontologia, gerindo conflitos entre várias alterações em uma mesma ontologia. O servidor do Web-Protégé faz chamadas para o servidor do Protégé Colaborativo que já fornece edição simultânea, transações e atomicidade nas operações (Tudorache, Vendetti e Noy, 2008).

O servidor gerencia os clientes conectados. Para cada ontologia é mantida um número de versão, sendo que esse é incrementado a cada alteração da ontologia (Tudorache, Vendetti e Noy, 2008). Cada cliente do Web-Protégé tem seu próprio número de versão que pode ser um número diferente da versão do servidor (Tudorache, Vendetti e Noy, 2008). Num intervalo de tempo definido (por padrão 5 segundos), os clientes buscam no servidor novas mudanças (Tudorache, Vendetti e Noy, 2008). O cliente envia ao servidor seu número de versão, e, por sua vez, o servidor envia ao cliente uma lista das mudanças entre as versões cliente e servidor 
(Tudorache, Vendetti e Noy, 2008). O cliente, com a lista de alterações, atualiza a cópia local da ontologia. Ainda no lado do cliente, existe a interface do usuário, um modelo da ontologia e o RPC (Remote Procedure Calls) módulo responsável pela comunicação com o servidor. O cliente tem um modelo interno da ontologia que representa o estado atual da ontologia no cliente. Os componentes de interface com o usuário usam um padrão de escuta que registra as mudanças no modelo do cliente (Tudorache, Vendetti e Noy, 2008). Atualmente, a comunicação entre o cliente e o servidor é feita através das chamadas RPC do GWT (Tudorache, Vendetti e Noy, 2008).

\subsubsection{Interface}

A interface do usuário inspirou-se em portais conhecidos, como o MyYahoo e iGoogle (Tudorache, Vendetti e Noy, 2008), foi implementada usando o GWT 2. A Figura 5 mostra a tela Inicial do Web-Protégé, em que (A) contém um link para fazer o login na ferramenta e em (B) aparece uma lista de todas as ontologias disponíveis. Essa lista contém o nome da ontologia, uma descrição e o usuário responsável por ela.

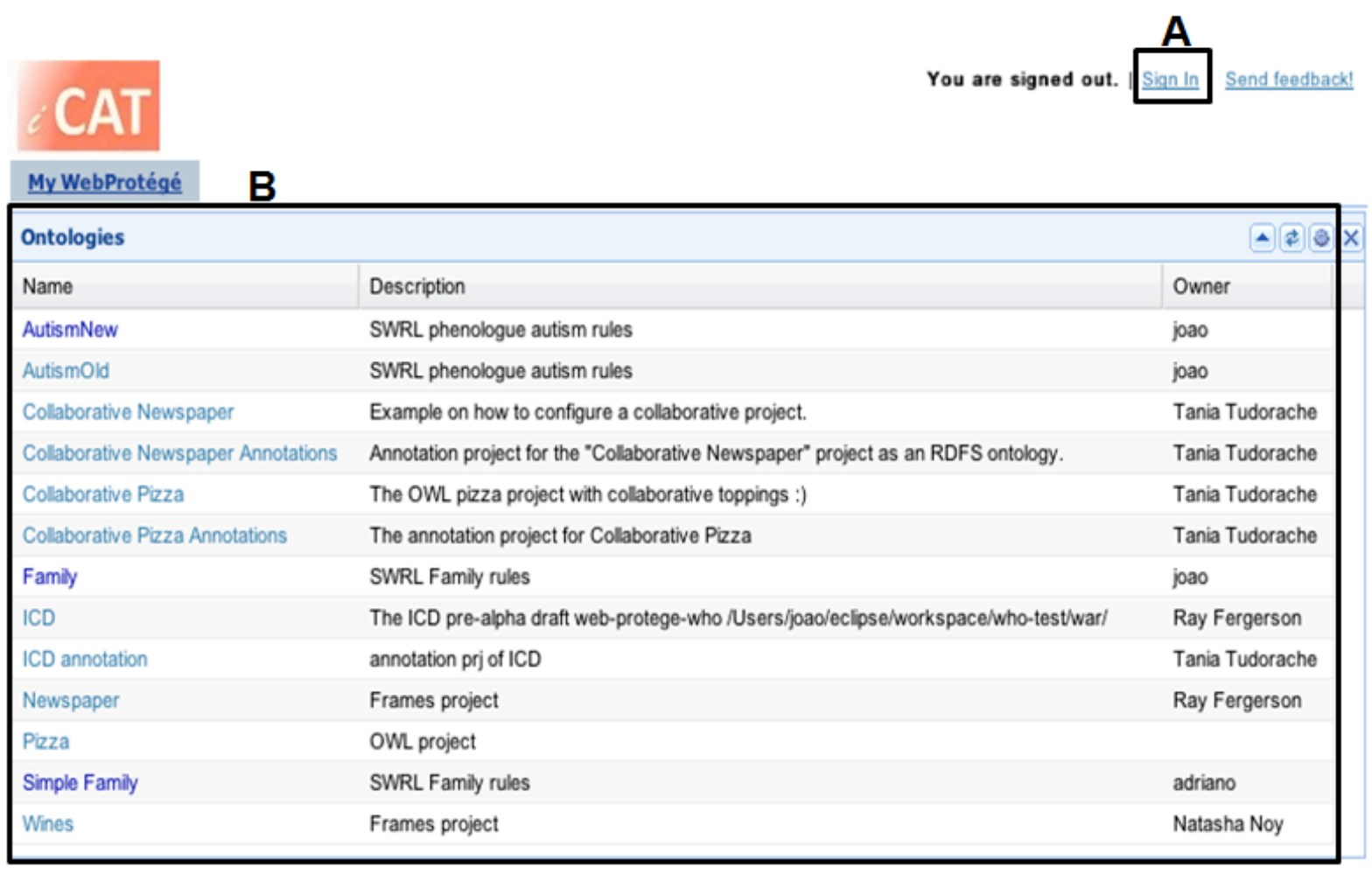

Figura 5 - Tela inicial do Web-Protégé: (A) Opção de login; (B) Listagem das ontologias.

A partir do link (Figura 5-(A)) é possível acessar a tela de login (Figura 6), com isso, a ferramenta tem o controle dos usuários e suas permissões para criação e edição de itens da 
ontologia. As configurações de restrições e cadastro de usuários só são acessíveis no servidor. Mais informações de como editar usuários e restringir certas operações podem ser encontradas no Guia do Administrador do Web-Protégé ${ }^{3}$.

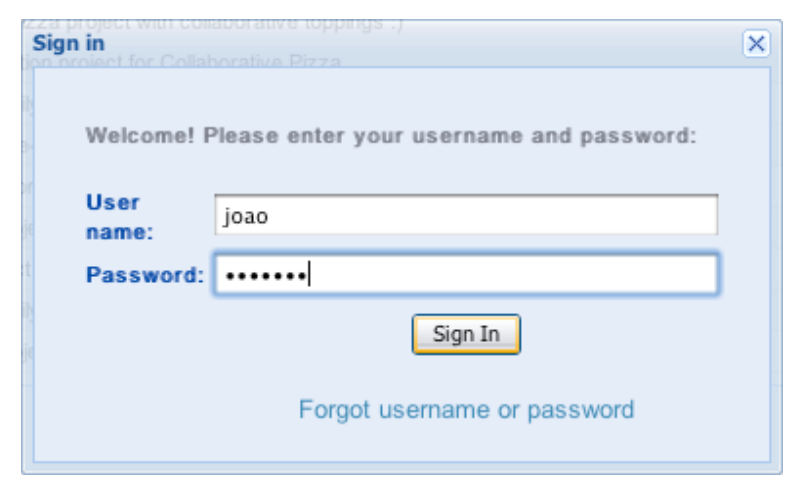

Figura 6 - Tela de Login do Web-Protégé.

O Web-Protégé usa abas para as ontologias selecionadas, como pode ser visto na Figura 7 (A), foi aberta uma nova aba para a ontologia Collaborative Pizza. Nessa mesma figura (B), pode-se identificar várias sub-abas (Classes, Properties, Individuals,...). Essas sub-abas são re-configuráveis pelo usuário e implementadas, pelo Web-Protégé como portlets que podem ser adicionadas por plug-ins. Uma Portlet é um componente gráfico básico do Web-Protégé (definido por uma interface específica) o qual todas as implementações de plug-ins devem implementar (cada plug-in tem que implementar pelo menos uma portlet).

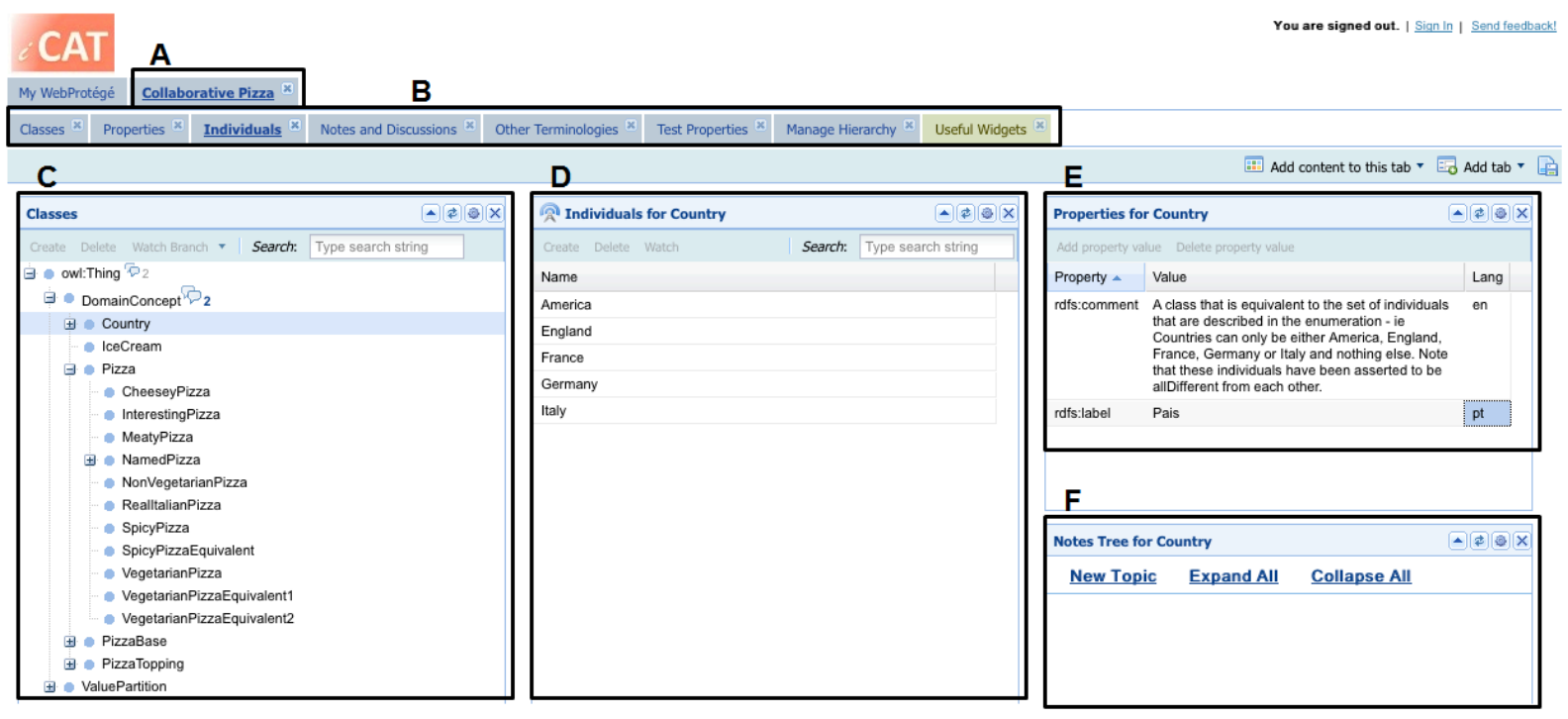

Figura 7 - Ontologia aberta no Web-Protégé: (A) Aba com a Ontologia Aberta; (B) Sub-Abas carregadas para esta ontologia; (C) Listagem das classes; (D) Listagem dos indivíduos; (E) Listagem das Propriedades; (F) Notas sobre um termo.

\footnotetext{
${ }^{3}$ http://protegewiki.stanford.edu/wiki/WebProtegeAdminGuide\#Configuring_projects.2C_users_and_access_policies
} 
$\mathrm{Na}$ Figura 7, está aberta a sub-aba Individuals, ela contém por default quatro portlets $(\mathrm{C}$, D, E e F). A portlet Classes (C) contém a visualização hierárquica de todas as classes da ontologia. Para cada classe selecionada são mostrados os indivíduos em (D), as propriedades em (E) e as anotações para discussão em (F).

Uma portlet pode estar em mais de uma sub-aba, isso dá ao Web-Protégé um grande poder de personalização das informações mostradas. O usuário pode escolher de uma lista de guias existentes e adicionar portlets dinamicamente. O usuário pode re-configurar a interface, personalizar o layout e guardá-lo para futuras sessões. Também é possível criar uma nova aba vazia e adicionar as portlets necessárias através de drag-and-drop. Mais informações sobre a configuração do layout podem ser vistas em no manual de configuração do Layout WebProtégé ${ }^{4}$ :

\subsection{Ferramentas de Regras}

\subsubsection{SWRL}

Segundo Zacharias (2008), o uso de regras na Web Semântica gerou interesse renovado e crescente no desenvolvimento de sistemas baseados em regras. $\mathrm{Na}$ literatura apenas são encontradas as seguintes ferramentas: o SWRLTab, Axiomé e o ACE View. As duas primeiras plug-ins do Protégé 3 e a ultima um plug-in do Protégé 4.

\subsubsection{SWRLTab}

A ferramenta SWRLTab foi desenvolvida como um plug-in para o Protégé 3. Esse plug-in é um ambiente de desenvolvimento para regras SWRL que usa a API Protégé-OWL (OWL 1.1). O SWRLTab tem suporte a edição, execução, sugestões de termos (autocomplete) e identificação de erros sintáticos em regras SWRL (seguindo a especificação de Horrocks et al. (2004)).

\footnotetext{
${ }^{4}$ Configurações de Layout do Web-Protégé: http://protegewiki.stanford.edu/wiki/WebProtegeLayoutConfig
} 


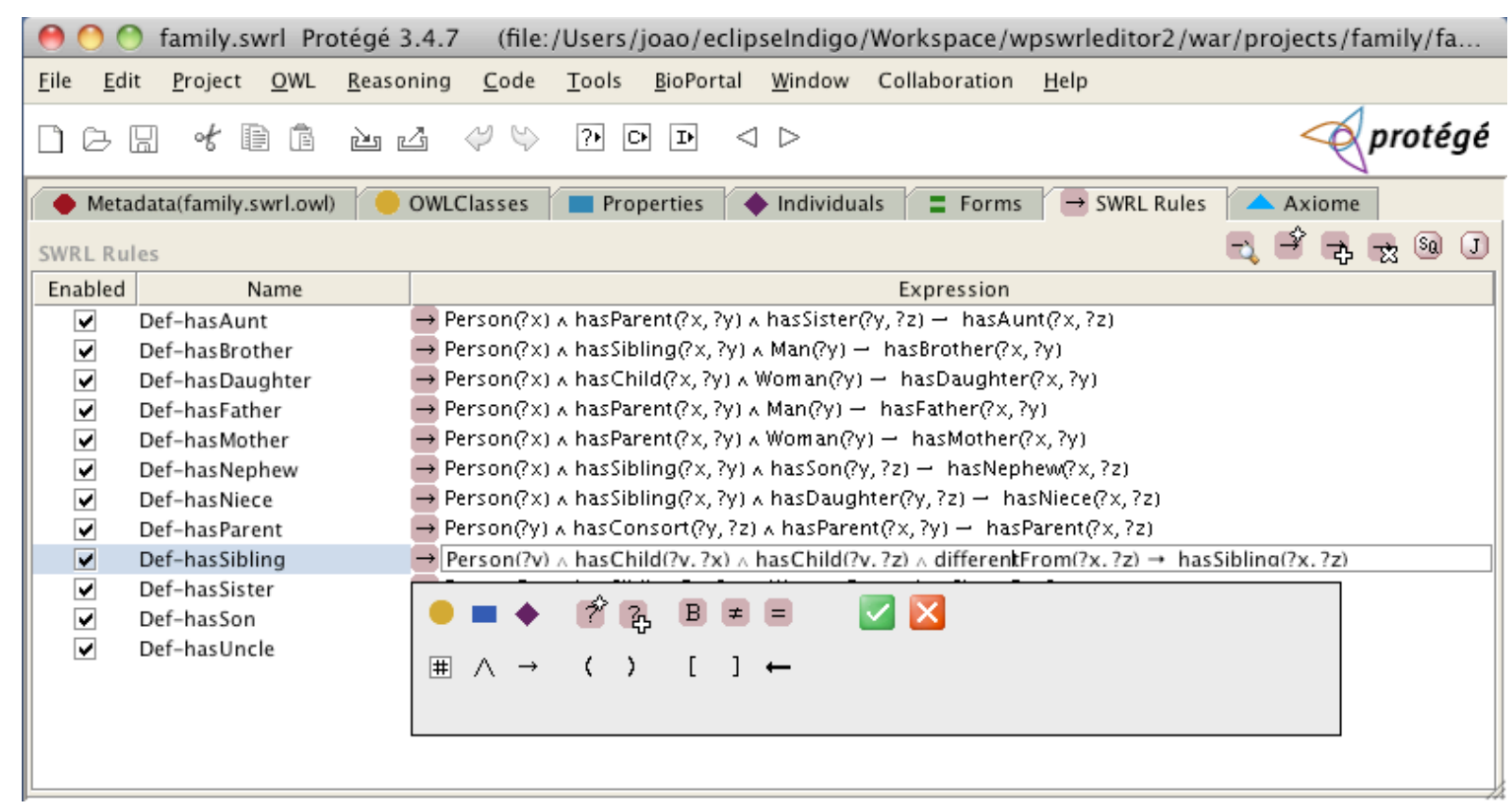

Figura 8 - SWRL Tab.

Na Figura 8 é apresentado o SWRL Tab. A lista das regras é apresentada no formato tabular, no qual é possível editá-las diretamente ou em um editor textual a parte. Para o SWRLTab, foi criada a SWRLAPI, uma extensão da API Protégé-OWL. A SWRLAPI tem um conjunto de interfaces Java para apoiar a construção de novas aplicações usando SWRL. Esta API tem vários componentes:

- SWRL Built-in Libraries: Uma série de bibliotecas de built-ins. Estão incluídos core built-ins, os definidos no Submission SWRL do W3C e built-ins para consulta em OWL.

- SWRL Built-in Bridge: dispõe de formas para criação de built-ins garantindo que estes sejam executados corretamente pela máquina de inferência;

- SWRL Bridge: define os padrões para a criação de built-ins e define também padrões para a máquina de inferência de regras;

- SWRL Rule Engine API: serve para criar instâncias para as máquinas de inferência. Por padrão utiliza a máquina de inferência JESS (Friedman-Hill, 2008);

- SQWRL Query API: disponibiliza o acesso as regras, através do JDBC e usa a linguagem de consulta Semantic Query-Enhanced Web Rule Language (SQWRL). SQWRL é uma linguagem de consulta de regras que utiliza a sintaxe SWRL juntamente com as operações SQL para obtenção de conhecimento de uma base OWL (O'Connor e Das, 2009); 
- SWRL Factory: Este é um recurso que é usado no SWRL Editor, uma vez que ele faz a manipulação das regras. Sendo assim, ele possui as opções de criação, edição e exclusão das regras. Todos os itens da ontologia possuem uma classe Java correspondente, permitindo assim realizar o mapeamento. Este componente foi usado para intercambiar as regras do formato do SWRLAPI para um formato próprio e viceversa (mais detalhes no capitulo de desenvolvimento).

\subsubsection{Axiomé}

O Axiomé também é um plug-in para o Protégé 3, ele usa a mesma API do SWRL Tab. Para o usuário, o Axiomé amplia a quantidade de recursos voltados a organização, visualização e edição das regras SWRL (Rivolli et. al., 2011). A ferramenta pode ser dividida em cinco partes (Hassanpour, O'Connor e Das, 2010) (Hassanpour, O'Connor e Das, 2009):

- Rule Graph: fornece um gráfico para navegar e explorar as regras e suas relações. Cada regra é apresentada como um nó e as arestas que ligam dois nós representam a existência de um átomo compartilhado entre elas;

- Rule Visualization: fornece a visualização de regras individuais numa estrutura de árvore. São usadas técnicas heurísticas para destacar os átomos mais importantes;

- Rule Paraphrasing: fornece uma explicação em forma de texto da regra. Gera paráfrases em inglês, através de uma estrutura em árvore em que se aplicam técnicas heurísticas;

- Rule Categorization: fornece uma categorização das regras. As regras são agrupadas em uma estrutura sintática por similaridade. Esta técnica está presente nas guias Rule Visualization, Rule Paraphrasing e Rule Elicitation;

- Rule Elicitation: fornece uma interface de auxilio a inserção de regras de um grupo do Rule Categorization. É oferecido um template de regra para facilitar a aquisição das mesmas;

\subsubsection{ACE View}

O ACE View (Kaljurand, 2008) é um plug-in para o Protégé 4, ele utiliza o Attempto Controlled English (ACE) para visualizar e editar ontologias (OWL) e para regras (SWRL) é apenas suportada a visualização. ACE é um subconjunto do Inglês (linguagem natural controlada), responsável por representar o conhecimento de forma inequívoca, ou seja, cada 
frase representa uma única forma lógica. O principal objetivo do ACE é oferecer a expressividade necessária para tarefas de engenharia do conhecimento, porém em uma linguagem próxima do inglês.

Os mapeamentos permitidos pelo ACE View são ACE $\rightarrow$ OWL/SWRL e OWL $\rightarrow$ ACE. O suporte a SWRL é limitado, uma vez que não existe um mapeamento SWRL $\rightarrow$ ACE, então só é possível visualizar as regras em ACE. Na Figura 9 é apresentada a tela principal do ACE, em que uma regra SWRL aparece selecionada. A ferramenta ACE View implementa um novo paradigma para criação e visualização de OWL e SWRL, uma vez que os formulários sintáticos não são mais necessários.

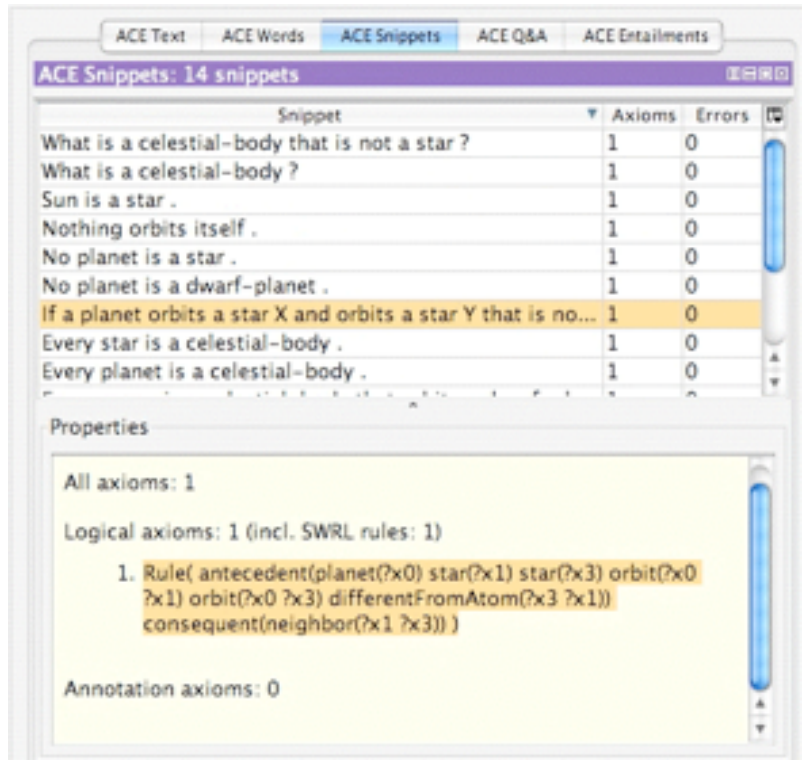

Figura 9 - Tela principal do ACE View.

\subsubsection{Motor de Regras de Negócio}

Motores de inferência para regras de negócios usam tecnologias mais consolidas, pois essas ferramentas encontram-se em desenvolvimento e uso há muito mais tempo que a própria existência da Web. Isso torna a investigação dessas ferramentas um passo importante para o levantamento de requisitos da nova ferramenta (Seção 5.1). A análise destas ferramentas foi conduzida a partir da revisão de Braye et. al. (2006) e de Zacharias (2008). Segue abaixo uma breve descrição das ferramentas analisadas.

- BRS Rule Track: fornece um ambiente completo para gerenciamento de regras de negócio, utiliza a linguagem BRS RuleSpeak, em que as regras são escritas em linguagem natural; 
- CLIPS: é uma ferramenta de domínio público para a construção de sistemas especialistas. É um acrônimo para C Language Integrated Production System. Não é uma ferramenta especifica para regras de negócio, porém pode ser usada para este fim, permitindo a definição de fatos, regras, funções e conceitos orientados a objetos. Existe uma versão para o Protégé é o CLIPSTab, disponível em http://clipsrules.sourceforge.net/;

- Drools: é um sistema de gestão de regras de negócios, com um motor de inferência. Integrada ao JBoos, utiliza-se de uma linguagem própria de regras e introduz uma nova plataforma de integração de regras, na qual integra regras, fluxo de trabalho e processamento de eventos. Atualmente o Protégé roda as regras usando o JESS, mas no momento, os parceiros de BMIR - Stanford University estão convertendo o sistema para executar as regras em Drools. Existe um plug-in para o eclispe disponível em http://jboss.org/drools.html;

- Ferramentas ORM: são um conjunto de ferramentas que suportam a linguagem Object Role Modeling (ORM). ORM é uma linguagem orientada a fatos para análise de sistemas a nível conceitual, por meio de notação gráfica, o que permite a criação de regras com diagramas. Ferramentas comerciais: Microsoft's Visio for Enterprise Architects e CaseTalk. Ferramentas de uso livre: VisioModeler, Infagon, NORMA e DOGMAModeler.

- Fico Blaze Advisor: utiliza a linguagem Structured Rule Language (SRL) para criação de regras. Provê um ambiente integrado para criação, desenvolvimento e teste de regras de negócio. Disponível em http://www.fico.com;

- IBM ILOG: permite o desenvolvimento de negócios dirigidos e aplicação das regras para executar uma política de negócios. Contém um conjunto de componentes de software que juntos consistem em um ambiente integrado para o desenvolvimento das regras. Disponível em http://www.ibm.com/software/websphere/ilog/;

- LibRT Rule Management System (RMS): permite a manutenção e gerenciamento de regras em diferente formalismos e formatos de representação do conhecimento. Disponível em http://www.librt.com/;

- OpenLexicon: é uma ferramenta open-source, que suportar regras de negócio para o gerenciamento de processos. Utiliza uma linguagem e um repositório próprio de regras. Disponível em: http://www.openlexicon.org/; 
- Oracle Business Rules: utiliza declarações próximas à linguagem natural para criar regras de negócio. Disponível em:

http://www.oracle.com/technetwork/middleware/business-rules/overview/;

- RuleXpress: utiliza a linguagem de regras BRS RuleSpeak, sendo semelhante a ferramenta BRS Rule Track. Disponível em http://www.rulexpress.com/;

- SAP NetWeaver Business Rules Management ou QuickRules Editor: é uma ferramenta que permite o gerenciamento de várias fases da vida de um sistema de regras: desenvolvimento, execução, modificação e otimização. Disponível em http://www.sap.com/platform/netweaver/components/brm;

- Translator: é a sigla de TRANSlator from LAnguage TO Rules. Uma ferramenta de uso livre disponível em uma aplicação Java Web Start. Não é específica para regras de negócio, porém tem sido empregada para este fim devido a sua simplicidade para usuários não especialistas. A ferramenta utiliza a linguagem ACE. Disponível em http://ruleml.org/translator/;

- Visual Rules: é uma plataforma para gerenciamento de regras de negócio por meio de gráficos. Disponível em http://www.visual-rules.com/;

\subsection{Interfaces e Recursos para Regras}

O levantamento das interfaces e recursos foi realizado em Silva (2012). Os resultados obtidos nesta etapa serviram de instrumento de captação de requisitos nas reuniões com os usuários do SWRL. Nas próximas subseções são apresentadas as principais interfaces encontradas.

\subsubsection{Tabelas de decisão}

As tabelas de decisão são formadas por linhas e colunas. Usam esse formato para descrever ou apresentar todas as situações que podem ocorrer em um determinando cenário e quais as que devem ser executadas em cada caso. Normalmente as linhas correspondem as regras e as colunas correspondem as condições/ações que as regras possuem. Assim as células possuem o valor para cada condição e ação. Esse tipo de interface se mostra mais eficiente para grandes conjuntos de regras com estruturas semelhantes. Encontrado na maioria das ferramentas de regras analisadas. Um exemplo pode ser visto na Figura 10: 


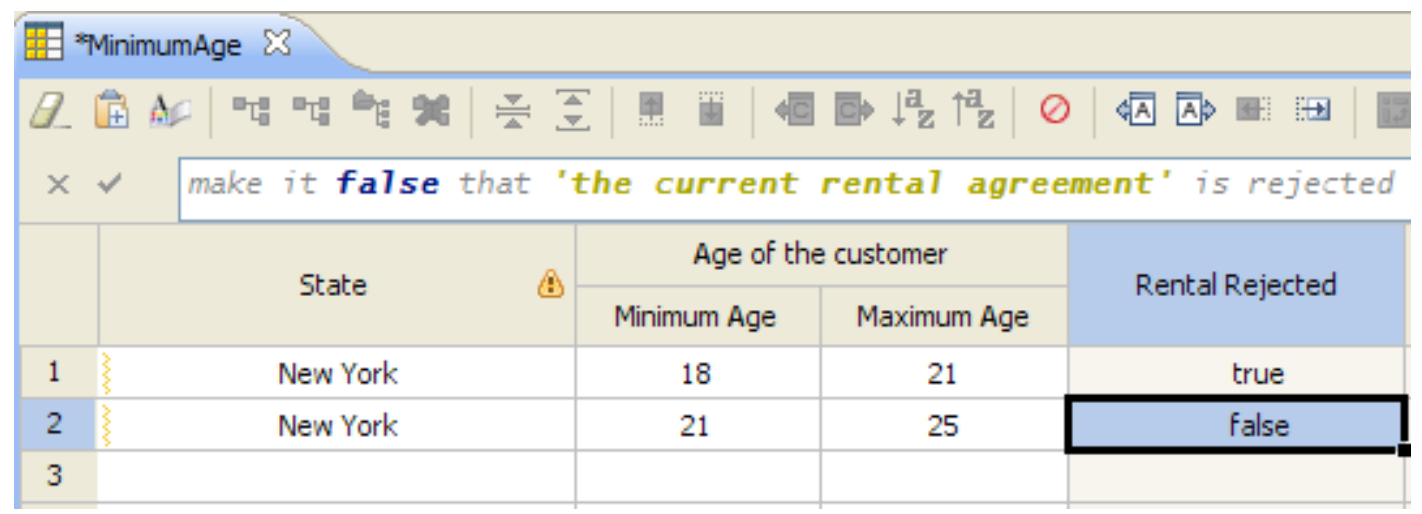

Figura 10 - Tabela de decisão em formato de planilha (IBM ILOG).

Essa interface pode ser encontrada nas ferramentas: Drools; FICO Blaze Advisor; RuleXpress; IBM ILOG; LibRT Rule Management System; Oracle Business Rules; Sap NetWeaver BRM; e Visual Rules.

\subsection{2 Árvores de decisão}

Árvores de decisão são alternativas para conjuntos de regras grandes que possuem diversos nós repetidos. Nessa representação, as regras são formadas por conjunto de nós, que se iniciam na raiz e vão até as folhas. Por exemplo, se uma árvore tem sete nós folhas, esse conjunto representa sete regras. Esta estrutura (Figura 11) pode ser utilizada para aquisição de novas regras, pois é possível reaproveitar nós repetidos.

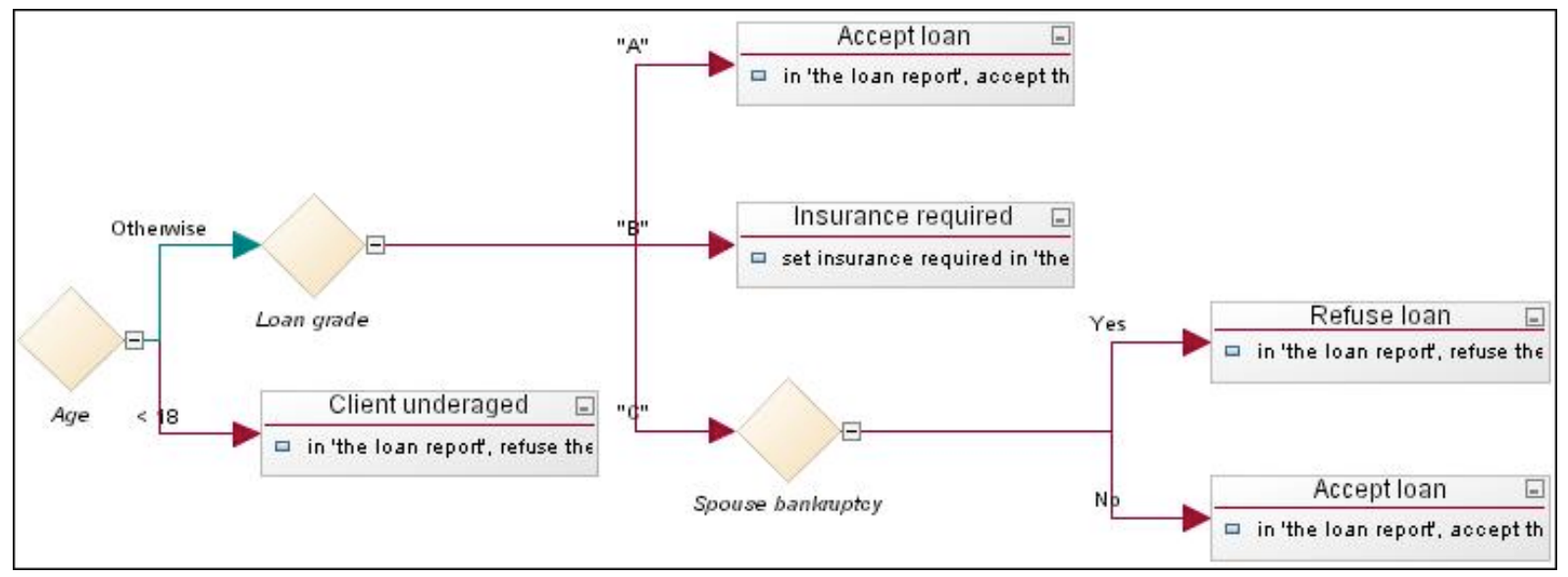

Figura 11 - Árvore de decisão (IBM ILOG).

Essa interface pode ser encontrada nas ferramentas: FICO Blaze Advisor; IBM ILOG; e LibRT Rule Management System. 


\subsubsection{Diagrama gráfico}

Diagramas facilitam a visualização e a criação de novas regras. Nos diagramas podem ser usados formas geométricas (representando tipos diferentes), cores, textos, imagens, símbolos e traços. Ao representar um conjunto de regras, os diagramas enfatizam características específicas ou o relacionamento entre as regras, como pode ser visto na Figura 12.

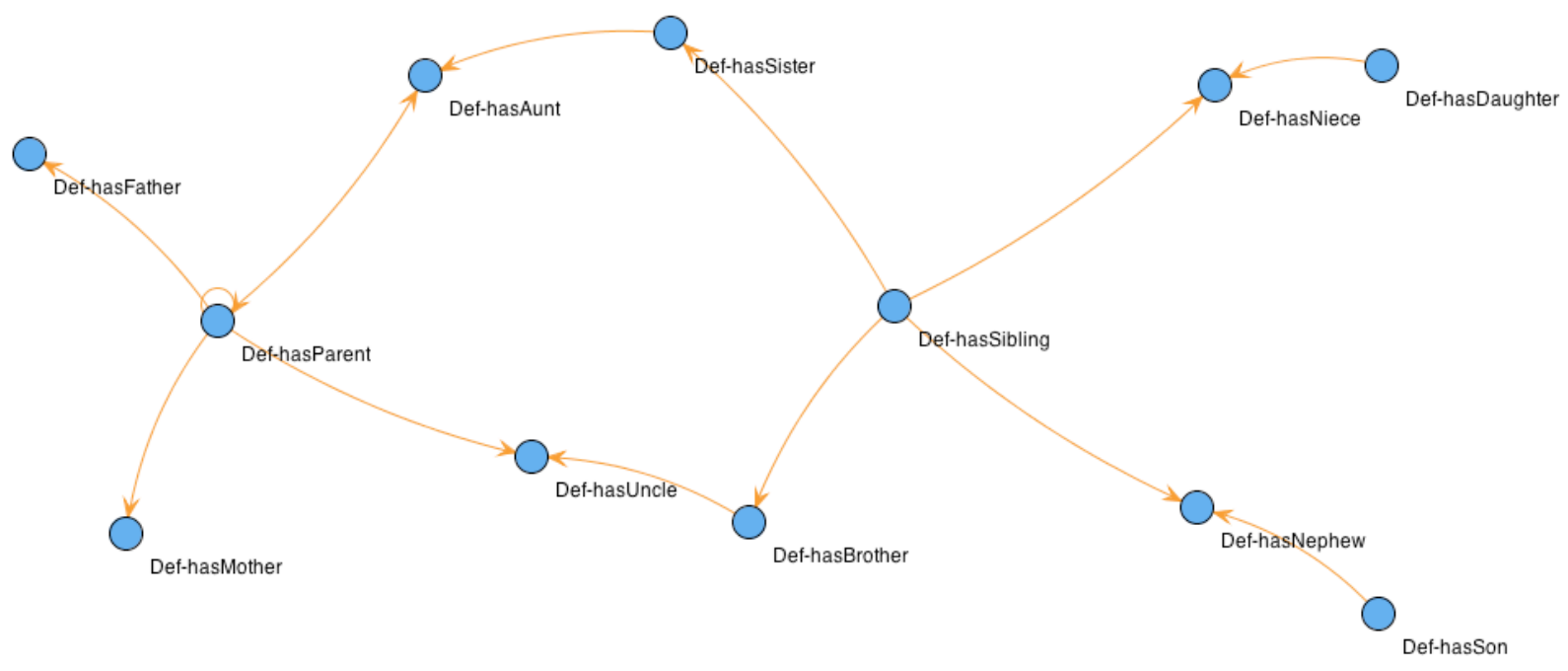

Figura 12 - Rule Graph - Dependência entre as regras (Axiomé).

Essa interface pode ser encontrada nas ferramentas: Axiomé; Ferramentas ORM; IBM ILOG (Graphical Business Object Model Editor); e, Visual Rules.

\subsubsection{Editor de texto}

Editores de texto normalmente são usados por usuários mais experientes com a linguagem. Alguns possuem os recursos de autocompletar, highlight da sintaxe, auto endentação, análise de erros e avisos, debug e testes. Na Figura 13, pode ser visto um editor que usa highlight. Essa interface pode ser encontrada nas ferramentas: Drools (editor do Eclipse); RuleXpress; e, SWRL Tab.

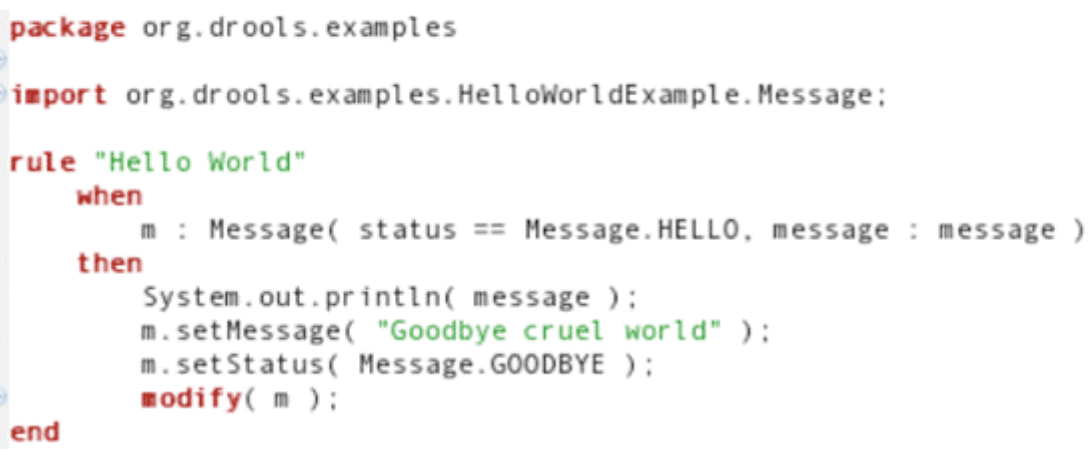

Figura 13 - Drools no Eclipse. 


\subsubsection{Formulários e templates}

Formulários e templates são usados na edição das regras, em que os usuários preenchem campos disponíveis. Formulários são estruturas mais genéricas, ou seja, os usuários podem modificar quais campos estão disponíveis. Já os templates são limitados a um grupo mais especifico de regras, ou seja, o usuário só pode criar regras com a mesma estrutura sintática. Essas interfaces eliminam detalhes de sintaxe como operadores or, and, etc. Algumas ferramentas geram automaticamente as estruturas de formulários, enquanto outras podem ser configuradas por especialistas. Na Figura 14 mostra um template do Axiomé, em que é mostrada uma estrutura fixa para inserção de uma regra. O template no Axiomé, só pode ser acessado a partir de um grupo regras, ou seja, não é possível inserir uma regra que não se encaixe em nenhum grupo.

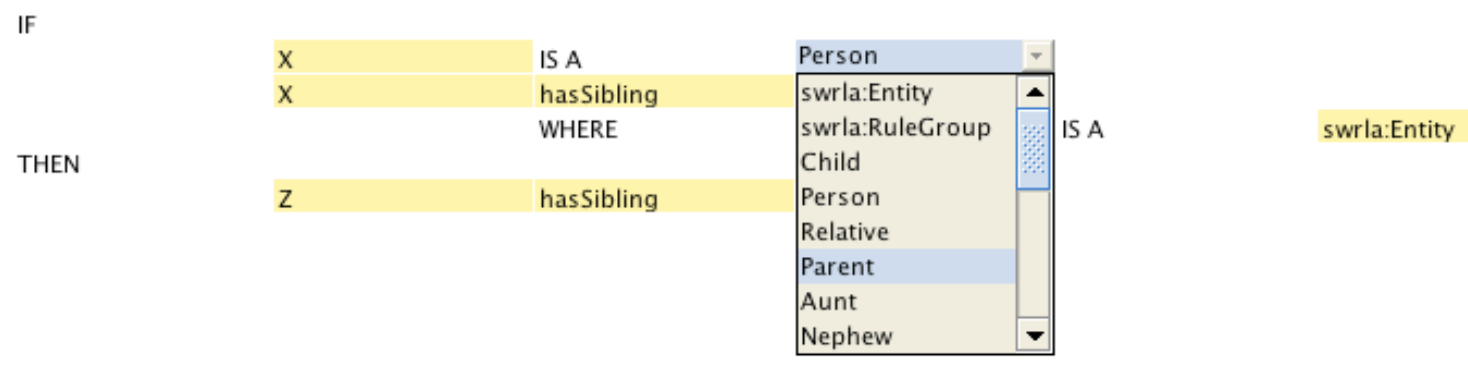

Figura 14 - Rule Elicitation - Template (Axiomé).

Essa interface pode ser encontrada nas ferramentas: Axiomé; Drools; FICO Blaze Advisor; IBM ILOG; OpenLexicon; Oracle Business Rules; e SAP NetWeaver BRM.

\subsubsection{Interface interativa (shell)}

O shell é um console de texto em que os usuários interagem com a interface através de linhas de comandos. Esse tipo de interface é mais utilizado por desenvolvedores técnicos. Nesta revisão de ferramentas relacionadas, foi encontrado apenas o CLIPS (Figura 15).

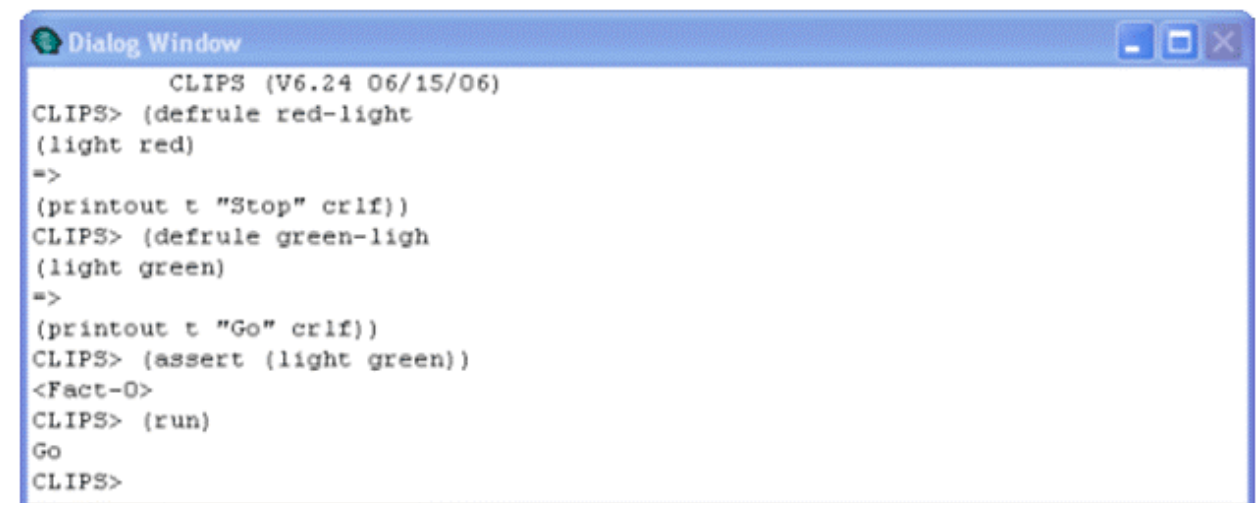

Figura 15 - Interface interativa (CLIPS). 


\subsubsection{Linguagem natural}

A linguagem natural, para os usuários não especialistas, é a melhor maneira para visualizar e editar regras, pois apresenta as regras em uma forma mais próxima da linguagem humana. Já do ponto de vista do desenvolvedor, esse tipo de interface gera desafios, como, por exemplo, tratar ambigüidades. Por causa dessas dificuldades, é mais comum encontrar somente a visualização em linguagem natural. A linguagem natural normalmente utilizada é o inglês. Na Figura 16 é apresentado o parafraseamento do Axiomé.

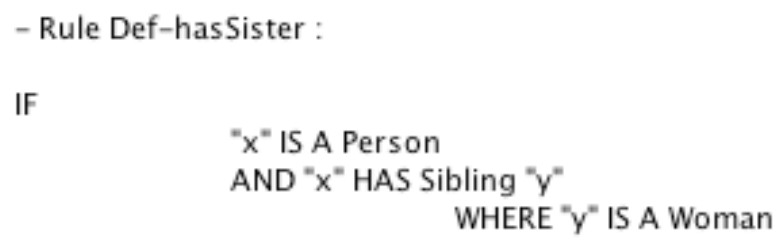

THEN

" $\mathrm{x}$ " HAS Sister " $\mathrm{y}$ "

Figura 16 - Rule Paraphrasin (Axiomé).

Essa interface pode ser encontrada nas ferramentas: ACE View; Axiomé; BRS Rule Track; FICO Blazer Advisor; ORM Tools; RuleXpress; e Translator.

\subsubsection{Outros Recursos}

Nas interfaces, foram identificados componentes (recursos) que enriquecem o processo de criação e visualização das regras. A seguir uma lista com um resumo sobre cada item:

- Nome e Descriçãa: A associação de um nome e uma descrição a regra pode facilitar o processo de busca. A maioria das linguagens de regras permite essa associação;

- Divisão das regras: $O$ gerenciamento e a divisão em partes é uma alternativa para facilitar o entendimento e manipulação de uma regra. As regras podem ser separadas em átomos e segmentos de regras. A divisão se mostra mais eficaz no processo de edição das mesmas, pois permite que uma regra possa ser criada a partir de sub-regras distintas;

- Representações Visuais: Representações visuais são usadas para abstrair regras, dando uma nova aparência a elas. As representações podem ocultar detalhes sintáticos da linguagem ou explicitar informações. Podem ser usadas cores, símbolos ou até a combinação de ambos; 
- Grupos e Categorias: Conjuntos de regras podem se tornar muito grandes. Agrupamentos podem facilitar a localização pelo usuário. A categorização pode ser feita de duas formas: manual, pelo próprio criador da regra, ou automática através de algoritmos. Na categorização manual, quando muitos usuários podem editar, é provável que ocorram critérios diferentes de categorização. Já na automática, não há garantias de que sempre serão gerados agrupamentos com utilidade para o usuário;

- Componentes de Sugestão: A sugestão de termos (autocompletar) contribui para a diminuição de erros de digitação;

- Ícones e símbolos: Ícones e símbolos podem ser usados para representar os recursos das ferramentas (botões, etc) e/ou representar características/partes das regras (a que tipo pertence uma parte da regra);

\subsection{Considerações Finais}

O Web-Protégé vem caminhando para se tornar uma alternativa web para o Protégé, porém não possui um editor de regras SWRL. Além disso, o Web-Protégé por ser um editor colaborativo de ontologias, facilita a criação de um plug-in para a edição colaborativa de regras SWRL.

Já para a edição/visualização de regras são encontradas apenas três ferramentas: SWRLTab, Axiomé e ACE View. Porém todas as ferramentas encontradas possuem recursos limitados, tornando difícil o processo de visualização e composição de regras. Além disso, nenhuma dessas ferramentas possui uma versão web.

Além disso, existem diversas técnicas e ferramentas relacionadas com regras de negócio que podem apontar novas direções para o aprimoramento e criação de novas técnicas relacionadas a regras SWRL (Rivolli, Orlando e Moreira, 2011).

Nessa seção foi possível identificar o cenário atual das ferramentas de regras, incluindo regras de negócios e SWRL. A partir desse estado da arte, foi possível levantar os requisitos juntamente com os usuários de regras SWRL. 


\section{Requisitos e Protótipo Horizontal}

Neste capítulo, são apresentados todos os passos executados no desenvolvimento do SWRL Editor: o levantamento de recursos e requisitos (Seção 5.1) para a nova ferramenta, a criação de protótipos (Seção 5.2) e as ferramentas/padrões usados (Seção 5.3) no desenvolvimento do plug-in. As fases de levantamento de requisitos e criação de protótipos andaram juntas, pois eram identificados os requisitos e logo em sequência feitos os protótipos. Caso fosse identificado algum problema, retornava-se a fase de levantamento de requisitos.

\subsection{Requisitos}

O levantamento dos requisitos contou com a participação dos desenvolvedores de regras SWRL do grupo BMIR - Stanford University e de Silva (2012). A partir das ferramentas, interfaces e recursos apresentados no Capítulo 4, foram definidos os possíveis recursos iniciais e, após algumas reuniões, chegou-se a uma lista inicial. Porém, ao longo do tempo foram sendo acrescentados outros recursos necessários, obtendo-se no final esta lista:

1. Árvore de decisão;

2. Editor de texto;

3. Formulários;

4. Linguagem natural;

5. Representações visuais;

6. Agrupamento;

7. Componentes de sugestão;

8. Ícones e símbolos;

9. Mecanismo de busca;

10. Customização;

11. Informações gerais sobre os conjuntos de regras;

12. Execução das regras;

A necessidade de uma ferramenta para edição colaborativa de SWRL foi o ponto mais importante para decidirmos usar uma implementação Web baseada na arquitetura de plug-in para o Web-Protégé. Um dos principais motivo de se ter uma versão Web do Protégé é 
facilitar a colaboração entre desenvolvedores, já que não é necessário instalar programas locais. Nessa ferramenta, as ontologias estão disponíveis de forma centralizada e compartilhada. Além disso, o Web-Protégé não possui nenhuma ferramenta para manipulação de SWRL. Durante todo projeto alguns requisitos muito importantes foram levantados:

13. Criar um sistema de sincronização das atualizações das regras em todos os clientes no mesmo padrão do Web-Protégé, uma vez que as regras podem ser alteradas ao mesmo tempo por usuários diferentes;

14. Criar uma ferramenta com a maior separação possível da SWRLAPI e da ProtégéOWL API usada no Web-Protégé. Uma vez que a SWRLAPI (que gerencia o SWRL no Protégé 3), não é mais usada no Protégé 4, e provavelmente o Web-Protégé seja portado para as APIs do Protégé 4;

15. Disponibilizar ao usuário a escolha de visualizar/editar as regras com o rdf:ID ou o rdfs:Label. O rdf:ID é um identificador único para cada termo da ontologia. Já o rdfs:Label é uma descrição para o termo da ontologia. Os rdfs:Labels podem tornar mais fácil o entendimento por não serem apenas um ID.

16. Uma arquitetura para que outros desenvolvedores possam implementar novos algoritmos de Agrupamento e de Árvore de decisão;

17. Integração com o sistema de controle de usuários e suas permissões para criação e edição de itens da ontologia. Sendo que esse controle deve ser integrado para permitir ou bloquear determinadas ações dos usuários.

18. Como o SWRL Editor é uma ferramenta open-source, é necessário que o desenvolvimento siga padrões de programação (Best practices) para facilitar seu futuro desenvolvimento por outros;

Alguns desses requisitos foram implementados em Silva (2012), já os demais foram terminados nesse trabalho. Abaixo uma tabela de requisitos implementados por cada trabalho:

Tabela 1 - Requisitos por Trabalho

\begin{tabular}{|l|c|c|c|}
\hline \multicolumn{1}{|c|}{ Requisito } & $\begin{array}{c}\text { Silva } \\
(\mathbf{2 0 1 2})\end{array}$ & Ambos & $\begin{array}{c}\text { Nesse } \\
\text { Projeto }\end{array}$ \\
\hline 1. Árvore de decisão & & & $\mathrm{X}$ \\
\hline 2. Editor de texto & $\mathrm{X}$ & & \\
\hline 3. Formulários & $\mathrm{X}$ & & \\
\hline 4. Linguagem natural & & & $\mathrm{X}$ \\
\hline 5. Representações visuais & $\mathrm{X}$ & & \\
\hline 6. Agrupamento & & $\mathrm{X}$ & \\
\hline
\end{tabular}




\begin{tabular}{|c|c|c|c|}
\hline 7. Componentes de sugestão & & $\mathrm{X}$ & \\
\hline 8. Ícones e símbolos & $\mathrm{X}$ & & \\
\hline 9. Mecanismo de busca & & $\mathrm{X}$ & \\
\hline 10. Customização & & & $\mathrm{X}$ \\
\hline 11. Informações gerais sobre os conjuntos de regras & $\mathrm{X}$ & & \\
\hline 12. Executar as regras & & & $\mathrm{X}$ \\
\hline 13. Sistema de gerenciamento de atualizações das regras & & & $\mathrm{X}$ \\
\hline 14. Separação de outras APIs & & & $\mathrm{X}$ \\
\hline 15. Trabalhar com rdf:ID ou o rdfs:Label & & & $\mathrm{X}$ \\
\hline 16. Arquitetura para novos algoritmos & & & $\mathrm{X}$ \\
\hline 17. Comunicar com o Login & & & $\mathrm{X}$ \\
\hline 18. Padrão de codificação & & & $\mathrm{X}$ \\
\hline
\end{tabular}

\subsection{Protótipo Final}

Foram feitos protótipos que foram apresentados em reuniões (via Web) para os desenvolvedores de regras do BMIR. Ao final obteve-se um protótipo inicial, que serviu de base para começar o desenvolvimento. Durante o desenvolvimento, os protótipos evoluíram até o modelo descrito pelas Figura 17 e Figura 18.

Na Figura 17 é apresentado um protótipo da tela de visualização, em (A) pode ser visto o SWRL Editor aberto em uma sub-guia. Dentro do SWRL Editor, no topo (B), existe uma barra de ferramentas com opções de configurações, informações sobre o conjunto de regras, botão para a inserção de uma nova regra e o acesso a criação dos filtros para o conjunto de regras. Na Figura 17 (C) aparece a listagem das regras e para cada regra aparecem, em (D), botões para editá-la, duplicá-la e mostrar regras similares a ela. 


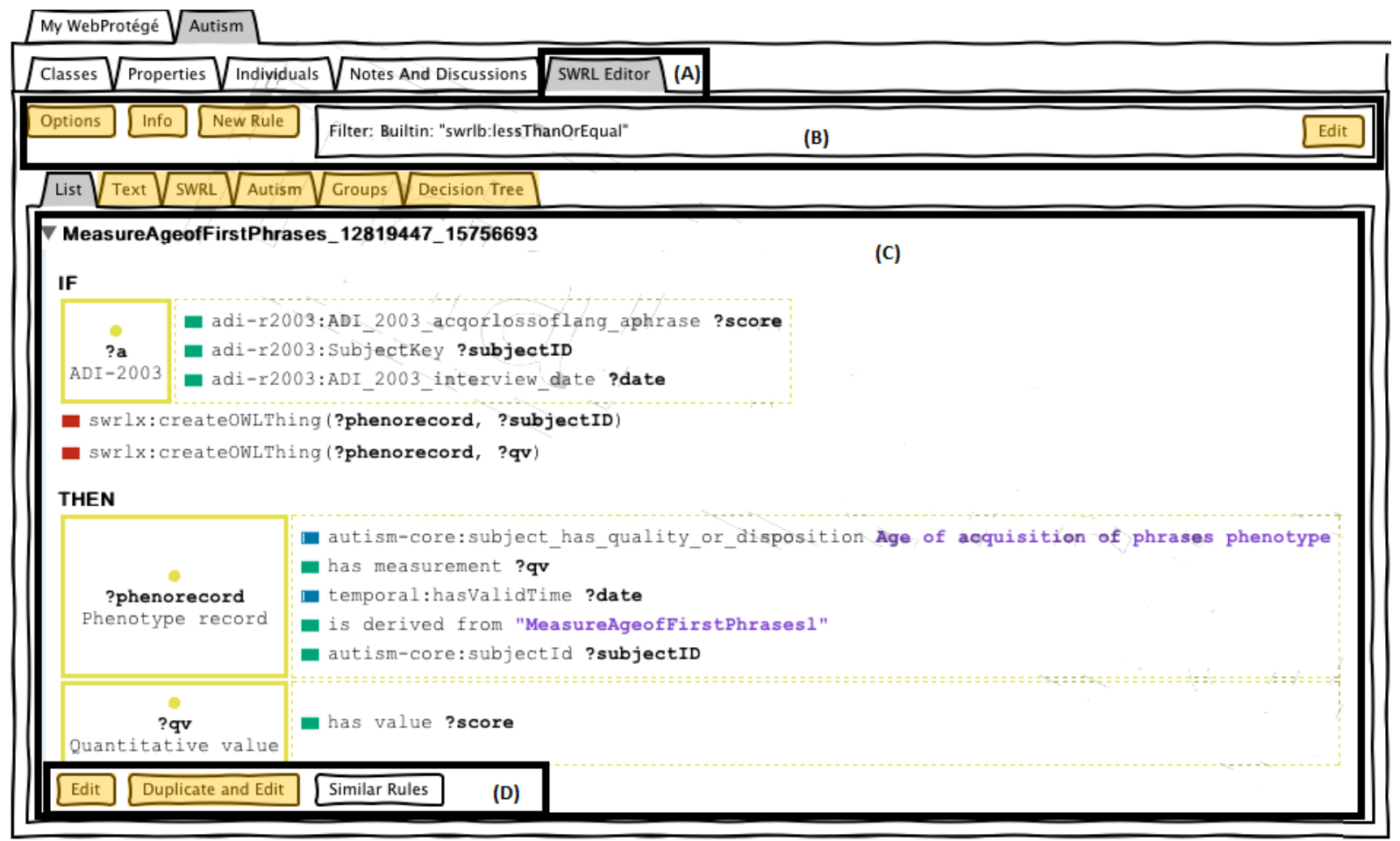

Figura 17 - Tela de visualização do Protótipo: (A) Acesso ao Plug-in SWRL Editor (B) Barra de Ferramentas; (C) Listagem das Regras; (D) Botões para cada regra.

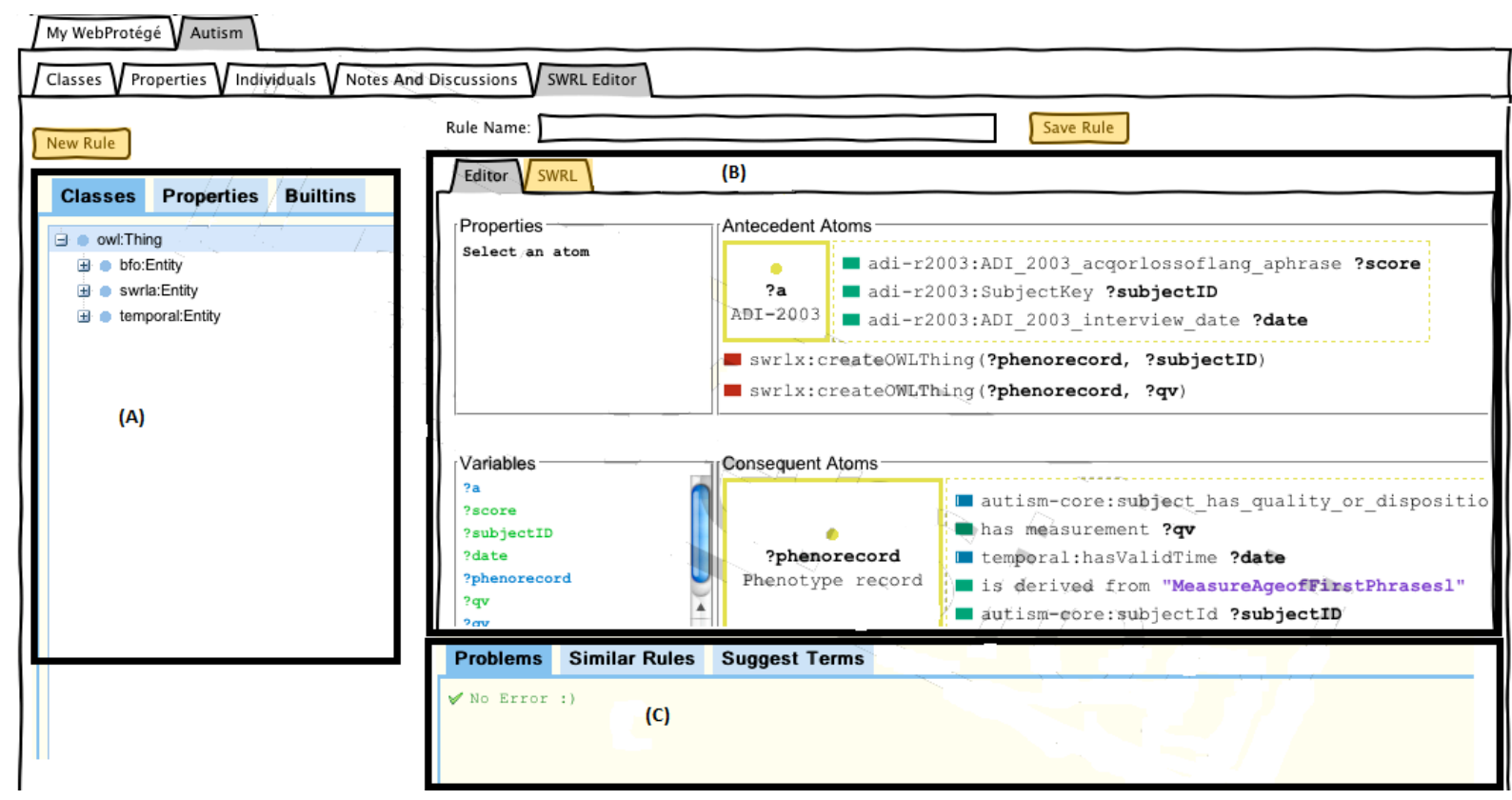

Figura 18 - Tela de composição do Protótipo.

Na Figura 18 já é observada a tela de composição (criação e edição) de regras. Na região (A) aparecem os itens da ontologia (classes, propriedades e built-ins) que são usados para ajudar os usuários a encontrar os termos usados na edição de uma regra. Em (B) aparecem as guias para editar as regras, que estão disponíveis em duas formas:

- $\quad$ Editor: aba para edição em formulário; 
- SWRL: aba para edição em SWRL com highlight;

Ainda na Figura 18, são apresentadas em (C), três abas com: a lista de erros e avisos, a lista de regras similares e sugestões de termos. A implementação tentou seguir a risca todos os itens estabelecidos na prototipação, mas algumas mudanças na interface foram necessárias. Um destes casos foi a adição posterior de um botão para executar as regras.

\subsection{Ferramentas e Padrões}

No desenvolvimento do SWRL Editor foram usados os frameworks GWT, MVP (Modelview-presenter), UiBinder, ClientBundle e ServiceLoader: O GWT é a ferramenta em que o Web-Protégé foi feito, por isso foi necessário entender as suas principais características. $\mathrm{O}$ MVP é padrão de modularização do código que foi adotado para facilitar a manutenção do código. UiBinder por sua vez é uma ferramenta do GWT para criar interfaces gráficas em XML. Já o ClientBundle é uma técnica de injeção de certos arquivos (CSS, ícones, ...) na ferramenta principal.

\subsubsection{GWT (Google Web Toolkit)}

A linguagem de desenvolvimento do Web-Protégé foi a Java devido a suas características como linguagem voltada a aplicações web e por ser a linguagem das principais bibliotecas e ferramentas a serem usadas. $\mathrm{O}$ uso de uma mesma linguagem em todo o projeto simplifica seu desenvolvimento.

Navegadores não executam aplicações Java de maneira nativa. É necessária a instalação de plug-ins. Para resolver esse problema o GWT foi adotado para o Web-Protégé e automaticamente para o SWRL Editor. O GWT é um framework para construção de aplicativos Web interativos de maneira rápida que compila programas em Java para Javascript permitindo que os mesmos sejam executados em navegadores, sem a necessidade de instalação de plug-ins. O GWT foi feito para facilitar e agilizar o processo de desenvolvimento das interfaces de aplicações RIA (Rich Internet Applications) utilizando AJAX (Asynchronous Javascript And XML). Basicamente, RIA são aplicações Web com alto grau de funcionalidade, com aparência e usabilidade aproximadas de uma aplicação desktop clássica, mas com a vantagem de não serem instaladas na máquina cliente.

O GWT enfatiza a reutilização de código, soluções eficientes para os desafios decorrentes da tecnologia AJAX (chamadas assíncronas de procedimento remoto), gerenciamento de 
histórico, favoritos, internacionalização e portabilidade entre navegadores. Sendo assim, o GWT é a opção para quem quer publicar suas aplicações web, porém prefere codificar em Java do quê em Javascript.

As principais vantagens do GWT são:

- Compilador que transforma código Java em JavaScript, gerando versões em código Javascript otimizado para cada navegador, evitando incompatibilidades entre navegadores e plataformas;

- Divisão em Cliente e Servidor; usa os princípios de Remote Procedure Call (RPC);

- Possibilidade de utilizar qualquer Debugger Java com o GWT;

- Controle total sobre a aplicação e possibilidade de extensão utilizando a JSNI (JavaScript Native Interface);

- Disponibilidade de muitos componentes gráficos já existentes.

Como comentado anteriormente, o GWT criar aplicativos com tecnologia AJAX. O termo AJAX é utilizado para especificar um conjunto de tecnologias que ajudam as aplicações Web a ficarem mais dinâmicas, evitando o carregamento de toda página, só atualizando o que for realmente necessário na página.

As principais vantagens do uso da tecnologia AJAX são: menor uso de banda, pois menos informações irão trafegar na rede; as páginas só serão atualizadas nas partes necessárias; muitos recursos que disponibilizam alta capacidade de interatividade e usabilidade.

\subsubsection{MVP (Model-view-presenter)}

Construções de aplicações, em que vários desenvolvedores podem trabalhar simultaneamente, podem tornar o código confuso. Padrões de projeto fornecem aos programadores um conhecimento de um todo para produzir uma boa arquitetura de funcionamento e uma fácil manutenção do código do software. Muitos obstáculos e dificuldades são encontrados quando tentamos construir aplicações de larga escala, no desenvolvimento de aplicações em GWT isso não é uma exceção.

Apesar de existirem diversos padrões de projeto, como Presentation-abstraction-control (PAC), Model-view-controle (MVC), Model-view-presenter (MVP) e outras, o MPV é a arquitetura que funcionam melhor com o desenvolvimento de aplicações em GWT por duas razões: 1) O modelo MVP desacopla o desenvolvimento de maneira que vários desenvolvedores possam trabalhar simultaneamente no código; 2) o MVP permite que os 
desenvolvedores utilizem boa parte dos testes escritos usando o JRE, ou seja, não necessitam de um browser.

Como o próprio nome do framework sugere, a divisão do código é feita em três componentes principais: o Model (Modelo), View (Interface gráfica) e o Presenter (Apresentador). Além desses componentes, outro de suma importância é o AppController (Gerenciador). O Model contém os objetos de negócios, no caso do SWRL Editor temos, por exemplo, as regras, etc. O View contém os componentes da interface gráfica, por exemplo botões, campos de texto, tabelas, etc. As classes do Presenter são as responsáveis por intermediar a passagens os dados do Model para as Views.

A Figura 19 mostra um exemplo de divisão em MVP. Nesse exemplo, ao acessar uma ferramenta no padrão MVP, primeiramente é iniciada a interface (View), sendo que essa exibe as regras. A interface faz uma requisição ao seu Presenter pelas regras. Caso as regras SWRL ainda não estejam no Model, elas serão buscadas no Servidor através de uma chamada RPC. Assim que o Model já estiver com as regras o Presenter envia as mesmas para serem mostradas na View.

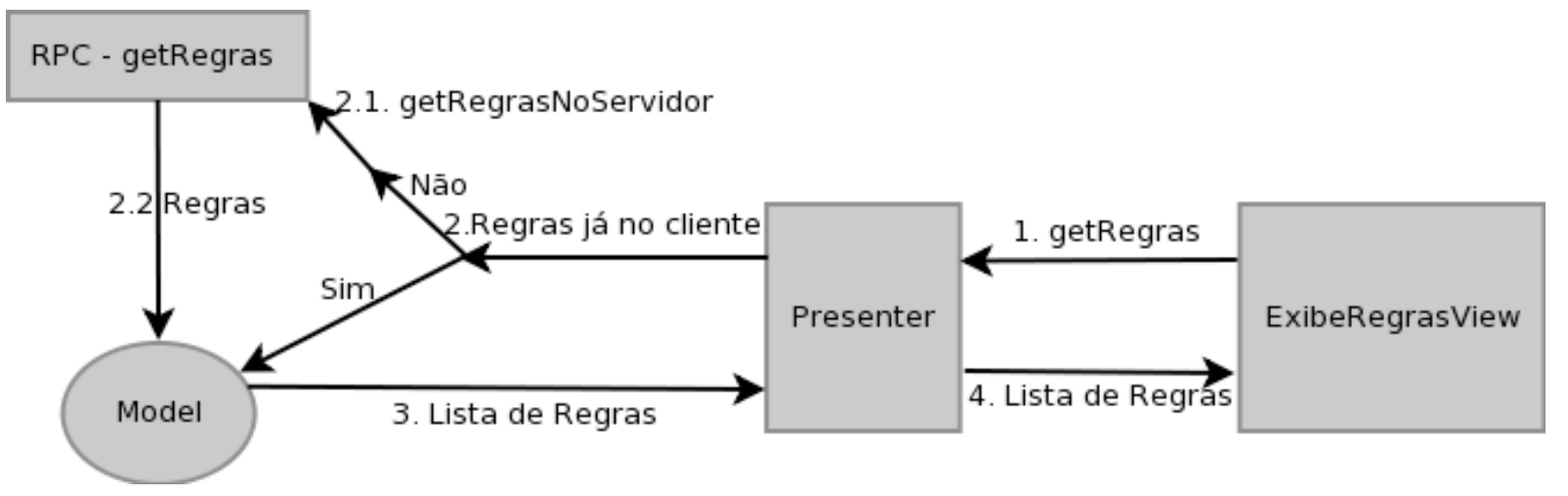

Figura 19 - Exemplo de uso do framework MVP.

Esse framework torna-se interessante dado que separa a ferramenta em 3 camadas. A camada View mantém as interfaces gráficas, não sendo necessário que ela manipule os dados do Model. A camada View apenas mantém as interfaces para representar visualmente os dados. O Presenter busca no servidor, manipula e trata os dados, repassando o resultado para a View ativa. Já o Model mantém todos os dados do lado do cliente. Dados são trazidos do servidor (pelo Presenter através de RPCs) e armazenados no cliente. 


\subsubsection{UIBinder}

Como o GWT é um framework em Java, normalmente as definições dos componentes estão juntas a implementações de seus métodos, isso torna o código mais difícil de manter. O framework UiBinder (parte do GWT) disponibiliza uma linguagem para definir interfaces gráficas em arquivos XMLs que ficam separado dos arquivos Java. É possível criar um componente gráfico (implementado como uma classe Java) onde todas as definições de interface, como layout, definição de componentes e atribuição de estilos (CSS), ficam separadas do código Java que implementa o comportamento desse componente.. Abaixo um exemplo que define diversas características de interface diretamente num arquivo XML.

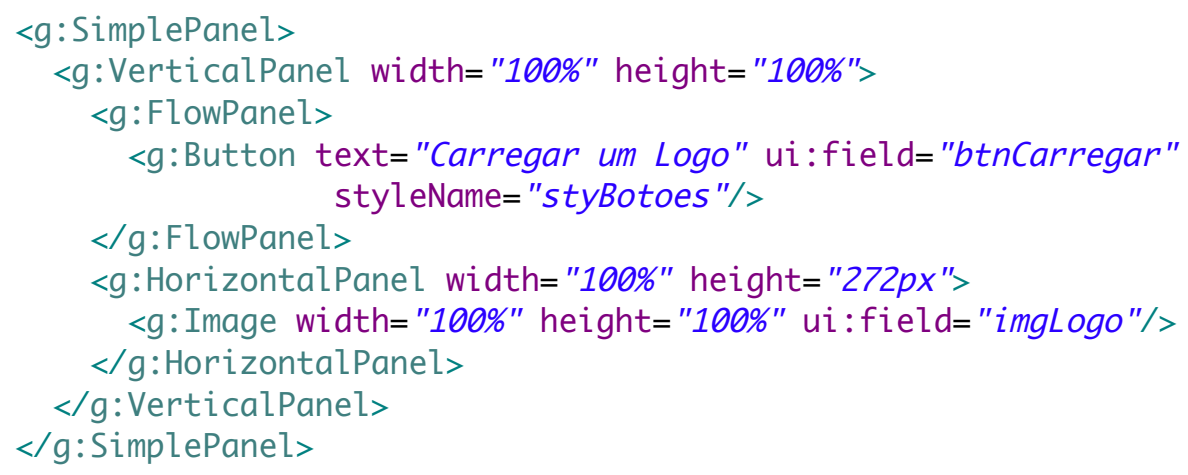

Além de ser uma forma mais concisa de declaração, o UIBinder também torna a aplicação mais eficiente, devido aos navegadores serem melhores em construir essas estruturas utilizando o DOM (Document Object Model). O DOM foi criado pelo W3C para representar como as marcações em HTML, XHTML e XML são organizadas e lidas pelos navegadores web. Como pode ser visto abaixo, no arquivo Java, apenas as declarações dos componentes são necessárias:

QUiField Button btnCarregar;

aUifield Image imgLogo;

Mais detalhes deste framework podem ser vistos em DevGuideUiBinder ${ }^{5}$.

\subsubsection{ClientBundle}

Arquivos como CSS, imagens, ícones da nova ferramenta devem ficar no projeto principal (no caso o projeto do Web-Protégé). Porém, espera-se que esses arquivos permaneçam com a nova ferramenta, para isso o ClientBundle, faz a injeção desses arquivos na ferramenta

\footnotetext{
${ }^{5}$ DevGuideUiBinder: http://code.google.com/webtoolkit/doc/latest/DevGuideUiBinder.html
} 
principal. Além disso, outro problema é referenciar um estilo CSS que não existe mais. Nem o compilador, nem os navegadores acusam erros e o mesmo vale para imagens que apenas não são mostradas. Como o ClientBundle cria o acesso desses arquivos por meio de métodos Java, isso garante que o aplicativo esteja realmente acessando um estilo de CSS existente. Neste caso, o compilador, na verificação de consistência, pode identificar a falta de algum estilo CSS.

Mais detalhes deste componente podem ser vistos em DevGuideClientBundle ${ }^{6}$.

\subsubsection{ServiceLoader}

Os algoritmos de agrupamento de regras e criação de árvores de decisão facilitam a manipulação de conjuntos grandes de regras. Porém, podem existir pesquisadores ou ontologias que necessitem de algoritmos diferentes. Para isso, foram criadas interfaces Java para novos algoritmos e estabelecida uma forma de agregá-los sem a necessidade de alterar o código da ferramenta. As interfaces Java serão apresentadas nas Seções 6.1.4.1 e 6.1.4.2. Já para a agregação automática foi usado a classe ServiceLoader do java.util.

A classe ServiceLoader é usada para carregar novas classes Java a partir de jar files. Ela lê um arquivo de configuração encontrado no arquivo JAR e, a partir dele, encontra as implementações de interfaces já definidas no programa. Por último, ele disponibiliza essas implementações na forma de uma lista de objetos.

Mais detalhes desse componente podem ser vistos em ServiceLoader ${ }^{7}$.

\subsection{Considerações Finais}

Durante o decorrer deste trabalho, foram levantados os requisitos do SWRL Editor. A partir deles foram desenvolvidos protótipos e estes apresentados para os pesquisadores do BMIR. Chegou-se a uma versão final do protótipo que está sendo apresentado neste capítulo. O material apresentado neste capítulo serviu como base para estudar as ferramentas e padrões necessários para o desenvolvimento do SWRL Editor: GWT, MVP, UiBinder, ClientBundle e ServiceLoader.

\footnotetext{
${ }^{6}$ DevGuideClientBundle: http://code.google.com/webtoolkit/doc/latest/DevGuideClientBundle.html

${ }^{7}$ ServiceLoader: http://docs.oracle.com/javase/7/docs/api/java/util/ServiceLoader.html.
} 


\section{SWRL Editor}

Como descrito anteriormente (Seção 1.3), parte do objetivo final deste trabalho é desenvolver uma ferramenta para a Edição/Visualização colaborativa de regras SWRL. Essa ferramenta foi desenvolvida em um processo interativo e contou com a colaboração dos desenvolvedores de regras SWRL do grupo BMIR.

Neste capítulo é descrita essa nova ferramenta, intitulada SWRL Editor, que foi desenvolvida nesse mestrado e que amplia os recursos já disponíveis em Silva (2012). Alguns itens ou parte deles apresentados neste capítulo foram desenvolvidos no mestrado de Silva, porém sua explicação é necessária para um melhor entendimento da ferramenta. Este capítulo está dividido em Servidor (Seção 6.1) e Cliente (Seção 6.2). O Servidor é responsável por modificar e armazenar os arquivos da ontologia. Além disso, os algoritmos de agrupamento e árvore de decisão são executados no servidor. Já no Cliente estão as interfaces gráficas para: representação, edição e busca de regras, entre outras funções.

\subsection{Servidor}

O Servidor centraliza as operações com as regras, por exemplo, ontologias e regras são carregadas de seus arquivos apenas uma vez e ficam disponíveis para todos os clientes através de chamadas RPC. Além disso, a centralização das operações é um ponto chave para que a ferramenta possa funcionar colaborativamente, já que o servidor atua como nó central de distribuição das alterações feitas por cada usuário.

O servidor também usa uma forma própria de representação de regras (Seção 6.1.1), que foi desenvolvida conjuntamente com Silva (2012), para garantir um maior desacoplamento das SWRLAPI e Protégé-OWL. Além disso, nesse mestrado foram criados intermediadores (Gerenciadores) (Seção 6.1.2) que realizam todas as operações de conversão entre o formato de regras usado pelo SWRL Editor e as APIs do Web-Protégé. Como o SWRL Editor é uma ferramenta que funciona de forma colaborativa (vários clientes manipulando a mesma ontologia), foi criado um gerenciador de atualizações (Seção 6.1.3) para que todos os clientes possam estar sincronizados. E, por último, são apresentados os sistemas de carregamento automático de algoritmos para agrupamento e para árvore de decisão (Seção 6.1.4). 


\subsubsection{Representação das regras}

O Web-Protégé utiliza a API Protege-OWL do Protégé versão 3, porém atualmente a última versão do Protégé é a 4 que usa a OWL-API, desenvolvida pela universidade de Manchester (Horridge e Bechhofer, 2009). Para facilitar uma futura migração para essa nova API ou para outras que o Protégé venha a usar, foi estabelecido um representação interna do SWRL Editor para regras.

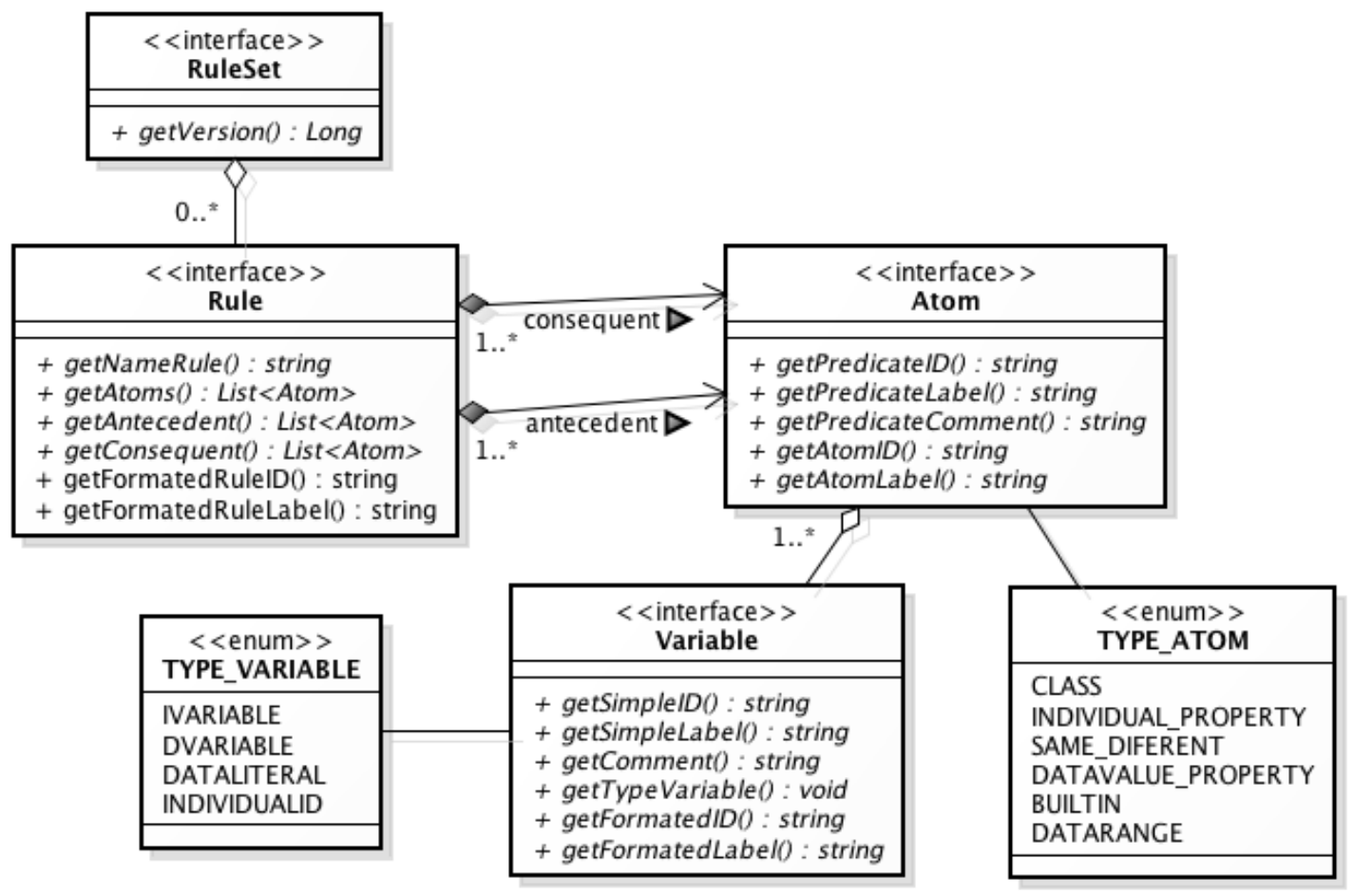

Figura 20 - Interfaces para a Representação das Regras do SWRL Editor.

A Figura 20 mostra as interfaces Java para representar as regras dentro do SWRL Editor. Nessa figura são vistas as interfaces RuleSet, Rule, Atom e Variable, elas representam as partes de um conjunto de regras. A interface Ruleset é responsável por conter todo um conjunto de regras. Os objetos de RuleSet devem possuir um número de versão, pois, com vários clientes editando regras simultaneamente, os conjuntos podem estar em versões diferentes (mais detalhes na Seção 6.1.3).

A interface Rule é responsável por representar uma regra. Para cada regra é possível ter uma lista de átomos do antecedente e/ou consequente. Além disso, é possível obter a regra em um formato texto usando o rdf:ID (getFormatedRuleID) ou o rdfs:Label (getFormatedRuleLabel) para nomear a regra e suas partes,. A escolha entre rdf:ID ou rdfs:Label é feita no lado do cliente e depende de como a ontologia usada com as regras usa esses dois campos. 
A interface Atom representa os átomos de uma regra. Os átomos são divididos em predicado e variáveis. O predicado é um termo da ontologia e a interface retorna seu rdf:ID e rdfs:Label (se existir algum label). Além disso, devem ser recuperados da ontologia os comentários referentes a esse predicado. Essa interface também possui a lista de variáveis do átomo e o tipo do predicado (TYPE_ATOM). A interface Atom deve também gerar um texto representando o átomo formatado usando o rdf:ID ou o rdfs:Label como seu nome (dependendo da opção escolhida pelo cliente).

A interface Variable representa as variáveis dos átomos. Ela é composta pelo nome da variável ou um termo da ontologia. Esse termo da ontologia pode conter um rdf:ID, um rdfs:Label e um rfds:Comment que também são mantidos dentro dessa interface.

\subsubsection{Gerenciadores}

Os gerenciadores foram criados para intermediar todas as consultas ou modificações na ontologia com a Protégé-OWL API. Eles convertem os elementos da ontologia, passando do formato da Protégé-OWL API para a representação do SWRL Editor e na edição de uma regra fazem o processo inverso. Por esse fato, os gerenciadores tornam-se importantes para tornar a ferramenta mais separada das APIs do Protégé, já que permitem mais de uma implementação para suas interfaces. Os gerenciadores foram divididos em dois (Figura 21): OntologyManager e SWRLManager.

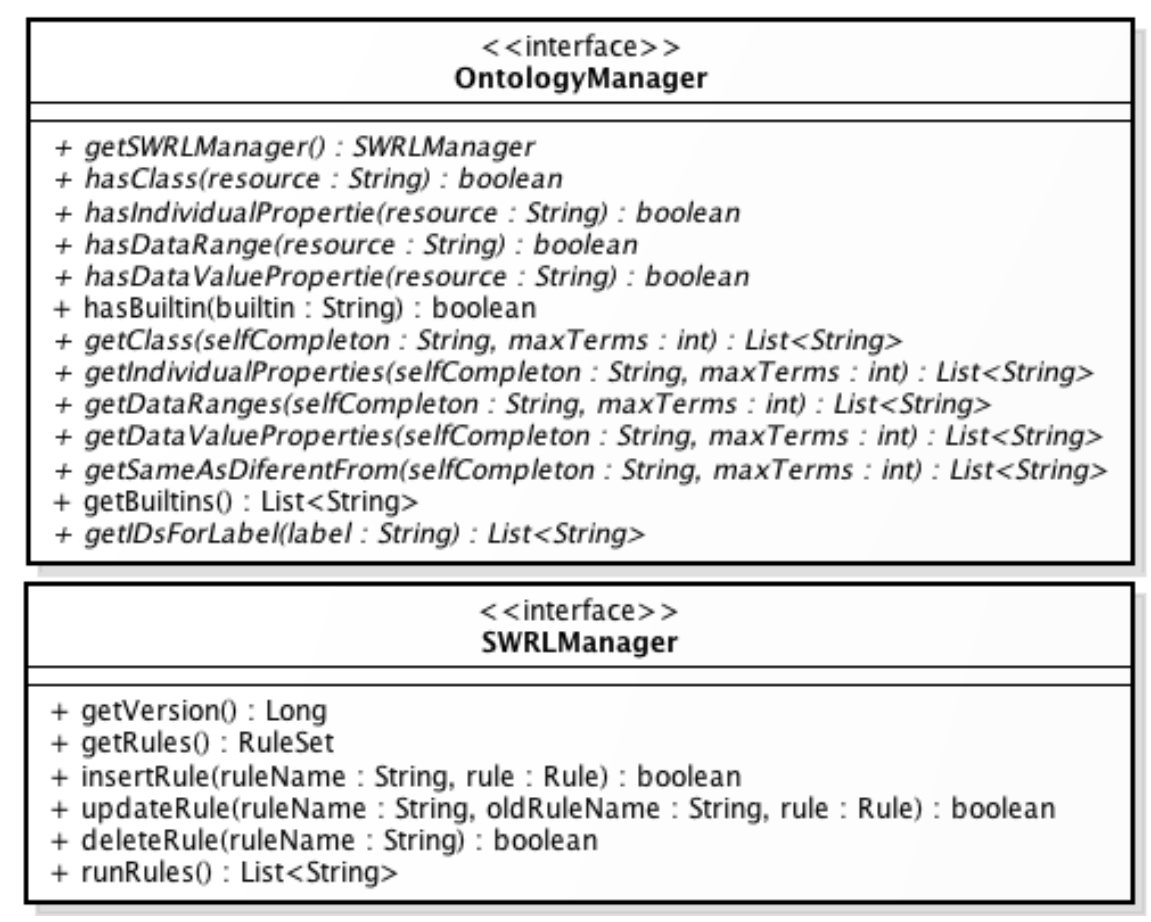

Figura 21 - Interfaces dos Gerenciadores. 
O OntologyManager é responsável por realizar consultas nos termos da ontologia e criar o SWRLManager. Os métodos hasclass, has Individualproperty, hasDataRange, hasDataValueProperty e hasBuiltin, apenas verificam a existência de um termo dentro da ontologia e são usadas para verificação de erros durante a edição de regras. Os métodos getclass, getIndividualProperties, getDataRanges, getDataValueProperties e getBuiltins são usados para gerar listas de sugestões de termos da ontologia. Essas operações têm como parâmetros um conjunto de caracteres que são as letras iniciais a serem buscadas nos termos da ontologia. Além disso, essas operações possuem como parâmetro um número máximo de termos retornados, isso é necessário, pois as ontologias podem conter muitos termos com iniciais semelhantes.

Ainda no OntologyManager, foi criada a operação getIDsForLabel que recebe um rdfs:Label e retorna a lista de rdf:IDs dos elementos da ontologia que usam esse rdfs:Label. Um dos requisitos do SWRL Editor é permitir que os usuários possam editar regras usando o rdfs:Label (para referenciar elementos da ontologia) pois eles geralmente tem nomes mais significativos. Porém, diferentemente do rdf:ID, o mesmo rdfs:Label pode ser usado em mais de um elemento da ontologia. Isso pode gerar redundâncias na criação das regras. Com a lista dos rdf:IDs associados a um rdfs:Label (retornada por esse método) é possível se descobrir qual elemento deve realmente ser usado.

O SWRLManager é responsável por manipular as regras SWRL, para isso existem as operações: getRules, insertRule, updateRule e deleteRule. Além disso, esse gerenciador tem uma operação para executar as regras (runRules). Outra parte importante é o versionamento das alterações das regras, em que, a operação getVersion, retorna o número da versão atual do conjunto de regras.

\subsubsection{Gerenciador de atualizações}

O Web-Protégé, por tratar-se de uma ferramenta de edição colaborativa de ontologias, possui um gerenciador de mudanças na ontologia (Collaboration API) (Tudorache, Vendetti e Noy, 2008). Porém, esse gerenciador de atualizações não controla alterações nas regras SWRL. Então, a partir da metodologia empregada na Collaboration API, foi criado um gerenciador de atualizações para as regras. 
Nesse novo gerenciador, a cada nova alteração nas regras é incrementado um número de versão contido no SWRLManager. Também é mantida uma lista de alterações, contendo o tipo de alteração e o que foi modificado. Da mesma forma como o Web-Protégé gerencia os elementos de uma ontologia, o cliente mantém um conjunto de regras com seu número de versão. Num intervalo definido nas configurações do Web-Protégé (por padrão 5 segundos), o cliente faz uma chamada RPC em que envia o número da versão local das regras para o servidor. Já do servidor, é retornada uma lista de alterações, que vão desde a versão do cliente até a versão do servidor. Quando o cliente recebe as alterações, ele atualiza o seu conjunto de regras e automaticamente os recursos de interfaces as mostram.

Só o gerenciador de atualizações modifica o conjunto de regras do cliente. As operações que modificam os conjuntos de regras (inserir, editar e excluir) enviam suas alterações para o servidor e, caso essas alterações sejam aceitas e implementadas no servidor, é retornado ao cliente o aviso de sucesso na operação e esse força o gerenciador de atualizações a buscar imediatamente pelas novas alterações.

\subsubsection{Sistemas de carregamento automático de algoritmos}

Um ponto bastante discutido neste trabalho foi a questão de quanto um algoritmo de visualização (agrupamento ou árvore de decisão) é importante para várias ontologias ou vários usuários. Mais de um algoritmo foi desenvolvido para criar essas visualizações, porém mesmo assim não é possível garantir que eles sempre sejam úteis para todos os usuários. Por esse motivo, no SWRL Editor foi implementado um sistema para carregamento automático de algoritmos para criação de agrupamentos e árvores de decisão.

Os algoritmos são carregados de forma automática usando a classe Java: ServiceLoader. Para o ServiceLoader carregar os algoritmos é necessário que esses sejam implementados usando as interfaces Java que o SWRL Editor disponibiliza para agrupamento ou para árvore de decisão. A seguir é mostrado como desenvolver novos algoritmos para agrupamento (Seção 6.1.4.1) e árvore de decisão (Seção 6.1.4.2).

O sistema de carregamento automático de algoritmos tornou-se uma ótima estratégia para usuários mais avançados que tenham interesse em desenvolver seus próprios algoritmos. Ele facilita essa operação já que para inserir um novo algoritmo é apenas necessário gerar um arquivo JAR com as implementações e o colocá-lo numa pasta do servidor, sem ser necessário alterar o código do SWRL Editor ou ter que parar o servidor do Web-Protégé. 


\subsubsection{Agrupamento}

O agrupamento foi incluído com o objetivo de facilitar a visualização de grandes conjuntos de regras. Essa técnica tem por objetivo facilitar a localização de regras pelo usuário dentro de um conjunto de regras. Como apresentado nos trabalhos relacionado, os agrupamentos podem ser manuais ou automáticos. O agrupamento por meio de algoritmos no SWRL Editor tornouse mais adequado devido ao fato da edição de regras poder ser colaborativa, o que pode levar a critérios diferentes no agrupamento manual (dependendo do usuário que faz o agrupamento).

Porém, o grande problema no agrupamento automático é que nem sempre um algoritmo é útil para todos os usuários ou para todas as ontologias. Pensando nisso, o sistema de carregamento automático de algoritmos é usado (usando a classe ServiceLoader) para carregar os algoritmos de agrupamento a partir da Interface GroupRules (Figura 22). A Interface GroupRules herda de Runnable, ou seja, vai herdar o método Run, sendo que este terá a função de gerar o agrupamento. Além disso, a interface GroupRules obriga a implementação dos métodos:

- getAlgorithmName - Retorna o nome do algoritmo, este nome fica disponível para o usuário escolher dentre a lista de algoritmos de agrupamento disponíveis;

- canSetNumberofGrups - Retorna se o algoritmo escolhe o número de grupos ou se o usuário deverá informá-los;

- setoWLModel - Informa o OWLModel da ontologia em que será gerado o agrupamento. O OWLModel é um componente da Protégé-OWL API que mantém todo o modelo da ontologia (até mesmo as regras). Usuários que não tem um domínio suficiente da nova representação das regras (Seção 6.1.1) podem usar o modelo da Protégé-OWL API;

- setRuleSet - Informa o RuleSet da ontologia em que será gerado o agrupamento. O Ruleset é um componente da nova representação das regras SWRL (Seção 6.1.1). Ele é indicado para usuários que querem garantir que as implementações de agrupamento sejam mais compatíveis com novas versões do Web-Protégé;

- getNumberOfGroups - Retorna o número de grupos gerados pelo algoritmo;

- getGroups - Retorna os nomes das regras em um lista de listas de regras. 


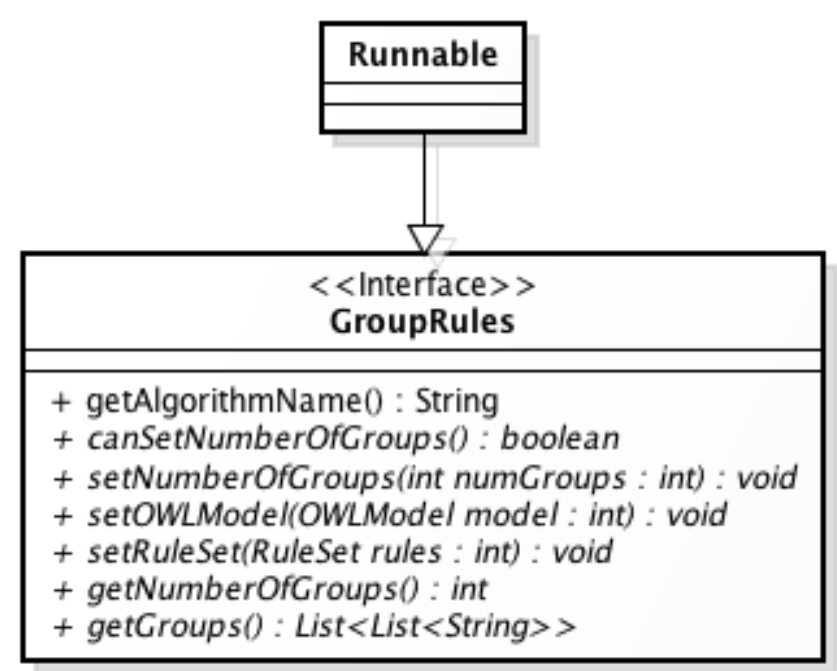

Figura 22 - Interfaces do Sistema de Carregamento Automático do Agrupamento.

Em Silva (2012) foi implementado a técnica de K-means em duas situações: Similaridade do Predicado e Similaridade do Átomo. Esses dois algoritmos, gerados a partir da técnica de $K$-means, foram re-implementados usando a Interface GroupRules para que fossem usados no sistema de carregamento automático de algoritmos. Além disso, foi implementado o algoritmo de agrupamento da ferramenta Axiomé (técnica que agrupa as regras pela sua estrutura sintática), para atender a um maior grupo de usuários/ontologias e validar o sistema de carregamento automático de algoritmos.

\subsubsection{2 Árvore de Decisão}

Em conjuntos de regras, o mesmo átomo pode ocorrer em diferentes regras. Podem ocorrer casos em que regras sejam diferentes por apenas um átomo extra. Para mostrar isso, foi desenvolvida a visualização em árvore de decisão. Da mesma forma que no agrupamento, não é possível garantir que um algoritmo de geração de árvore de decisão seja útil para todos os usuários ou para todas as ontologias. Pensando nisso, foi adotado o sistema de carregamento automático de algoritmos também para a árvore de decisão. 


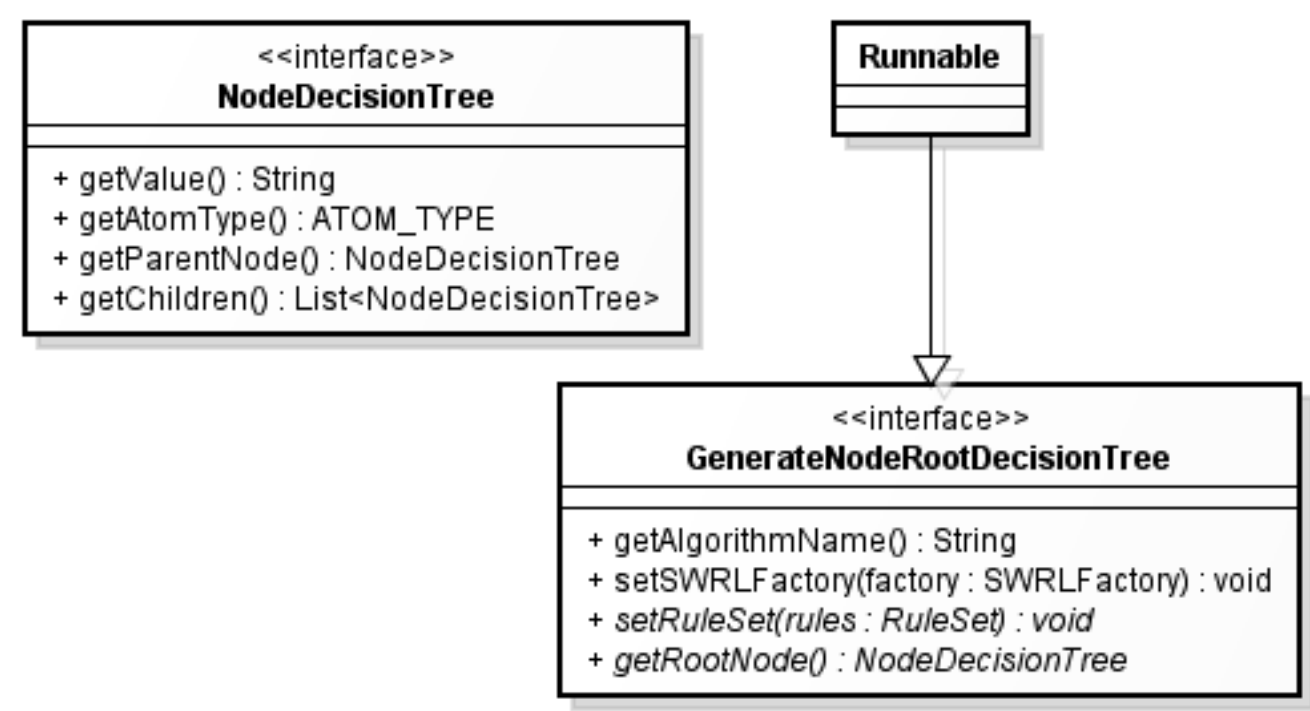

Figura 23 - Interfaces do Sistema de Carregamento Automático da Árvore de Decisão.

Para o sistema de carregamento automático de algoritmos de geração de árvores de decisão foi desenvolvida a Interface Java: GenerateNodeRootDecisionTree (Figura 23). Ela herda de Runnable, ou seja, vai herdar o método Run, sendo que este terá a função de gerar a árvore. Além disso, essa interface obriga a implementação dos métodos:

- getAlgorithmName - Retorna o nome do algoritmo, esse nome fica disponível para o usuário escolher na lista de algoritmos de geração de árvores de decisão;

- setOWLModel - Seta o OWLModel da ontologia em que será gerada a árvore de decisão;

- setRuleSet - Seta o Ruleset da ontologia em que será gerada a árvore de decisão;

- getRootNode - Retorna um objeto da interface NodeDecisionTree que é o nodo raiz da árvore gerada.

A interface NodeDecisionTree é utilizada para representar os nodos da árvore de decisão. Essa interface contém os seguintes métodos:

- getValue - Retorna o valor do nodo que será exibido na árvore de decisão;

- getAtomType - Retorna o tipo do átomo que esse nodo representa. É usado para diferenciar visualmente os nodos da árvore.

- getParentNode - Retorna o nodo pai. Usado para navegar a partir das folhas da árvore.

- getChildren - Retorna todos os nodos filhos ligados a esse nodo. 
Para validar o sistema de carregamento automático dos algoritmos de geração de árvores de decisão foram criados três algoritmos que serão descritos na seção 6.2.1.3.

Tanto o sistema para carregamento automático para algoritmos de agrupamento de regras como para geração de árvores facilitaram enormemente a inserção de novos algoritmos no SWRL Editor e foram sugestões de usuários do BMIR - Stanford University.

\subsection{Cliente}

No Cliente foram desenvolvidas as seguintes funcionalidades: Integração com o Login do Web-Protégé (Seção 6.2.6), visualização das regras em paráfrases (Seção 6.2.1.1), implementação do algoritmo de agrupamento do Axiomé (Seção 6.2.1.2), árvore de decisão (Seção 6.2.1.3), melhorias na composição de regras (Seção 6.2.3), mecanismos de filtragem de regras (Seção 6.2.2), atalho por URLs (Seção 6.2.5) e configurações do sistema (Seção 6.2.3).

Para acessar o cliente do SWRL Editor é necessário escolher uma das ontologias (Figura 5). Na Figura 24 é mostrado o Web-Protégé após se ter acessado a Ontologia da Família. Nessa figura é possível ver a guia SWRL Editor (A), onde se encontra a nova ferramenta.

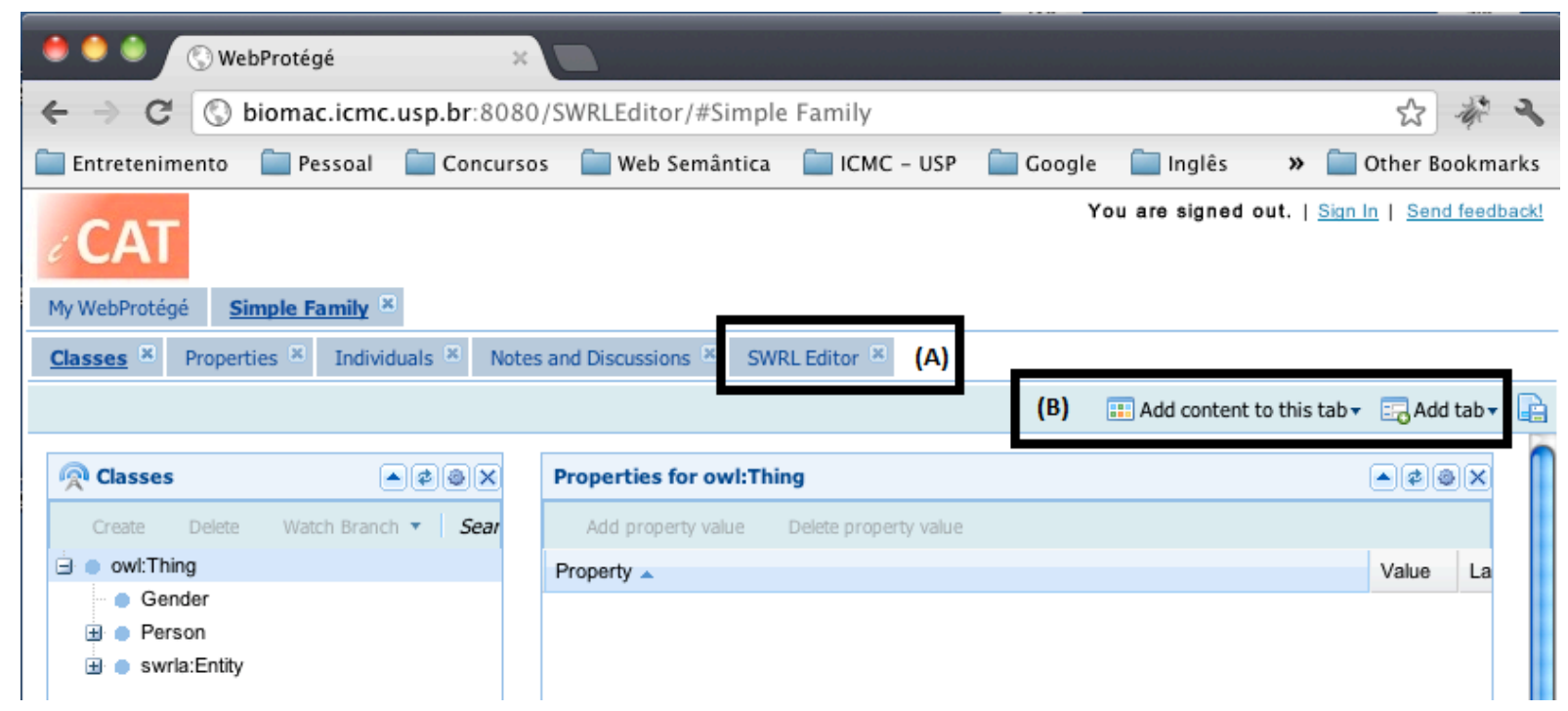

Figura 24 - Tela após o acesso a ontologia da família: (A) Acesso ao plug-in; (B) Acesso a todos os plug-ins não carregados automaticamente.

O Web-Protégé, após acessar a ontologia, carrega automaticamente os principais plug-ins (guias). Como não existe no Web-Protégé um plug-in para manipulação de SWRL, foi definido que o SWRL Editor é carregado automaticamente. Porém, caso seja fechado o plugin, é possível acessá-lo novamente usando os botões Figura 24 (B). 


\subsubsection{Visualização}

A página inicial do SWRL Editor é a Visualizations (Figura 25). Essa página é dividida em:

- Barra de Ferramentas (A) - Da esquerda para a direita: Options é o acesso as configurações do SWRL Editor; Info é o acesso as informações gerais do conjunto de regras; New Rule acessa a tela de composição para inserção de uma nova regra; Run Rules executa as regras no servidor. O botão Edit em Rule Filter acessa a tela para modificar o filtro das regras exibidas.

- Formas de Visualização dos Conjuntos de Regras (B) - Da esquerda para a direita: A guia List mostra as regras em uma visualização hierárquica (Silva, 2012). A guia Text mostra as regras usando Parafraseamento (Seção 6.2.1.1). A guia SWRL mostra as regras usando SWRL com Highlight (Silva, 2012). A guia Autism mostra uma representação visual especial só para o autismo desenvolvida por Silva (2012) e que não é mais mostrada por default. A guia Groups dispõe das técnicas para agrupamento (criado em Silva (2012) e complementado na Seção 6.2.1.2). A guia Decision Tree contém as técnicas para transformar os conjuntos de regras para um formato de árvore (6.2.1.3).

- Botões para cada regra (C) - Para cada regra, nas guias List, Text, SWRL e Autism, existem botões para manipulação. Da esquerda para a direita são eles: O botão Edit Rule que coloca a regra em modo de edição. O botão Duplicate and Edit que faz uma cópia da regra e coloca a essa copia em modo de edição. O botão Delete excluí uma regra do conjunto. O botão Similar Rules mostra uma lista de regras similares usando um dos algoritmos de agrupamento.

- Barra de Status (D) - Serve como status do sistema, sendo utilizada para mostrar o numero de regras filtradas/número total de regras do conjunto. 


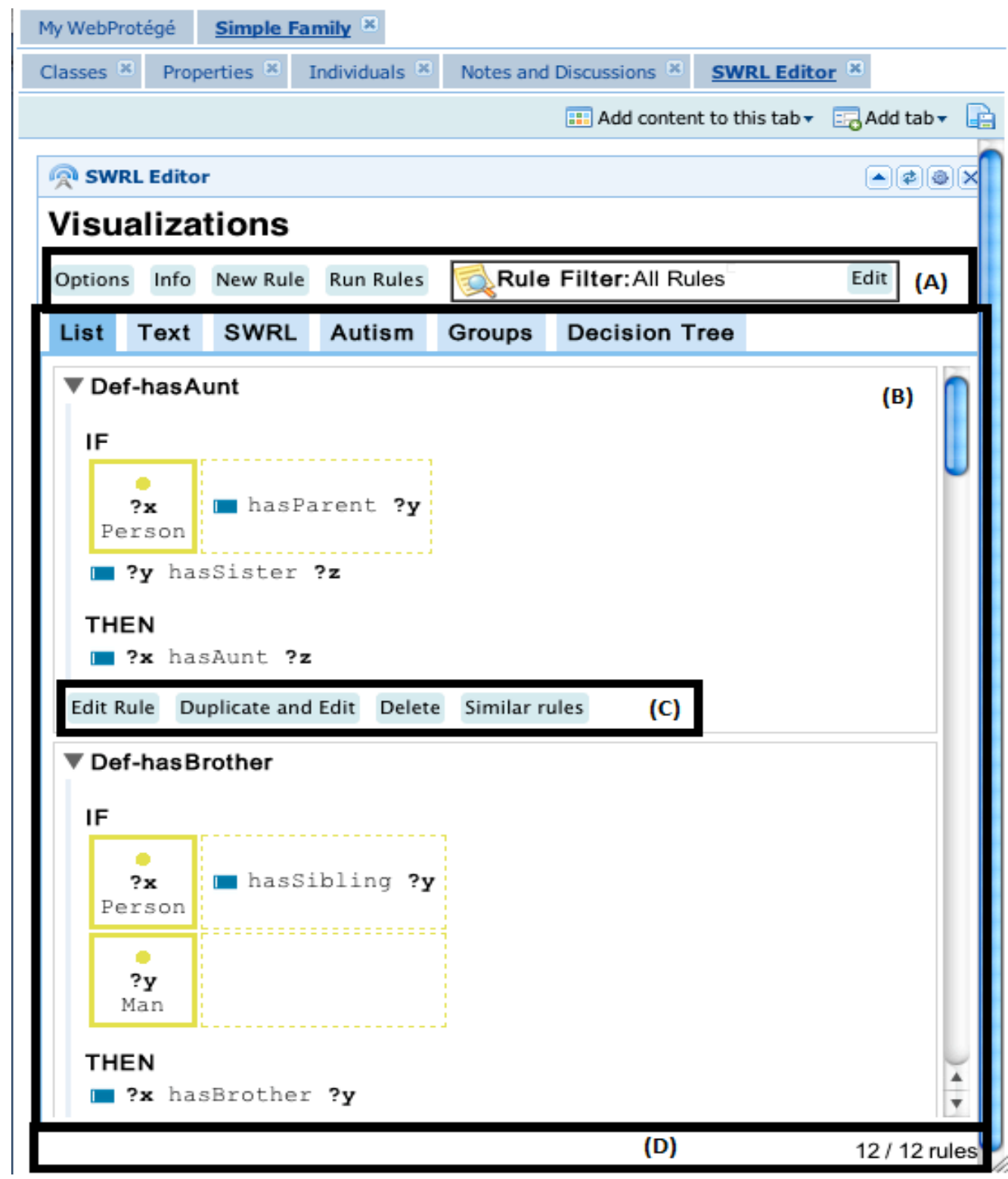

Figura 25 - SWRL Editor - Visualização: (A) Barra de Ferramentas; (B) Formas de Visualização dos Conjuntos de Regras; (C) Botões para cada regra; (D) Barra de Status do plug-in.

\subsubsection{Representação em Paráfrases}

Essa representação fornece uma explicação em forma de texto da regra. É uma reimplementação de uma técnica do Axiomé para gerar paráfrases em inglês. Apenas foi implementada uma mudança para essa técnica: a utilização de negrito em termos de ligação (IF, IS, AN, ...) entre os átomos de uma regra. A mudança é simples, porém torna mais fácil a leitura (Figura 26). Além disso, o SWRL Editor oferece a possibilidade de entrar em modo de edição a partir da representação em parafraseamento. Não edita o parafraseamento, mas acessa a edição desta regra. 


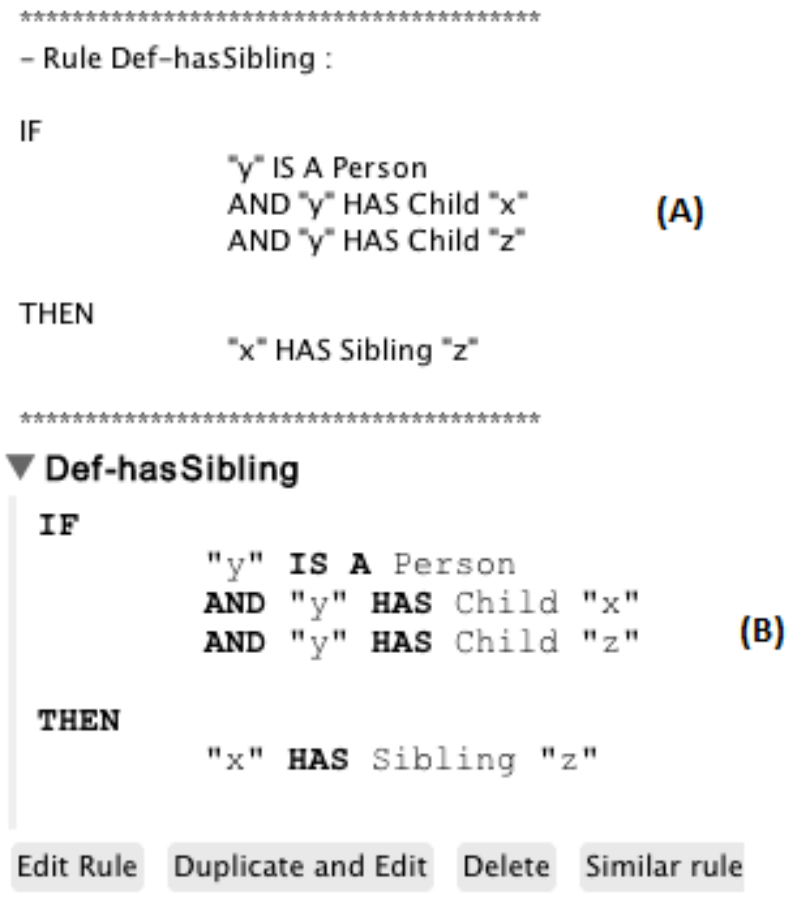

Figura 26 - Parafraseamento: (A) Na ferramenta Axiomé ; (B) No SWRL Editor.

\subsubsection{Agrupamento}

Em Silva (2012), foram desenvolvidas duas técnicas de agrupamento com o objetivo de agrupar por similaridade ao invés de usar a estrutura da regra. Porém, não se chegou a um consenso de qual das técnicas poderia ser mais útil, com o desenvolvimento do sistema de carregamento automático de algoritmos (Seção 6.1.4.1) as duas (e outras) podem ser usadas.

Para demonstrar que o sistema de carregamento automático de algoritmos pode facilitar a implementação de novas técnicas, foi implementada a técnica de agrupamento do Axiomé. A explicação sobre a implementação desse algoritmo pode ser visto no Apêndice A.

Essa técnica consiste em gerar uma expressão canônica (assinatura) com números e símbolos que identificam a estrutura da regra. Com essas expressões geradas, é possível separar as regras em grupos por estrutura sintática das regras. Essa técnica agrega uma nova forma de agrupar as regras no SWRL Editor, sem perder as técnicas anteriores. Porém como pode ser visto na Figura 27, o SWRL Editor agrega ao agrupamento as técnicas de visualizações (visualização hierárquica, parafraseamento ou SWRL com Highlight), ou seja, além de agrupar mostra em um formato mais amigável (do que em texto do Axiomé). 


\begin{tabular}{|c|c|c|c|c|}
\hline \multicolumn{2}{|c|}{$\nabla$ Group1 (4 rules) } & Group & Name & Expression \\
\hline \multicolumn{2}{|c|}{$\nabla$ Def-has Nephew } & \multicolumn{2}{|c|}{$\ni$ Group 1} & $(12 \#(1))-(2)$ \\
\hline \multirow{2}{*}{\multicolumn{2}{|c|}{ (2) }} & & Def-hasSister & Person $(? x) \wedge$ hasSibling $(? x, ? y) \wedge$ Woman $(? y) \rightarrow$ \\
\hline & & & Def-hasMother & $\operatorname{Person}(? \mathrm{x}) \wedge$ hasParent $(? \mathrm{x}, ? \mathrm{y}) \wedge$ Woman $(? \mathrm{y}) \rightarrow$ \\
\hline $2 x$ & & & Def-hasDaughter & $r$ Person $(? x) \wedge$ hasChild $(? x, ? y) \wedge$ Woman $(? y) \rightarrow h$ \\
\hline $\begin{array}{c}\text { ?x } \\
\text { Person }\end{array}$ & Whassibling ?y & & Def-hasFather & Person $(? \mathrm{x}) \wedge$ hasParent $(? \mathrm{x}, ? \mathrm{y}) \wedge \operatorname{Man}(? \mathrm{y}) \rightarrow$ has \\
\hline \multirow{2}{*}{\multicolumn{2}{|c|}{ qy hasSon ?z }} & & Def-hasSon & Person $(? \mathrm{x}) \wedge$ hasChild $(? \mathrm{x}, ? \mathrm{y}) \wedge \operatorname{Man}(? \mathrm{y}) \rightarrow$ hass \\
\hline & & & Def-hasBrother & Person $(? x) \wedge$ hasSibling $(? x, ? y) \wedge \operatorname{Man}(? y) \rightarrow$ has \\
\hline \multicolumn{2}{|c|}{ THEN } & \multicolumn{2}{|c|}{$\ni$ Group2 } & $(12 \#(2))-(2)$ \\
\hline \multicolumn{2}{|c|}{ ?x hasNephew ?z } & & Def-hasNephew & Person $(? x) \wedge$ hasSibling $(? x, ? y) \wedge$ hasSon $(? y, ? z)$ \\
\hline \multicolumn{2}{|c|}{ Def-hasUncle } & & Def-hasUncle & Person $(? x) \wedge$ hasParent $(? x, ? y) \wedge$ hasBrother $(? y$, \\
\hline \multicolumn{2}{|c|}{ Def-hasAunt } & & Def-hasAunt & Person $(? \mathrm{x}) \wedge$ hasParent $(? \mathrm{x}, ? \mathrm{y}) \wedge$ hasSister $(? \mathrm{y}, ? \mathrm{z}$ \\
\hline \multicolumn{2}{|c|}{ Def-has Niece } & & Def-hasNiece & Person $(? \mathrm{x}) \wedge$ hasSibling $(? \mathrm{x}, ? \mathrm{y}) \wedge$ has Daughter $(?$ \\
\hline \multicolumn{2}{|c|}{ Group2 (6 rules) } & \multicolumn{2}{|c|}{$\ni$ Group3 } & $(12) \wedge(2)-(2)$ \\
\hline \multicolumn{2}{|c|}{ Group3 (1 rules) } & $\square$ & Def-hasParent & Person $(? y) \wedge$ hasConsort $(? y, ? z) \wedge$ hasParent $(? x$ \\
\hline
\end{tabular}

Figura 27 - Técnica de agrupamento do Axiomé - Na esquerda com o SWRL Editor; Na direita com o Axiomé.

\subsubsection{3 Árvore de Decisão}

Da mesma forma que no agrupamento, árvores de decisão usam o sistema de carregamento automático de algoritmos. Para demonstrar a importância da árvore de decisão foram desenvolvidos 3 algoritmos:

- Ocorrência de átomos (Figura 28) - Essa técnica apenas cria uma árvore com base em um ranking de ocorrência de átomos, ou seja, átomos que mais ocorrem tendem a estar mais perto da raiz.

- Dependência de variáveis (Figura 29) - Essa técnica cria as árvores levando em conta a dependência das variáveis.

- Paráfrases (Figura 30) - Divide o parafraseamento (Seção 6.2.1.1) em pequenas paráfrases e com isso cria uma árvore mantendo a ordem original da paráfrase.

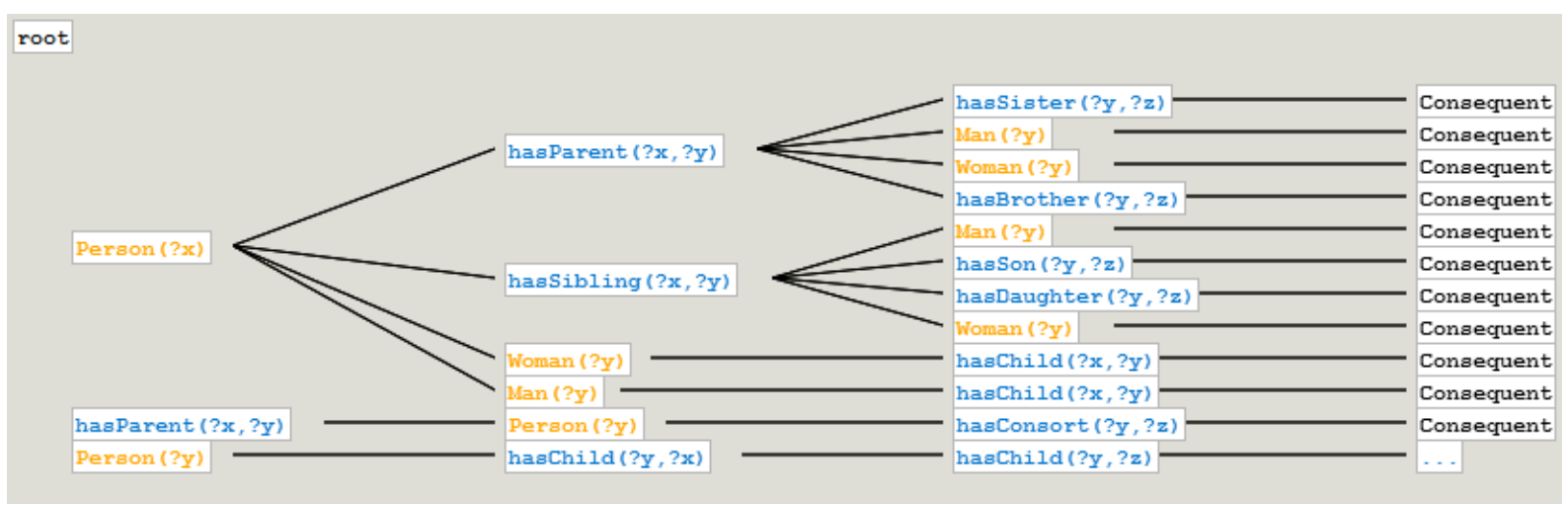

Figura 28 - Árvore de decisão - Ocorrência de átomos. 


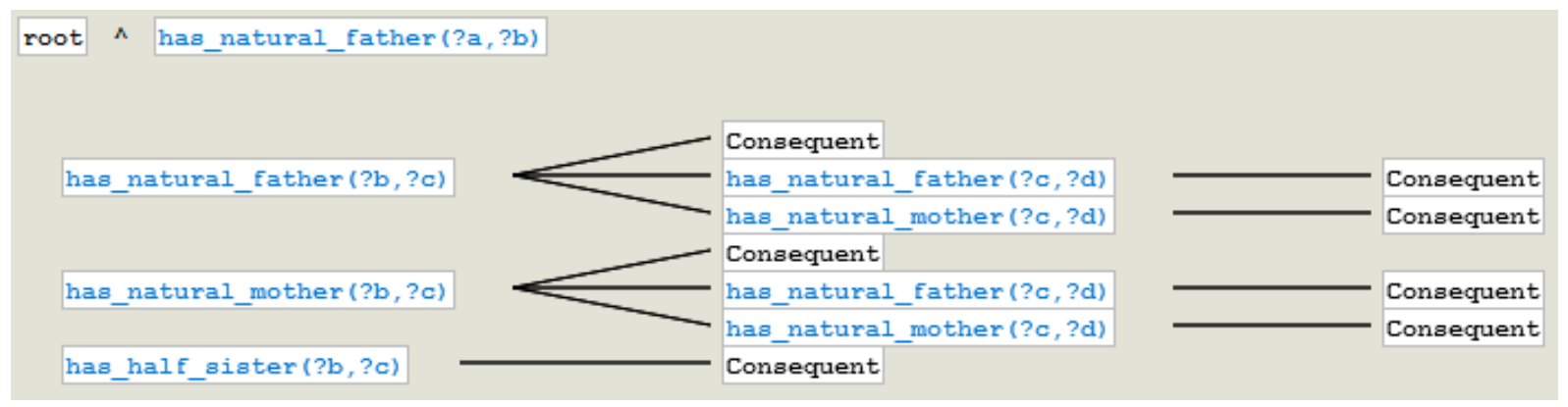

Figura 29 - Árvore de decisão - Dependência de variáveis.

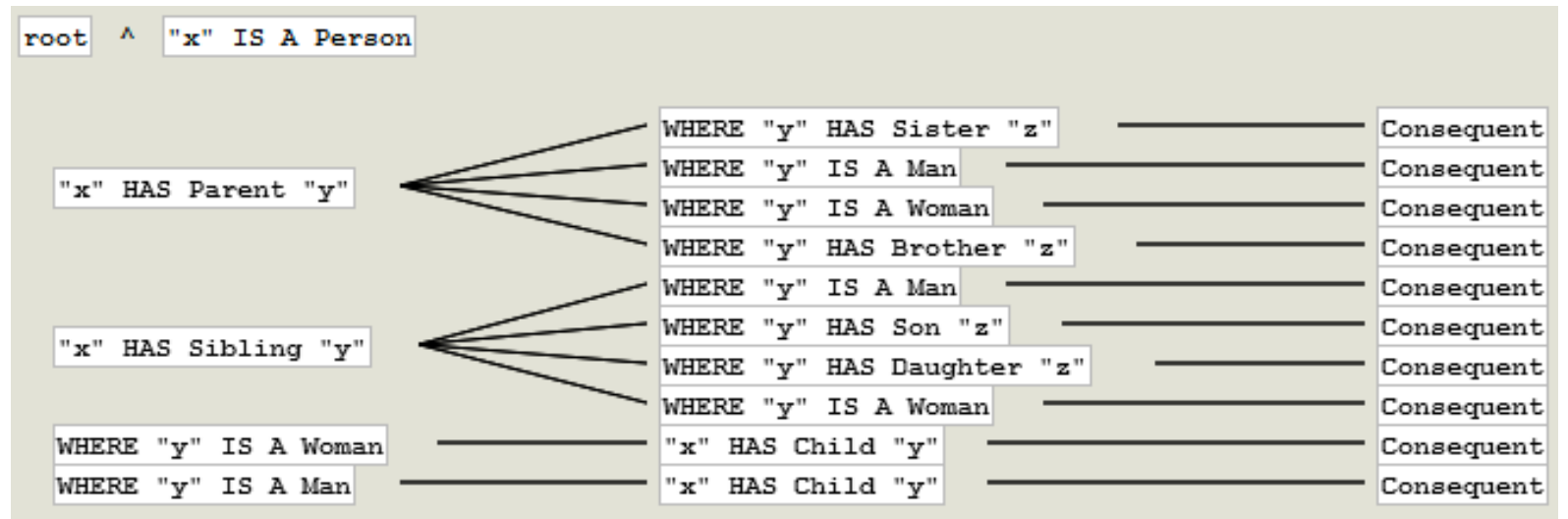

Figura 30 - Árvore de decisão - Paráfrases.

A funcionalidade das árvores de decisão é uma das principais contribuições deste trabalho, pois essa técnica nunca foi usada para regras SWRL e mostra-se como uma forma fácil de navegar em conjuntos de regras. Através dela é possível encontrar facilmente regras com antecedentes iguais ou semelhantes. Na Figura 31 é possível identificar que ocorrem antecedentes com mais de um consequente. De cima para baixo, na primeira ocorrência de um antecedente com dois consequentes, ao passar o mouse sobre os dois consequentes é possível perceber que eles são diferentes. Sendo assim, pode ser que não seja um erro, mas uma opção de projeto. Já na segunda ocorrência, quando são olhados os consequentes é possível identificar que eles são iguais (um erro). Como os algoritmos de árvore de decisão juntam átomos semelhantes é possível identificar os tipos de repetição que merecem atenção. 


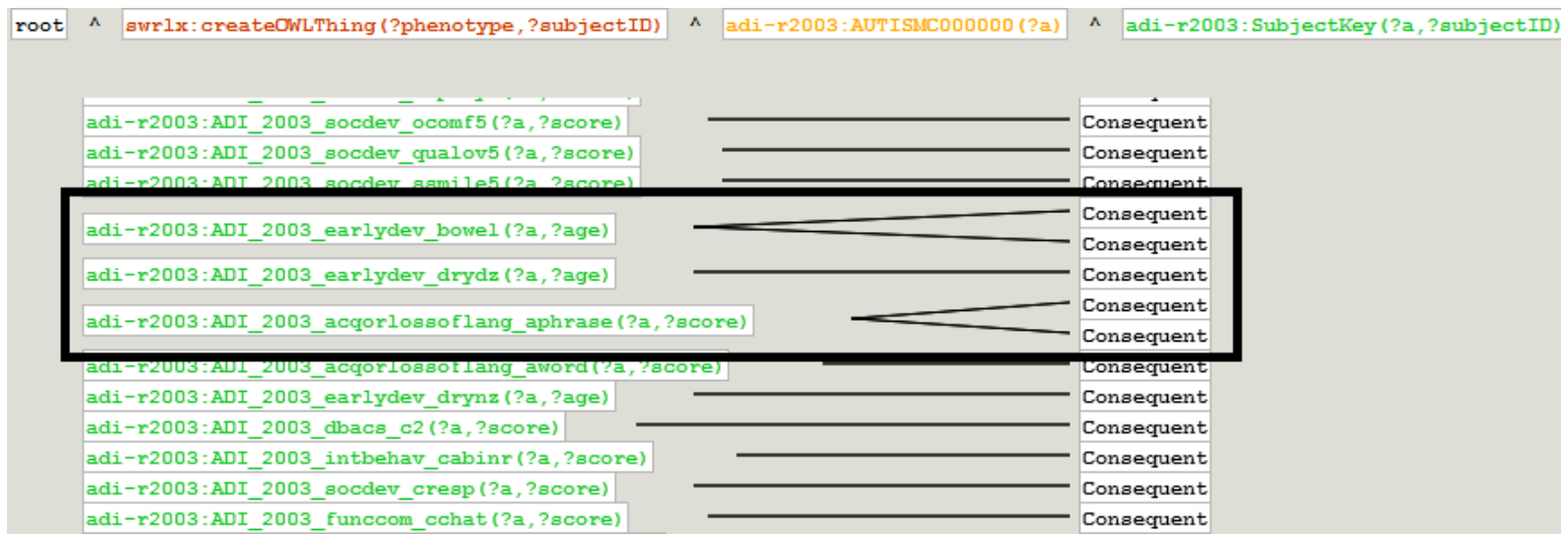

Figura 31 - Árvore de decisão - Identificação de regras com antecedentes iguais.

Muitas regras se diferenciam às vezes por um ou dois átomos. Então como ocorrem muitas repetições nos átomos das regras, a árvore de decisão pode ser usada para fazer o reaproveitamento de átomos. A Figura 32 mostra a tela da árvore de decisão, como pode ser visto na imagem, ao se clicar sobre um nodo da árvore são mostradas opções em um menu popup. Quando o nodo for um átomo do antecedente, o menu irá mostrar a opção para reaproveitar todos os átomos até a raiz, em uma nova regra. Já quando o nodo for um consequente, o menu mostrará a opção de editar essa regra.

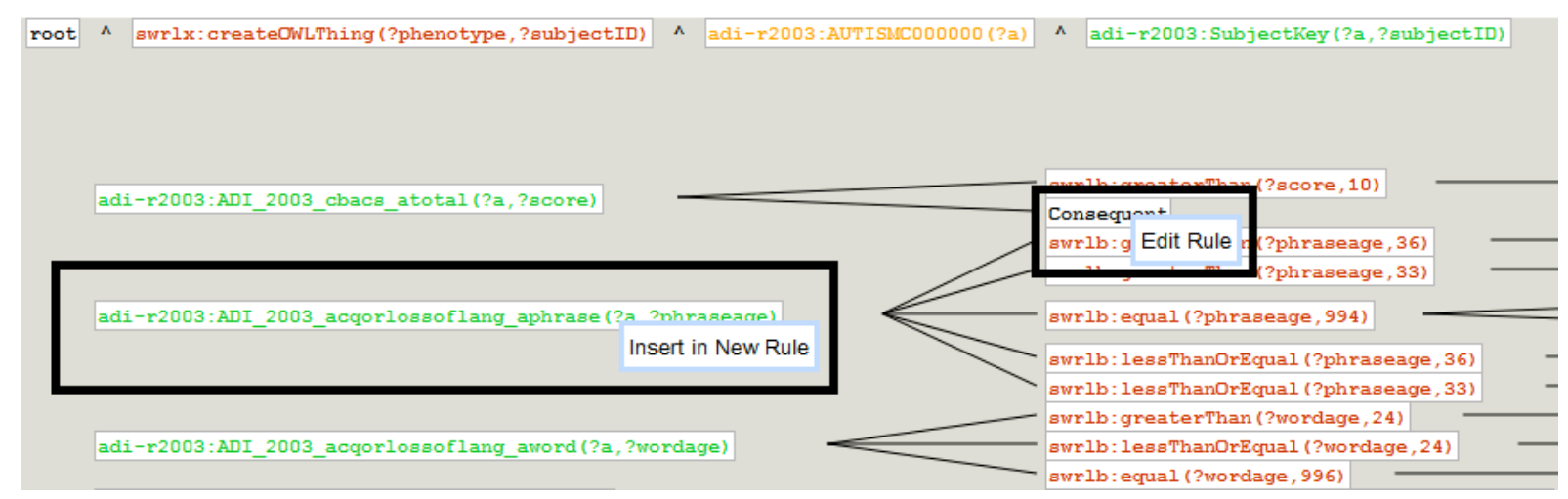

Figura 32 - Árvore de decisão - Botão direito sobre os nós.

\subsubsection{Filtros}

Como conjuntos de regras tendem a crescer, torna-se cada vez mais difícil localizar regras, então foi adicionada uma interface para filtrar regras SWRL. Para essa funcionalidade, foi estudada uma forma de facilitar o uso dos operadores lógicos AND, OR e NOT. Procurou-se tornar a busca completa, mas sem torná-la complexa para o usuário.

Nessa interface, o usuário pode usar os operadores lógicos AND, OR e NOT para criar uma expressão lógica para filtrar regras. O filtro é montado usando a interface do usuário na 
Figura 33, em que há um campo para cada operador lógico, respectivamente, 1, 2 e 3. Nesses campos, os valores de filtro são separados por espaços, expressões com espaços devem ser delimitadas por "" (exemplo "casa e carro").

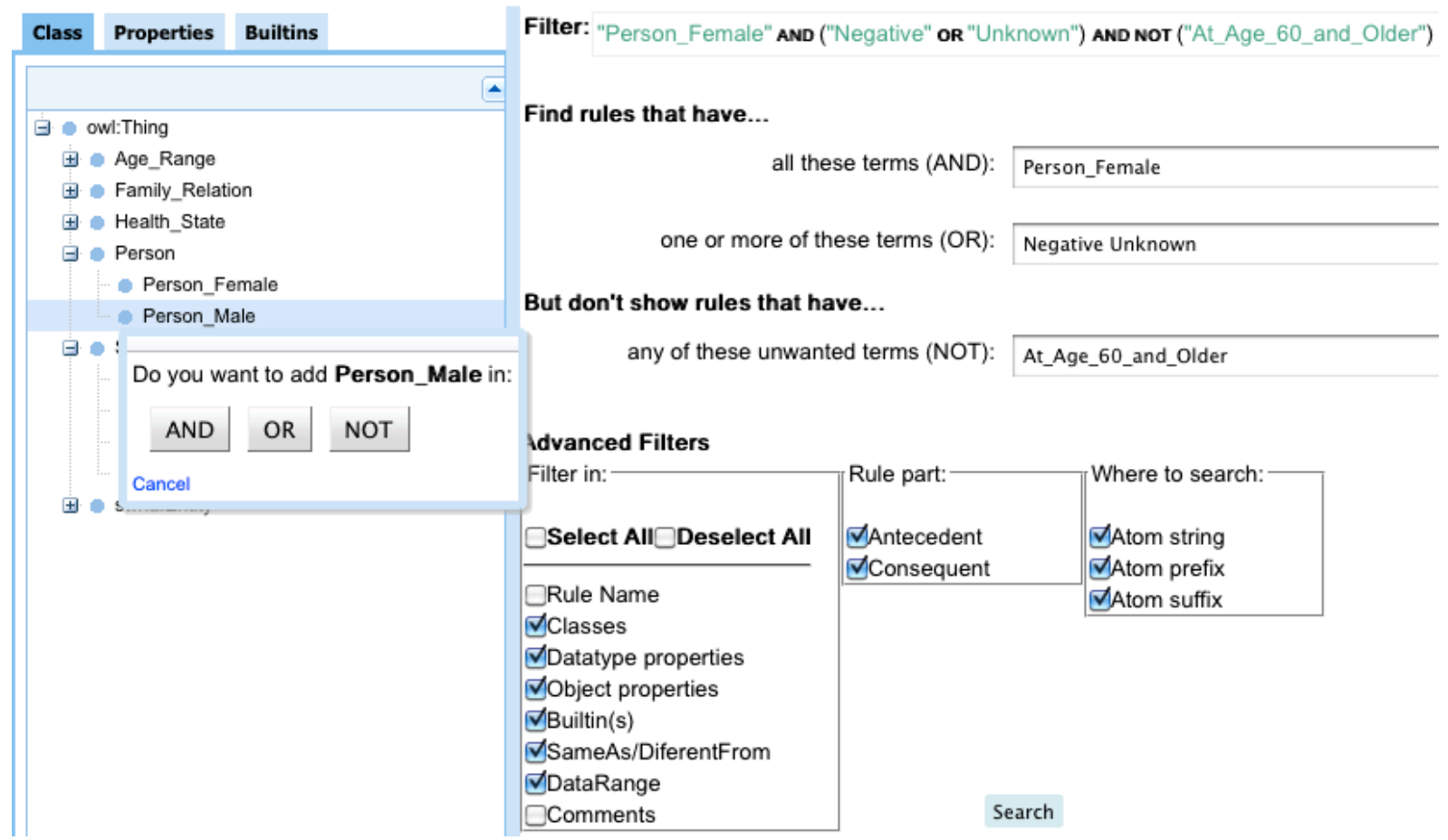

Figura 33 - Filtro das regras.

O filtro utiliza a expressão lógica montada (Figura 33, parte superior) para procurar automaticamente no rdf:ID e no rdfs:Label dos predicados de cada átomo. Além disso, a interface fornece opções avançadas para filtrar, sendo possível escolher partes de uma regra e tipos de átomos a serem filtrados. É possível escolher filtrar no Nome da regras, em Class, Datatype properties, Object properties, Buitins, SameAs/DiferentFrom, DataRange, Comments (Comentários dos predicados de cada átomo). Também é possível filtrar somente no antecedente ou no consequente. As opções para a filtragem ainda permitem os usuários realizem buscas nos prefixos, sufixos ou qualquer parte da string que representa cada átomo.

$\mathrm{Na}$ Figura 33, na lateral esquerda, encontram-se três guias (Class, Properties e Bultins) com os termos da ontologia. Essas guias são usadas para facilitar a inserção de termos da ontologia em uma busca. Como pode ser visto nessa figura, assim que o usuário clica na classe Person_Male a interface oferece a opção para escolher a qual operador lógico quer inserir.

Quando o usuário termina de montar o filtro, basta clicar no botão Search (localizado no lado direito parte inferior) que o filtro será executado e o seu resultado será mostrado na tela 
de visualização do SWRL Editor. Na Figura 34 é mostrada a tela de visualização com o filtro de regras modificado. Apenas as regras que obedecerem as condições desse filtro serão mostradas na interface e poderão ser usadas nas outras ferramentas.

\section{Visualizations}

Figura 34 - Resultado do filtro de regras.

\subsubsection{Composição}

O processo de criação de regras é ativado na ferramenta quando o usuário clica em New Rule ou quando ele opta por editar uma regra específica (Silva, 2012) numa das interfaces de visualização. O modo de composição disponibiliza dois modos de trabalho:

- Editor - Utiliza a representação hierárquica para apresentar e organizar os átomos da regra e um formulário para editar (Silva, 2012);

- SWRL - Editor SWRL com Highlight, no qual o usuário escreve a regra utilizando a sintaxe SWRL (Silva, 2012);

As contribuições deste trabalho para a composição foram a sugestão de termos (autocompletar) e o uso dos rdfs:Labels na edição das regras. A primeira funcionalidade consiste em sugerir termos a medida em que o nome de algum elemento da ontologia é digitado. Como ontologias podem ser muito grandes, por padrão, cada vez que o usuário acrescenta mais uma letra o autocompletar sugere no máximo 8 termos da ontologia (a medida que o usuário digita mais letras um desses 8 termos vai ser o que ele procura). $\mathrm{Na}$ Figura 35 (A) é mostrada a sugestão de termos por meio do autocompletar. O usuário digitou “Au" e o autocompletar sugeriu 4 termos. Nesse exemplo, os rdfs:Labels estão sendo usados como nomes das classes OWL. Além de rdfs:Labels terem nomes mais intuitivos, geralmente com poucas letras já se consegue uma lista de poucos termos. 


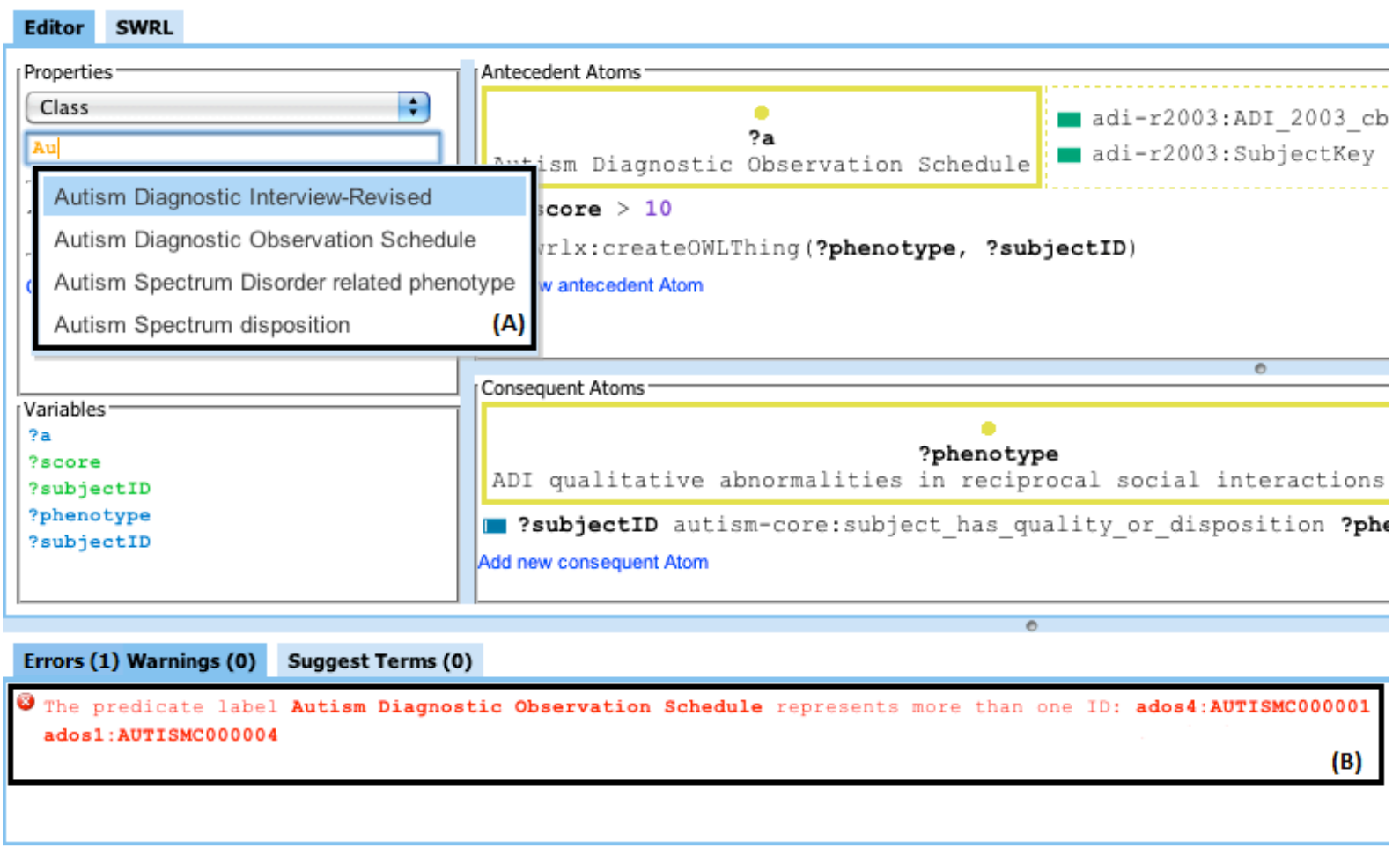

Figura 35 - Composição - (A) Autocompletar; (B) Mensagem de erro de redundância de rdfs:Labels.

Foi também implementado o tratamento de erros de redundância que os rdfs:Labels podem gerar. Na Figura 35 - (B) é mostrada a seguinte mensagem de erro: "The predicate label Autism Diagnostic Observation Schedule represents more than one ID: ados 4:AUTISMC000001, ados1:AUTISMC000004". O usuário poderá então usar um dos dois rdf:IDs para representar o elemento e assim evitar o erro.

\subsubsection{Opções}

As configurações do SWRL Editor servem para tornar a ferramenta mais amigável e facilitar os processos de visualização e edição de regras. As configurações do SWRL Editor foram divididas em três partes (Figura 36): General, Composition e Visualization. As configurações gerais servem para toda a ferramenta.

\section{Options}

General Composition Visualization
Using:
rdfs:Label :

Figura 36 - Opções Gerais do SWRL Editor. 
Na Figura 36 é apresentada a tela das configurações gerais, nela somente existe uma configuração para usar rdf:ID ou rdfs:Label. O rdf:ID é um identificador único para cada termo da ontologia, já o rdfs:Label é uma descrição para o termo da ontologia. Usando a ontologia do autismo, na Tabela 2 é mostrado alguns rdf:ID de termos da ontologia com o seu respectivo rdfs:Label. Fica evidente que os rdfs:Labels podem tornar mais fácil o entendimento e a edição das regras.

Tabela 2 - rdf:ID versus rdfs:Label

\begin{tabular}{|l|l|}
\hline \multicolumn{1}{|c|}{ rdf:ID } & \multicolumn{1}{c|}{ rdfs:Label } \\
\hline adi-r2003:AUTISMC000000 & Autism Diagnostic Interview-Revised \\
\hline ados1:AUTISMC000004 & Autism Diagnostic Observation Schedule \\
\hline ados4:AUTISMC000001 & Autism Diagnostic Observation Schedule \\
\hline vabs_survey:AUTISMC000003 & Vineland Adaptive Behavior Scales \\
\hline Autism-core:AUTISMC100000 & Phenotype Record \\
\hline Autism-core:AUTISMC100002 & Quantitative value \\
\hline NIF-Invertigation:birnlex_2387 & Citation Record \\
\hline Autism-core:AUTISMC1000069 & Present \\
\hline Autism-core:AUTISMC1000070 & Repetitive stereotypical behavior \\
\hline
\end{tabular}

Essa é outra contribuição deste trabalho, pois é permitido ao usuário escolher a opção de visualizar e editar as regras usando rdfs:Labels. Porém, isso pode acarretar problemas na edição, pois um mesmo rdfs:Label pode estar em mais de um termo da ontologia. Um exemplo está na Tabela 2 em que os termos ados1:AUTISMC000004 e ados 4 : AUTISMC000001 compartilham um mesmo rdfs:Label. Mas mesmo selecionando a opção para usar rdfs:Label o usuário poderá usar um rdf:ID durante a edição (Figura 35).

\begin{tabular}{|l|}
\hline General Composition Visualization \\
\hline Visible tabs: \\
ØEditor \\
ØSWRL \\
\hline Default selected tab: \\
Editor \\
Type View in Similar Rules \\
List \\
\hline
\end{tabular}

Figura 37 - Opções de Composição do SWRL Editor. 
Já as configurações de composição (Figura 37), servem para ajustar a interface de composição de regras. Com essas configurações é possível desabilitar uma das guias (Editor ou SWRL) e também pode-se definir uma das guias como default para quando é ativada a composição. Além disso, na composição pode-se mostrar regras similares, para mostrar essas regras é possível escolher um dos quatros modos de visualização de regras (List, Text, SWRL, Autism).

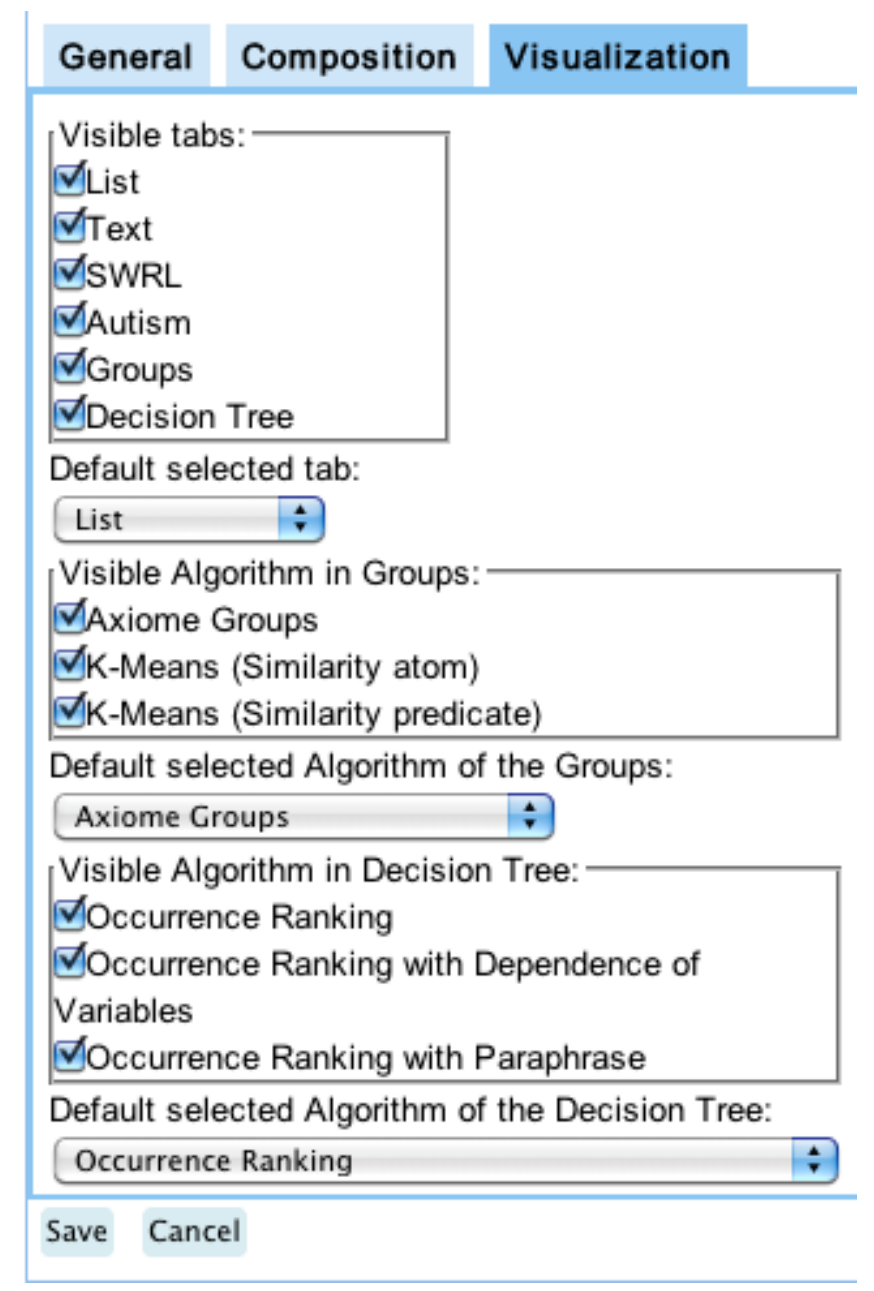

Figura 38 - Opções de Visualização do SWRL Editor.

Por último temos a guia de configurações de visualização (Figura 38) que contém configurações para esconder algumas das guias (List, Text, SWRL, Autism, Groups ou Decision Tree) ou escolher uma delas para ser a guia padrão acessada ao se entrar no modo de composição. Ela também pode desabilitar alguns dos algoritmos de agrupamento ou de criação de árvores de decisão e definir algoritmos padrão para cada caso.

Como pode ser visto na barra inferior da Figura 38, existe um botão para salvar as configurações. Essas configurações são salvas no servidor, em um arquivo XML, juntamente com o nome do usuário e a ontologia utilizada. Então, toda a vez que o usuário faz o login, 
essas informações são recuperadas desses arquivos XML do servidor. Caso o usuário altere as configurações sem estar logado, essa informação fica temporariamente salva no cliente do SWRL Editor e vai ser perdida quando ele recarregue a página do Web-Protégé (ou desligar o navegador).

\subsubsection{URLs}

O GWT mantém o histórico do navegador como uma pilha de tokens (identificadores são definidos por \# na URL). Quando o aplicativo inicia, a pilha está vazia. A medida que o usuário interage com o aplicativo, o mesmo vai adicionando itens (tokens) a essa pilha. Isso permite navegar entre estados ou acessar um estado do aplicativo. Para tornar o acesso mais eficiente no SWRL Editor, a URL vai sendo gerada a partir da navegação do usuário.

Por padrão, foram definidos quatro pontos principais de acesso: opções, filtro, visualização e composição que usam respectivamente os seguintes tokens: options, filter, visualization e composition. Abaixo um exemplo de como acessar a interface de visualização da ontologia da família, para acessar as demais interfaces é necessário apenas mudar os tokens da URL:

http://dominio.com/SWRLEditor/\# visualization:ontology=Family\&tab=SwrlEditorTab

\subsubsection{Login}

Como mencionado na seção 4.1.2.2, o Web-Protégé possui um sistema de controle de usuários e suas permissões para criação e edição de itens da ontologia. Esse controle foi integrado ao SWRL Editor, permitindo ou bloqueando para determinados usuários a criação ou edição de regras SWRL. Os botões New Rule, Edit Rule, Duplicate and Edit, Delete e Run Rules permanecem desabilitados até o usuário fazer o login. Após fazer o login, caso o usuário tenha permissão, os botões são habilitados. A Figura 39 apresenta os botões desabilitados. Além disso, nessa figura é possível ver botões que permanecem habilitados: Options, Info, Edit do Filtro e Similar Rules. As funções desses botões não afetam nenhum item da ontologia, então foi definido que não é necessária permissão para uso deles. 


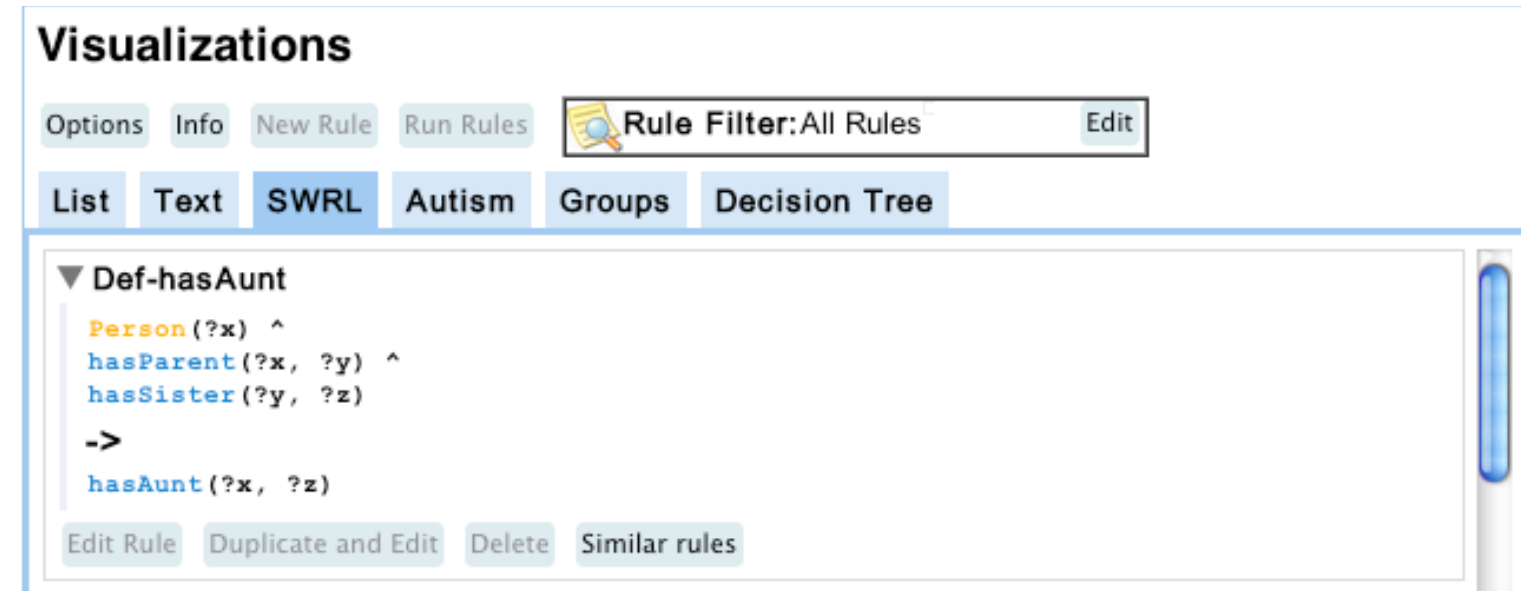

Figura 39 - SWRL Editor antes de fazer o login.

\subsubsection{Execução das regras}

Os passos para executar as regras são:

1. O usuário requisita ao servidor a execução das regras;

2. No servidor é limpo o motor de inferência (por padrão do Protégé 3 o JESS é usado);

3. Depois são importadas a ontologia OWL e as regras SWRL para o motor de inferência;

4. São executadas as regras no motor de inferência;

5. São transferidas as mudanças para a ontologia OWL do servidor;

6. Por último, as alterações são enviadas ao cliente.

Depois das regras serem executadas, o Web-Protégé salva a ontologia com todas as alterações.

\subsubsection{Resultados}

\subsubsection{Estudo de caso}

Os primeiros protótipos dessa ferramenta foram desenvolvidos para a Autism Phenologue Rules (Silva, 2012), mas muitos dos recursos foram criados de forma a serem genéricos para várias ontologias. Nesse momento foi feito um estudo que identificou quais recursos eram utilizáveis para outras ontologias. Para isso, foram usadas mais duas ontologias com regras: 
- Breast Cancer Grading Ontology ${ }^{8}$ - São regras usadas para classificação do câncer de mama. Esse conjunto de regras é composto por 12 regras, que são utilizados para atribuir uma nota a um tumor a partir dos três critérios de NGS (Next-Generation Sequencing).

- Family Health History Ontology ${ }^{9}$ - Este conjunto de regras é composto de 159 regras, que são usados para calcular três gerações de relações de parentesco biológico.

Foram utilizados todos os recursos do SWRL Editor nessas outras duas ontologias e foram encontrados os seguintes problemas:

- A visualização do autismo (Silva, 2012) não funcionou para nenhuma das duas ontologias, isso se deve ao fato do padrão da Autism Phenologue Rules ser muito específico a seu campo de aplicação.

- Os agrupamentos por meio dos algoritmos de K-meas implementados (Silva, 2012) não funcionaram na Breast Cancer Grading Ontology, eles precisam de conjuntos maiores de regras para ser darem bons resultados.

Os demais recursos do SWRL Editor obtiveram os mesmos resultados que na Autism Phenologue Rules. Com isso, pode ser concluído que a ferramenta pode ser considerada uma ferramenta que funciona para conjuntos de regras SWRL em geral, mesmo com alguns detalhes a serem melhorados.

\subsubsection{Comparação de Ferramentas}

Nesta subseção, é apresentada uma comparação entre recursos/interfaces das ferramentas de manipulação de SWRL que são encontradas na literatura. São comparadas ao SWRL Editor as seguintes ferramentas: SWRL Tab, Axiomé e ACE View. As ferramentas SWRL Tab e Axiomé têm seus recursos acoplados a Protege-OWL do Protégé 3. Já o ACE View possuiu seus recursos ligados a OWL-API do Protégé 4. As três ferramentas são muito acopladas as APIs das suas respectivas versões do Protégé, já o SWRL Editor, possui uma separação quase total das APIs do Web-Protégé (através das classes OntologyManager e SWRLManager) tornando mais fácil uma futura migração. Outra vantagem sobre as demais é o fato de que seus recursos estão disponíveis na Web e, por essa razão, podem beneficiar-se

\footnotetext{
${ }^{8}$ Breast Cancer Grading Ontology: Disponível em: http://bioportal.bioontology.org/ontologies/1304

${ }^{9}$ Family Health History Ontology: Disponivel em: http://bioportal.bioontology.org/ontologies/1126
} 
dos recursos de colaboração que a Web trás e, mais especificamente, dos recursos que o WebProtégé trás para colaboração.

Para fazer a comparação, utilizaremos os principais recursos/interfaces encontrados em sistemas de regras de negócios e regras SWRL (Rivolli, Orlando e Moreira, 2011) e (Zacharias, 2008). A Tabela 3 mostra a comparação entre as quatros ferramentas (para o SWRL Editor são incluídos os recursos desenvolvidos em Silva (2012) ):

Tabela 3 - Comparação das características entre as principais ferramentas para edição de regras SWRL

\begin{tabular}{|c|c|c|c|c|}
\hline Recurso/Interfaces & $\begin{array}{c}\text { SWRL } \\
\text { Editor }\end{array}$ & $\begin{array}{c}\text { SWRL } \\
\text { Tab }\end{array}$ & Axiomé & $\begin{array}{c}\text { ACE } \\
\text { View }\end{array}$ \\
\hline Plataforma & Web & Desktop & Desktop & Desktop \\
\hline Tabela de decisão & $\checkmark$ & & & \\
\hline Árvore de decisão & & & $\checkmark$ & \\
\hline Diagrama gráfico & $\checkmark$ & $\checkmark$ & $\checkmark$ & \\
\hline Editor de texto & $\checkmark$ & & & \\
\hline Editor de texto com Highlight & $\checkmark$ & & $\checkmark$ & \\
\hline Formulário/Template & Parcial & & Parcial & $\checkmark$ \\
\hline Linguagem natural & $\checkmark$ & & $\checkmark$ & \\
\hline Representação visual & $\checkmark$ & & $\checkmark$ & \\
\hline Agrupamento & $\checkmark$ & $\checkmark$ & & \\
\hline Sugestão de termos & $\checkmark$ & $\checkmark$ & $\checkmark$ & $\checkmark$ \\
\hline Mecanismos de busca & $\checkmark$ & & & \\
\hline Informações gerais sobre as regras & $\checkmark$ & & & \\
\hline Customização & $\checkmark$ & & & \\
\hline Adição de novos algoritmos & $\checkmark$ & & & \\
\hline Edição de Regras com rdfs:Label & $\checkmark$ & $\checkmark$ & $\checkmark$ & \\
\hline Detecção de erros & $\checkmark$ & $\checkmark$ & \\
\hline Execução das regras & $\checkmark$ & $\checkmark$ & \\
\hline
\end{tabular}

Podemos ver que o Editor SWRL apresenta larga vantagem de recursos sobre as outras ferramentas, pois ele implementa a maioria dos recursos usados em ferramentas de regras (para SWRL e para regras de negócios). Por exemplo, se um usuário precisa encontrar regras repetidas no conjunto, a árvore de decisão é fácil e intuitiva para mostrar visualmente as regras que têm exatamente o mesmo antecedente e depois é só verificar se os conseqüentes são iguais. Não há recurso semelhante em outras ferramentas para SWRL. Alguns dos 
recursos da Tabela 3 que estão no SWRL Editor e em pelo menos mais uma ferramenta, foram melhorados no SWRL Editor, por exemplo: o Agrupamento no SWRL Editor implementa os recursos do Axiomé e ainda permite a inclusão de novos algoritmos e é utilizado em combinação com as técnicas de visualização do SWRL Editor; os Mecanismos de busca que usa o mecanismo de filtros não disponível nas outras ferramentas; ou ainda a Detecção de erros que é mais que completa que os demais (Silva 2012).

Nós testamos o SWRL Editor usando três ontologias (com conjuntos de regras SWRL): Autism Phenologue Rules, Breast Cancer Grading Ontology, Family Health History Ontology. Ao usar a ontologia Autismo, fomos capazes de encontrar facilmente problemas, como regras repetidas, que escaparam a seus desenvolvedores usando as outras ferramentas.

Também é importante mencionar o fato de que o Editor SWRL está integrado com os recursos do Web-Protégé. Por exemplo, os usuários podem anotar componentes utilizados nas regras, podendo adicionar comentários e discutir on-line (em tempo real). Eles também podem discutir alterações que são documentadas usando tags, tais como, Class Created ou Property Modified, usando a ontologia CHAO. Como grandes conjuntos de regras, normalmente, são mantidos por grupos de usuários distribuídos, o SWRL Editor torna-se ideal por aceitar a manipulação de conjuntos de regras de forma colaborativa. Assim resultando em uma única ferramenta que pode apoiar mais eficazmente o trabalho desses grupos. Essa é uma das mais importantes contribuições do editor SWRL, já que nenhuma das outras ferramentas encontradas na literatura oferece esse tipo de suporte.

\subsubsection{Considerações Finais}

Neste capítulo foi apresentado o SWRL Editor, um editor mais completo em relação a outros editores de regras SWRL. Ele foi desenvolvido como um plug-in para o Web-Protégé. O SWRL Editor incorpora diversos recursos para auxiliar na criação e na visualização de regras SWRL. Esse editor é uma nova alternativa para manipulação colaborativa de regras SWRL. Ele tem um grande potencial para tornar-se referência na manipulação de regras SWRL. 



\section{Conclusão}

A linguagem SWRL é muito útil para desenvolvedores de ontologias, pois faz inferências de novos conhecimentos sobre indivíduos da ontologia (OWL). Um dos principais problemas no uso de SWRL é que grandes conjuntos de regras são mantidos de forma colaborativa e, à medida que crescem, os desenvolvedores começam a ter problemas no seu gerenciamento. Para auxiliar no desenvolvimento desses conjuntos de regras, foi desenvolvido um Editor/Visualizador colaborativo de regras SWRL. Para isso foram incorporadas as melhores técnica em Edição/Visualização de outros domínios de regras (ex. Regras de negócio). Ampliando o conjunto de recursos desenvolvidos em Silva (2012) obteve-se o SWRL Editor, o Editor/Visualizador mais completo para regras SWRL.

Após seu desenvolvimento, foi feita uma comparação com outras 3 ferramentas de Edição/Visualização de SWRL disponíveis na literatura. Nessa comparação foi possível constatar que o SWRL Editor tem uma vantagem esmagadora sobre elas, pois ele implementa a maioria dos recursos citados em (Zacharias, 2008) e (Rivolli, Orlando e Moreira, 2011). Além disso, até mesmo recursos que já estão em outras ferramentas para SWRL foram melhorados.

O SWRL Editor foi desenvolvido inicialmente para atender ao desenvolvimento da Autism Phenologue Rules. Porém, como a ferramenta tornou-se muito completa em relação a outras da mesma linha, foram feitos testes com outras ontologias da área de informática biomédica. Esses testes constataram que, com exceção do código desenvolvido especificamente para a Autism Phenologhe Rules (guia Autism), todas as outras funcionalidades da ferramenta podiam ser usadas para edição de regras SWRL em outras ontologias.

O objetivo principal deste trabalho foi desenvolver soluções para implementar um editor de regras SWRL que incorporasse as melhores técnicas em Edição/Visualização de outros domínios de regras para obter uma ferramenta mais completa que as disponíveis. Como mostrado no capítulo 6 , esse objetivo foi atingido.

A seguir é apresentado um resumo das contribuições deste trabalho (Seções 7.1 e 7.2) e sugestões para trabalhos futuros (Seção 7.3). 


\subsection{Contribuições}

As contribuições desse projeto são divididas em duas partes:

- Ampliação dos recursos no servidor: As principais contribuições nessa parte foram permitir que usuários possam trabalhar colaborativamente com a nova ferramenta $\mathrm{e}$ fazer o desacoplamento das APIs do Web-Protégé (SWRLAPI e Protégé-OWL).

○ Criação de um formato de representação próprio para o SWRL Editor Essa nova representação garante um maior desacoplamento das APIs do Protégé 3, tornando assim mais fácil, uma futura migração para outras APIs;

○ Gerenciadores do SWRL - Esses são responsáveis pela comunicação entre o SWRL Editor e as APIs do Protégé;

○ Gerenciadores de Atualização - Esses são responsáveis por sincronizar as atualizações das regras para todos os usuários que estão usando a ferramenta;

○ Sistema de carregamento automático de algoritmos - Esse sistema é responsável por carregar novos algoritmos para agrupamento de regras e criação de árvores de decisão. Ele tornou-se uma opção interessante pelo fato de permitir que usuários mais avançados possam desenvolver seus próprios algoritmos de acordo com suas necessidades específicas;

- Adequação da interface gráfica: As principais contribuições dessa parte foram as implementações de recursos considerados importantes em Zacharias (2008) e não desenvolvidos em Silva (2012).

○ Árvores de decisão - A árvore decisão é uma técnica usada para facilitar a navegação em conjuntos de regras. Apesar de não haver um consenso sobre uma técnica ideal para essa visualização, foram desenvolvidos 3 algoritmos (cada um com suas vantagens). Outro ponto interessante é o fato de que a navegação na árvore de decisão ajuda a encontrar possíveis problemas de lógica nas regras, dado que muitas regras possuem poucos átomos diferentes. A árvore de decisão também é usada para reaproveitar átomos de uma regra para criação de outras;

- Agrupamento - Nesse recurso foi implementado o algoritmo de agrupamento do Axiomé. Demonstrado que novos algoritmos podem ser facilmente implementado para o SWRL Editor. Outro ponto interessante é o fato do SWRL Editor agregar ao agrupamento suas representações visuais (como 
visualização hierárquica) tornando a combinação de técnicas numa forma visualmente melhor;

- Filtro - As principais contribuições do sistema de filtragem são o uso de cláusulas AND, OR e NOT que dão uma maior liberdade na montagem do filtro, mas sem serem complexas de usar;

○ Opções - Servem para ajustar os recursos disponíveis no SWRL Editor, mas a principal contribuição é a possibilidade de usar os rdfs:Labels que tornam as regras mais compreensíveis aos usuários;

- Autocompletar - A sugestão de termos foi usada no processo de composição como uma estratégia para facilitar o uso de termos da ontologia.

- Parafraseamento das regras - Para essa representação visual foi implementada e melhorada a técnica usada no Axiomé, negritando alguns termos das paráfrases gerada. Consegue-se com essa visualização uma forma mais fácil de entender as regras;

- Além disso, outro recurso considerado importante foi:

○ Integração com o Login - Por ser uma ferramenta Web, ela está aberta a todos. Então o SWRL Editor foi integrado ao sistema de login do WebProtégé, garantido assim a segurança dos dados.

\subsection{Publicações e Prêmios relacionados ao trabalho}

Como resultados deste trabalho, foram aceitos para publicação os seguintes artigos:

Artigo aceito no ICEIS 2012 - International Conference on Enterprise Information Systems: "SWRL RULE EDITOR: A WEB APPLICATION AS RICH AS DESKTOP BUSINESS RULE EDITORS" (Orlando et al., 2012);

Artigo publicado no WebMedia 2011 - Simpósio Brasileiro de Sistemas Multimídia e Web : "Regras SWRL: Análise de similaridade e detecção de erros" (Rivolli et al., 2011a);

Artigo publicado no WebMedia 2011 - Simpósio Brasileiro de Sistemas Multimídia e Web - Workshop de Ferramentas e Aplicações (WFA) : "Ferramenta web para visualização e composição de regras SWRL” (Rivolli et al., 2011b); 
Prêmio de melhor ferramenta do X Workshop de Ferramentas e Aplicações do XVII Simpósio Brasileiro de Sistemas Multimídia e Web : "Ferramenta web para visualização e composição de regras SWRL” (Rivolli et al., 2011b);

\section{Artigo publicado no ICEIS 2011 - International Conference on Enterprise Information} Systems : "An Analysis of Rules-Based Systems to Improve SWRL Tools” (Rivolli, Orlando e Moreira, 2011);

\subsection{Trabalhos Futuros}

Como trabalhos futuros podem ser citados:

- Avaliação de usabilidade - Avaliação quantitativa e qualitativa dos recursos desenvolvidos, verificando o impacto na interação com o usuário;

- Detecção de erros semânticos - Atualmente, erros semânticos são identificados só pela máquina de inferência, ou seja, é necessário iniciar o processo de inferência para descobrir esses erros. Porém, o ideal seria que esses erros fossem identificados no processo de criação das regras;

- Detecção de relevância e relações semânticas entre as Regras - A medida em que conjuntos de regras crescem, é desejável destacar regras SWRL mais relevantes para a ontologia;

- Suporte à linguagem natural - O uso de linguagem natural na visualização das regras SWRL pode tornar-se uma estratégia interessante para usuários não técnicos em computação;

- Explorar técnicas que visualizem a localização das regras dentro do contexto da ontologia.

- Explorar técnicas que visualizem o conjunto de regras levando em conta a hierarquia da ontologia; 


\section{Referências}

AHMEDI, L.; ABAZI-BEXHETI, L.; KADRIU, A. A Uniform Semantic Web Framework for Co-authorship Networks. IEEE Ninth International Conference on Dependable, Autonomic and Secure Computing (DASC), p. 958-965, 2011. doi: 10.1109/DASC.2011.159.

ANTONIOU, G.; HARMELEN, F. A Semantic Web Primer, 2nd Edition. The MIT Press. 2008. ISBN: 978-0-262-01242-3

ASSUMPÇÃO, F. B.; PIMENTEL, A. C. M. Autismo infantil. Bras. Psiquiatr. v 22(Supl I), p. 37-9, 2000. Disponível em: http://www.scielo.br/pdf/rbp/v22s2/3795.pdf, acesso em Mar. 2012.

BERNERS-LEE, T.; FISCHETTI, M. Weaving the Web: The Original Design and Ultimate Destiny of the World Wide Web. HarperSanFrancisco, 2008. ISBN: 978-0062515872.

BERNERS-LEE, T.; HENDLER, J.; LASSILA, O. The Semantic Web. Scientific American, p. 34-43, 2001. Disponível em: http://www.scientificamerican.com/article.cfm?id=thesemantic-web, acesso em Jan. 2012.

BERNSTAM, E. V.; SMITH, J. W.; JOHNSON, T. R. What is biomedical informatics?. Journal of Biomedical Informatics, TX, US, v. 43 n. 1 p. 104-110. Fev 2010. doi: 10.1016/j.jbi.2009.08.006

BRAYE, L.; RAMEL, S.; GRÉGOIRE, B.; LEIDNER, S.; SCHMITT, M. State of the Art Business Rules Languages. Public Research Centre Henri Tudor, 2006. Disponível em: http://efficient.citi.tudor.lu/cms/efficient/content.nsf/0/4A938852840437F2C12573950056F7 A9/\$file/BusinessRulesLanguages_D3.1.pdf, acesso em Jun. 2010.

BROOKSBANK, C.; CAMERON, G.; THORNTON, J. The European Bioinformatics Institute's data resources: towards systems biology. Nucleic Acids Research, v. 38, p. 17-25. 2005. doi: 10.1093/nar/gki026.

CHAI, Y.; XIA, T.; ZHU, J.; LI, H. Intelligent Digital Photo Management System Using Ontology and SWRL. International Conference on Computational Intelligence and Security (CIS), p. 18-22, 2010. doi: 10.1109/CIS.2010.11. 
CHANDRASEKARAN, B.; JOSEPHSON, J. R.; BENJAMINS, V. R. What Are Ontologies, and Why Do We Need Them?. IEEE Intelligent Systems, Piscataway, NJ, USA, v. 14, n. 1, p. 20-26. Jan. 1999. doi: 10.1109/5254.747902.

CHEN, R., BAU, C., HUANG, Y. Development of anti-diabetic drugs ontology for guidelinebased clinical drugs recommend system using OWL and SWRL. Fuzzy Systems (FUZZ). 2010. doi:10.1109/FUZZY.2010.5584139.

DZIEKANIAK, G. V.; KIRINUS, J. B. Web Semântica. Revista Eletrônica de Biblioteconomia e Ciência da Informação, Santa Catarina, Brasil, 2004. Disponível em: http://www.periodicos.ufsc.br/index.php/eb/article/view/155/5471. acesso em Fev. de 2011.

ERDMANN, M.; MAEDCHE, A.; SCHNURR, H. P.; STAAB, S. From manual to semiautomatic semantic annotation: About ontology-based text annotation tools. In: Proceedings of the COLING 2000 Workshop on Semantic Annotation and Intelligent Content, Luxemburgo. Ago. 2000. doi: 10.1.1.2.4325.

FEIGENBAUM, L.; HERMAN, I.; HONGSERMEIER, R; NEUMANN, E.; STEPHENS, S. The Semantic Web in action, Scientific American, p. 64-71, Dez. 2007. Disponível em: http://www.ncbi.nlm.nih.gov/pubmed/18237102, acesso em Jan. 2010.

FRIEDMAN-HILL, E. Jess the Rule Engine for the Java ${ }^{\text {TM }}$ Platform. Sandia National laboratories, versão 7.1, Jul. 2008. disponível em http://herzberg.ca.sandia.gov/docs/ Jess 71.pdf, acesso em Jun. 2011.

FRITH, U.; HILL, E. L. Autism: Mind and Brain. Oxford University Press. 2003. ISBN: 9780198529248.

GENNARI, J. H.; MUSEN, M. A.; FERGERSON, R. W.; GROSSO, W. E.; CRUBÉZY, M.; ERIKSSON, H.; NOY, N. F.; TU, S. W. The evolution of Protege: an environment for knowledge-based systems development. International Journal of Human-Computer Studies, v. 58, p. 89-123, 2003.

GRAU, B. C.; HORROCKS, I.; MOTIK, B.; PARSIA, B.; PATEL-SCJMEODER, P.; SATTLER, U. OWL 2: The next step for OWL. Journal of Web Semantics: Science, Services and Agents on the World Wide Web, Amsterdam, Netherlands, v. 6, n. 4, p. 309-322. Nov. 2008. doi: 10.1016/j.websem.2008.05.001.

GRUBER, T. R. A translation approach to portable ontology specifications. Knowl. Acquis. London, UK, v. 5, n. 2, p. 199-220. Jun. 1993. doi: 10.1006/knac.1993.1008. 
GUARINO, N. Formal Ontology and Information Systems. In N. Guarino, editor, Proceedings of the 1st International Conference on Formal Ontologies in Information Systems, FOIS'98, Trento, Italy. IOS Press, June 1998.

HASSANPOUR, S.; O'CONNOR, M. J.; DAS, A. K. Exploration of SWRL Rule Bases through Visualization, Paraphrasing, and Categorization of Rules. In: Proceedings of the 2009 International Symposium on Rule Interchange and Applications (RuleML 2009), Las Vegas, Nevada, p. 246-261. 2009. doi: 10.1007/978-3-642-04985-9_23.

HASSANPOUR, S.; O'CONNOR, M. J.; DAS, A. K. Visualizing Logical Dependencies in SWRL Rule Bases. The International RuleML Symposium on Rule Interchange and Applications, Washington, DC, p. 259-272. 2010.

HASSANPOUR, S., O'CONNOR, M. J., DAS, A. K. Evaluation of Semantic-Based Information Retrieval Methods in the Autism Phenotype Domain. AMIA Annual Symposium. 2011.

HEFLIN, J. W3C Recommendation: OWL Web Ontology Language - Use Cases and Requirements. 2004. Disponível em: www.w3.org/TR/2004/REC-webont-req-20040210. acesso Fev. 2012.

HORRIDGE, M.; BECHHOFER, S. The OWL API: A Java API for Working with OWL 2 Ontologies, In: Proceedings of the OWL Experienced and Directions Workshop (OWLED 2009), Chantilly, Virginia. 2009. doi: 10.1.1.163.7035.

HORRIDGE, M.; KNUBLAUCH, H.; RECTOR, A.; STEVENS, R.; WROE, C. A practical guide to building OWL ontologies using the protégé-OWL plugin and CO-ODE tools edition 1.0. University Of Manchester. 2004. Disponível em: http://www.co-ode.org/resources/, acesso em Dez. 2011.

HORROCKS, I; PATEL-SCHNEIDER, P. F.; BOLEY, H.; TABET, S.; GROSOF, B.; DEAN, M. SWRL: A Semantic Web Rule Language Combining OWL and RuleML. W3C. Maio 2004. Disponível em: http://www.w3.org/Submission/SWRL/, acesso em Jan. 2012.

KALJURAND, K. ACE View - an ontology and rule editor based on Attempto Controlled English. In: Proceedings of the Fifth OWLED Workshop on OWL: Experiences and Directions (OWLED 2008), v. 432, p. 1-12, Out. 2008. doi: 10.5167/uzh-8822.

KIM, Y.S.; LEVENTHAL, B.L.; KOH, Y.J.; FOMBONNE, E.; LASKA, E.; LIM, E.C.; CHEON, K.A.; KIM, S.J.; KIM, Y.K.; LEE, H.; SONG, D.H.; GRINKER, R.R. Prevalence of 
Autism Spectrum Disorders in a Total Population Sample. Am J Psychiatry, v. 168(9), p. 90412. Maio 2011.

KLYNE, G.; CARROL, J. J.; McBRIDE, B. (Editors). Resource Description Framework (RDF): Concepts and Abstract Syntax. W3C. Fev. 2004. Disponível em:

http://www.w3.org/TR/2004/REC-rdf-concepts-20040210/, acesso em Set. 2009.

KNUBLAUCH, H.; FERGERSON, R. W.; NOY, N. F.; MUSEN, M. A. The Protégé OWL Plugin: An Open Development Environment for Semantic Web Applications. ISWC 2004:Third International Semantic Web Conference. Hiroshima, Japan , p. 229-243. 2004. doi: 10.1.1.89.9268.

LASSILA, O.; SWICK, R. (Editors). Resource Description Framework (RDF) model and syntax specification. W3C. Fev. 2004. Disponível em: http://www.w3.org/TR/REC-rdfsyntax/, acesso em Out. 2009.

LEVY, M., O'CONNOR, M. J., RUBIN, D. L. Semantic Reasoning with Image Annotations for Tumor Assessment. AMIA Annual Symposium. 2009.

McGUINNESS, D. L.; HARMELEN, F. (Editors). OWL Web Ontology Language Overview. W3C. Fev. 2004. Disponível em: http://www.w3.org/TR/2004/REC-owl-features-20040210/, acesso em Jun. 2009.

MOTIK, B.; GRAU, B. C.; HORROCKS, I.; WU, Z.; FOKOUE, A.; LUTZ, C. (Editors). OWL 2 Web Ontology Language Profiles. Techical Report. 2009. Disponível em: http://www.w3.org/TR/owl2-profiles/. acesso em Fev. 2012.

NDAR. Frequently Asked Questions. 2010. Disponível em: http://ndar.nih.gov/ ndarpublicweb/faq.go, acesso em Fev. 2011.

NDAR. About NDAR. 2011. Disponivel em: http://ndar.nih.gov/ndarpublicweb/aboutNDAR.go. acesso em Fev. 2012.

NOY, N. F.; McGUINNESS, D. L. Ontology Development 101: A Guide to Creating Your First Ontology. Stanford Knowledge Systems Laboratory Technical Report KSL-01-05. 2001.

NOY, N. F.; CHUGH, A.; LIU, W.; MUSEN. M. A. A framework for ontology evolution in collaborative environments. The Semantic Web, p. 544-558, 2006. doi:

$10.1007 / 11926078 \_39$. 
O’CONNOR, M.; KNUBLAUCH, H.; TU, S.; GROSOF, B.; DEAN, M.; GROSSO, W.; MUSEN, M. Supporting Rule System Interoperability on the Semantic Web with SWRL Fourth International Semantic Web Conference (ISWC2005), Galway, Ireland, 2005.

Disponível em: http://bmir.stanford.edu/file_asset/index.php/1157/BMIR-2005-1080.pdf, acesso em Maio de 2012.

O'CONNOR, M. J.; MUSEN, M. A.; DAS, A. K. Using the Semantic Web Rule Language in the Development of Ontology-Driven Applications. In: Handbook of Research on Emerging Rule-Based Languages and Technologies: Open Solutions and Approaches, Hershey, Pennsylvania, p. 525-539. Capítulo XXII, 2009.

O'CONNOR, M. J.; DAS, A. K. SQWRL: a Query Language for OWL. OWL: Experiences and Directions (OWLED 2009), Chantilly, VA, v. 271, p. 3-22. 2009. doi:

10.1016/j.entcs.2011.02.008.

ORLANDO, J.P.; RIVOLLI, A.; HASSANPOUR, S.; O'CONNOR, M. J.; DAS, A. K.; MOREIRA, D. A. SWRL Rule Editor: A Web Application as Rich as Desktop Business Rule Editors, ICEIS 2012: International Conference on Enterprise Information Systems, Wroclaw, Poland. p. 1-6, Jun 2012.

RIVOLLI, A.; ORLANDO, J. P.; MOREIRA, D. A. An Analysis of Rules-Based Systems to Improve SWRL Tools. ICEIS 2011: International Conference on Enterprise Information Systems, Beijing, China, p. 191-194. Jun. 2011.

RIVOLLI, A.; ORLANDO, J. P.; SERIQUE, K.; MOREIRA, D. A. Ferramenta web para visualização e composição de regras SWRL. XVII WebMedia: Simpósio Brasileiro de Sistemas Multimídia e Web: Workshop de ferramentas e aplicações, Florianópolis, SC. v. 2 p. 85-87. Out. 2011a.

RIVOLLI, A.; ORLANDO, J. P.; YAMAMOTO, C. H.; MOREIRA, D. A. Regras SWRL: Análise de similaridade e detecção de erros. XVII WebMedia: Simpósio Brasileiro de Sistemas Multimídia e Web, Florianópolis, SC. v. 2 p. 19-22 Out. 2011 b.

ROSSELLO-BUSQUET, A.; BREWKA, L. J.; SOLER, J.; DITTMANN, L. OWL Ontologies and SWRL Rules Applied to Energy Management. International Conference on Computer Modelling and Simulation (UKSim), p. 446-450, 2011. doi:

10.1109/UKSIM.2011.91.

RUBIN D. L.; MOREIRA, D. A.; KANJAMALA, P. P.; MUSEN, M. A. Bioportal: A web portal to biomedical ontologies. In Symbiotic Relationships between Semantic Web and Knowledge Engineering (AAAI Spring Symposium Series), v. 1, p. 1-4. 2008. Disponível em: 
http://bmir.stanford.edu/publications/view.php/bioportal_a_web_portal_to_biomedical_ontolo gies, acesso em Maio 2012.

RUBIN, D. L.; NOY, N. F.; MUSEN, M. A. Protégé: A Tool for Managing and Using Terminology in Radiology Applications. In: Journal of Digital Imaging, v. 20, n. 1, p. 34-46. Nov. 2007. doi: 10.1007/s10278-007-9065-0.

SADOUN, D.; DUBOIS, C.; GHAMRI-DOUDANE, Y.; GRAU, B. An Ontology for the Conceptualization of an Intelligent Environment and Its Operation. Mexican International Conference on Artificial Intelligence (MICAI), p. 16-22, 2011. doi: 10.1109/MICAI.2011.32.

SEO, S.; KWON, A.; KANG, J.; HONG, J.W. OSLAM: Towards ontology-based SLA management for IPTV. IEEE International Symposium on Integrated Network Management (IM), p. 1228-1234, 2011. doi: 10.1109/INM.2011.5990570.

SILVA, A. R. Aprimorando a visualização e composição de regras SWRL na Web. Dissertação (Mestrado em Ciências de Computação e Matemática Computacional) - Instituto de Ciências Matemáticas e de Computação, Universidade de São Paulo, São Carlos, 2012. Disponível em: http://www.teses.usp.br/teses/disponiveis/55/55134/tde-27022012-142801. acesso em Maio 2012.

SMITH, B.; WELTY, C. Ontology: Towards a New Synthesis. In: FOIS'01: Proceedings of the international conference on Formal Ontology in Information Systems, Ogunquit, Maine, USA, p. 3-9. 2001. doi: 10.1145/505168.505201.

SMITH, M. K.; WELTY, C.; McGUINNESS, D. L. (Editors). OWL Web Ontology Language Guide. W3C. Fev. 2004. Disponível em: http://www.w3.org/TR/owl-guide/, acesso em Fev. 2012.

STAAB, S.; MAEDCHE, A.; HANDSCHUH, S. An annotation framework for the semantic web. In: Proceedings of the First Workshop on Multimedia Annotation, Tokyo, Japan, p. 3031. 2001. doi: 10.1.1.25.910.

STUDER, R.; BENJAMINS, R.; FENSEL, D. Knowledge Engineering: Principles and Methods. IEEE Transactions on Data and Knowledge Engineering, v. 25(1-2), p. 161-197, 1998. doi: 10.1.1.41.1007.

SWRLLanguage. SWRL: A Semantic Web Rule Language Combining OWL and RuleML. . 2012. Disponível em: http://protege.cim3.net/cgi-bin/wiki.pl?SWRLLanguageFAQ, acesso em Maio 2012. 
TANANTONG, T.; NANTAJEEWARAWAT, E.; THIEMJARUS, S. Towards Continuous Electrocardiogram Monitoring Based on Rules and Ontologies. International Conference on Bioinformatics and Bioengineering (BIBE), p. 327-330, 2011. doi: 10.1109/BIBE.2011.61. THIREOU, T.; SPYROU, G.; ATLAMAZOGLOU, V. A survey of the availability of primary bioinformatics web resources. Genomics Proteomics Bioinformatics, Athens, Greece, v. 5, p. 70-76. 2007. doi: 10.1016/S1672-0229(07)60017-5

TU, S.; TENNAKOON, L.; O'CONNOR, M. J.; SHANKAR, R.; DAS, A. K. Using an integrated ontology and information model for querying and reasoning about phenotypes: the case of autism. In: Proceedings of the American Medical Informatics Association, Washington, DC, v. 6, p. 727-731. Nov. 2008.

TUDORACHE, T.; VENDETTI, J.; NOY, N. F. Web-Protégé: A Lightweight OWL Ontology Editor for the Web. In: OWLED 2008: OWL: Experiences and Directions, Karlsruhe, Germany. Out. 2008. doi: 10.1.1.142.8568.

USCHOLD, M.; GRÜNINGER, M. Ontologies and semantics for seamless connectivity. SIGMOD Rec, NY, USA v. 3, n. 4, p. 58-64. 2004. doi: 10.1145/1041410.1041420.

USCHOLD, M.; JASPER R. A Framework for Understanding and Classifying Ontology Applications. In: BenjaminsVR (ed) IJCAI'99 Workshop on Ontology and Problem Solving Methods: Lessons Learned and Future Trends. Stockholm, Sweden. 1999. doi: 10.1.1.39.6456

VESIN, B.; IVANOVIC, M.; KLASNJA-MILICEVIC, A.; BUDIMAC, Z. Rule-based reasoning for altering pattern navigation in Programming Tutoring System. International Conference on System Theory, Control, and Computing (ICSTCC), p. 1-6, 2011.

W3C OWL Working Group. OWL 2 Web Ontology Language Document Overview. W3C. Out. 2009. Disponível em: http://www.w3.org/TR/owl2-overview/, acesso em Dez. 2009.

WILLINSKY, J.; QUINT-RAPOPORT, R. How Complementary and Alternative Medicine Practitioners Use PubMed. J Med Internet Res, Vancouver, BC, Canada, v. 9(2), p. 19, 2007. Disponível em: http://ukpmc.ac.uk/abstract/MED/17613489, acesso em Jan. 2012.

WU, G. Semantic Web. IN-TECH. 2010. ISBN 978-953-7619-54-1

WUSHENG, W.; WEIPING, L.; ZHONGHAI, W.; WEIJIE, C.; TONG, M. An OntologyBased Context Model for Building Context-Aware Services. International Conference on Intelligent Systems, Modelling and Simulation (ISMS), p. 296-299, 2011. doi: 10.1109/ISMS.2011.52. 
YOUNG, L.; TU, S.; TENNAKOON, L.; VISMER, D.; ASTAKHOV, V.; GUPTA, A.; GRETHE, J.; MARTONE, M.; DAS, A.; MCAULIFFE, M. Ontology Driven Data Integration for Autism Research. 22nd IEEE International Symposium on Computer Based Medical Systems, Albuquerque, NM, p. 1-7, 2009.

ZACHARIAS, V. Development and verification of rule based systems - a survey of developers. In: Rule Representation, Interchange and Reasoning on the Web: International Symposium, Orlando, Florida, USA, v. 5321, p. 6-16, 2008. doi:10.1007/978-3-540-888086 - 4 . 


\section{Apêndice A - Implementação do Agrupamento do}

\section{Axiomé}

Segue a explicação de como implementar a técnica de agrupamento do Axiomé. Para explicar o funcionamento desse algoritmo será usada essa regra de exemplo:

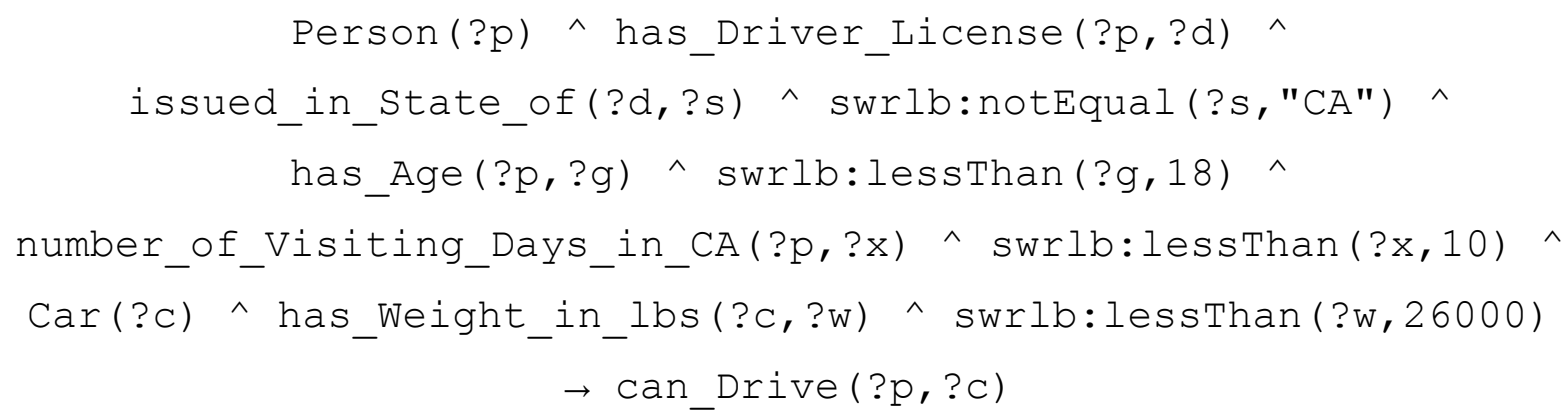

Essa técnica consiste em gerar uma expressão canônica (assinatura) com números e símbolos que identificam a estrutura da regra. Primeiramente são geradas duas árvores (uma para o antecedente e outra para o consequente) de dependência de variáveis entre os átomos.

Na Figura 40 é mostrada a árvore de dependência de variáveis do antecedente da regra de exemplo. Esse diagrama possui duas raízes, ou seja, as variáveis p e c não dependem de outras variáveis, por isso viram raízes. Todos os átomos que usem $\mathrm{c}$ ou $\mathrm{p}$ ficam ligados as suas respectivas raízes. Já átomos que dependam de outra variável, por exemplo o issued_in_state_of(?d,?s) que depende da variável ?d do átomo has_Driver_License (?p, ?d), são inseridos em um nível adiante desse nodo. 


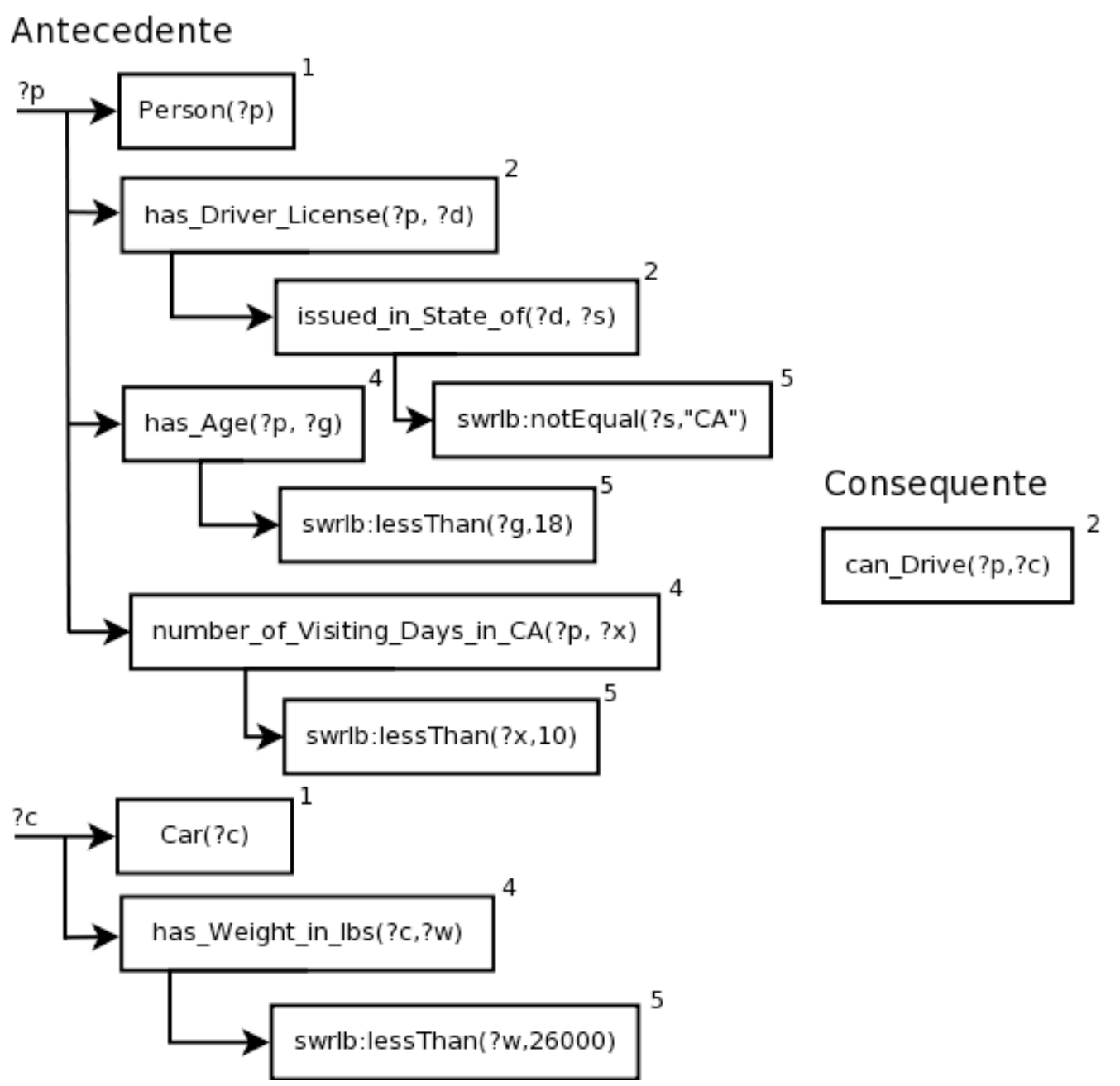

Figura 40 - Diagrama da árvore de dependência de variáveis do antecedente de uma regra.

Para definir a assinatura, a partir da árvore de dependência, é necessário um alfabeto $(\Sigma)$ e um conjunto de quantificadores (Q) (Hassanpour, O'Connor e Das, 2009), tal que:

$$
\begin{aligned}
& \Sigma=\{1,2,3,4,5,6\} \\
& \mathrm{Q}=\{-, \wedge,(), \#,+\}
\end{aligned}
$$

Tabela 4 - Agrupamento Axiomé - Alfabeto

\begin{tabular}{|c|l|}
\hline$\Sigma$ & \multicolumn{1}{|c|}{ Tipos de Átomos } \\
\hline 1 & Class \\
\hline 2 & Object property \\
\hline 3 & Same/different \\
\hline 4 & Datatype property \\
\hline 5 & Built-in \\
\hline 6 & Data range \\
\hline
\end{tabular}


A Tabela 4 apresenta os valores para cada tipo de átomo. Esses valores já estão inseridos na Figura 40 para facilitar a montagem da expressão. Já a Tabela 5 apresenta os quantificadores da expressão:

Tabela 5 - Agrupamento Axiomé - Quantificadores

\begin{tabular}{|c|l|}
\hline $\mathrm{Q}$ & \multicolumn{1}{|c|}{ Função } \\
\hline- & Separar o antecedente do consequente. \\
\hline$\wedge$ & Separar entre raízes diferentes. \\
\hline$(\quad)$ & São usados para juntar átomos que dependem de uma variável. \\
\hline$\#$ & É usado para representar o avanço a um próximo nível da árvore. \\
\hline+ & É usado para mostrar o uso repetido de um mesmo tipo de átomo. \\
\hline
\end{tabular}

Com base na Figura 40, vamos começar a montar a expressão a partir da raiz ?p. Como todos que estão nessa raiz dependem dessa variável, começa-se com " (". O primeiro átomo é Person ( ?p) e ele é uma Class da ontologia, ou seja, é representado por "1" na expressão (Conforme a Tabela 4). O segundo átomo é has_Driver_License(?p, ?d) e é representado por "2" na expressão. Já esse átomo possui um filho, então deve ser inserido na expressão o separador "\#”. Agora o átomo issued_in_State_of (?d, ?s) depende da variável ?d, então é necessário abrir outro “(" e após isso é inserido o "2" que representa o tipo desse átomo. Esse átomo possui também um filho então novamente insere-se um “\#” e um “(" por ter a dependência de outra variável. Nesse nível da árvore, encontra-se o átomo swrlb: notEqual (?s, "CA") que é representado por "5". Esse átomo é um nó folha, então recua-se níveis na árvore até encontrar o próximo átomo. Como nesse caso é recuado dois níveis é inserido “) ) “ na expressão. Até o momento obtém-se a seguinte expressão: (12\# (2\# (5)) .

Como existe outros átomos dependentes da variável ?p, continua-se a expressão inserindo "4" referente ao átomo has_Age ( ?p, ?g). Como o próximo átomo ligado a variável ?p (number_of_Visiting_Days_in_CA (?p,?x)) é do mesmo tipo que o anterior, é inserido um "+" pela repetição.

Agora se avança um nível por isso insere-se um“\#”, como muda também a variável de dependência insere-se também um "(". Nesse nível, encontra-se o swrlb: lessThan $(? g, 18)$ representado pelo tipo "5". Como esse último átomo era uma folha é necessário inserir um ”)" para voltar um nível. O átomo 
number_of_Visiting_Days_in_CA (?p, ?x) foi inserido com um "+" anteriormente. Então por isso, é avançado um nível, então se insere um “\#”, como muda a dependência da variável é inserido outro “(“. Nesse nível, encontra-se o átomo swrlb: lessThan ( ?w, 26000), representado por "5" na expressão. Como é um nó folha insere-se um ") " para voltar um nível na árvore. Chegou-se a um ponto que não existem mais dependências de ?p, ou seja, fecha-se novamente o ") ". Até o momento obteve-se a seguinte expressão: (12\# (2\# (5)) 4+\# (5) \# (5)) .

Agora se inicia uma nova raiz (?c), para isto, insere-se um "^" como separador. Seguemse os mesmo passos anteriores até terminar o antecedente. Após isso, usa o ”-“para separar o antecedente do consequente. E por final, repetem-se os passos para criar a expressão consequente, da mesma forma que no antecedente. Ao final obtém-se a seguinte expressão:

$$
(12 \#(2 \#(5)) 4+\#(5) \#(5)) \wedge(14 \#(5))-(2)
$$

